\title{
Cathode Design for Aqueous Rechargeable Multivalent Ion Batteries: Challenges and Opportunities
}

\author{
Yiyang Liu, Guanjie He,* Hao Jiang, Ivan P. Parkin, Paul R. Shearing, and Dan J. L. Brett*
}

With the rapid growth in energy consumption, renewable energy is a promising solution. However, renewable energy (e.g., wind, solar, and tidal) is discontinuous and irregular by nature, which poses new challenges to the new generation of large-scale energy storage devices. Rechargeable batteries using aqueous electrolyte and multivalent ion charge are considered more suitable candidates compared to lithium-ion and lead-acid batteries, owing to their low cost, ease of manufacture, good safety, and environmentally benign characteristics. However, some substantial challenges hinder the development of aqueous rechargeable multivalent ion batteries (AMVIBs), including the narrow stable electrochemical window of water ( $\approx 1.23 \mathrm{~V})$, sluggish ion diffusion kinetics, and stability issues of electrode materials. To address these challenges, a range of encouraging strategies has been developed in recent years, in the aspects of electrolyte optimization, material structure engineering and theoretical investigations. To inspire new research directions, this review focuses on the latest advances in cathode materials for aqueous batteries based on the multivalent ions $\left(\mathrm{Zn}^{2+}, \mathrm{Mg}^{2+}, \mathrm{Ca}^{2+}, \mathrm{Al}^{3+}\right)$, their common challenges, and promising strategies for improvement. In addition, further suggestions for development directions and a comparison of the different AMVIBs are covered.

\section{Introduction}

To meet the current and growing future energy demand, the development of renewable energy sources is receiving increasing attention. ${ }^{[1-3]}$ However, these energy sources, such as wind, tidal, solar and geothermal, are discontinuous and irregular by nature; therefore, grid-scale energy storage solutions are required to underpin the continued growth of the renewable energy sector; advanced batteries are one option for achieving this. ${ }^{[4-6]}$ Since the successful commercialization of lithium-ion batteries (LIBs) by Sony in the 1990 s, the past three decades have witnessed the widespread use of LIBs in many fields, from mobile electronic devices and electric vehicles to grid-scale energy storage systems..$^{[7-10]}$ Nevertheless, different from the small and medium-sized energy storage applications, the grid-scale energy storage market has been identified as a highly cost-sensitive battlefield with a rigorous security requirement. Additionally, compared with the applications in the mobile phones and vehicles, the grid-scale electrochemical energy storage devices have a lower demand in energy and power density, because the weight of the devices is not the key constraint. Unfortunately, although Libased batteries demonstrate many merits in electrochemical performances and technological maturity, the fatal shortcomings such as high cost (\$13000 per ton for lithium metal), insufficient lithium reserve and potential safety issues, act to retard LIB deployment and long-term prospects in this battlefield. ${ }^{[11,12]}$ In particular, the frequent safety incidents in recent years, such as Boeing 787 battery fires (2013), Samsung Note 7 explosion (2016), and spontaneous combustion of TESLA Model S (2019), have
Y. Liu, Dr. G. He, Prof. P. R. Shearing, Prof. D. J. L. Brett

Electrochemical Innovation Lab (EIL)

Department of Chemical Engineering

University College London (UCL)

London WCIE 7JE, UK

E-mail: g.he@ucl.ac.uk; d.brett@ucl.ac.uk

Y. Liu, Dr. G. He, Prof. I. P. Parkin

Christopher Ingold Laboratory

Department of Chemistry

University College London (UCL)

20 Gordon Street, London WCIH OAJ, UK

The ORCID identification number(s) for the author(s) of this article can be found under https://doi.org/10.1002/adfm.202010445.

(C) 2021 The Authors. Advanced Functional Materials published by Wiley$\mathrm{VCH} \mathrm{GmbH}$. This is an open access article under the terms of the Creative Commons Attribution License, which permits use, distribution and reproduction in any medium, provided the original work is properly cited.

\author{
Dr. G. $\mathrm{He}$ \\ School of Chemistry \\ University of Lincoln \\ Brayford Pool, Lincoln LN6 7TS, UK \\ Prof. H. Jiang \\ Key Laboratory for Ultrafine Materials of Ministry of Education \\ Shanghai Engineering Research Center of Hierarchical Nanomaterials \\ School of Materials Science and Engineering \\ East China University of Science \& Technology \\ 130 Meilong Road, Shanghai 200237, China \\ Prof. P. R. Shearing, Prof. D. J. L. Brett \\ The Faraday Institution \\ Quad One \\ Becquerel Avenue, Harwell Campus, London OX11 ORA, UK
}

DOI: 10.1002/adfm.202010445 
Table 1. The comparison between monovalent and multivalent charge carriers. ${ }^{[26,62,118,192]}$

\begin{tabular}{|c|c|c|c|c|c|c|c|}
\hline Items/charge carriers & $\mathrm{Li}^{+}$ & $\mathrm{Na}^{+}$ & $\mathrm{K}^{+}$ & $\mathrm{Zn}^{2+}$ & $\mathrm{Mg}^{2+}$ & $\mathrm{Ca}^{2+}$ & $\mathrm{Al}^{3+}$ \\
\hline Atomic weight $\left[\mathrm{g} \mathrm{mol}^{-1}\right]$ & 6.94 & 22.99 & 39.1 & 65.41 & 24.31 & 40.08 & 26.98 \\
\hline Standard potential (V vs. SHE) & -3.04 & -2.713 & -2.924 & -0.763 & -2.356 & -2.84 & -1.676 \\
\hline Ionic radius $[\AA ̊]$ & 0.76 & 1.02 & 1.38 & 0.75 & 0.72 & 1 & 0.53 \\
\hline Hydrated ionic radius $[\AA ̊]$ & 3.82 & 3.58 & 3.31 & 4.3 & 4.28 & 4.12 & 4.75 \\
\hline Charge density $\left[\mathrm{C} \mathrm{mm}^{-3}\right]$ & 52 & 24 & 11 & 112 & 120 & 52 & 364 \\
\hline Theoretical specific capacity $\left[\mathrm{mAh} \mathrm{g}^{-1}\right]$ & 3860 & 1166 & 685 & 820 & 2206 & 1337 & 2980 \\
\hline Volumetric energy density [mAh $\left.\mathrm{cm}^{-3}\right]$ & 2061 & 1129 & 610 & 5855 & 3834 & 2072 & 8046 \\
\hline Density of the metal $\left[\mathrm{kg} \mathrm{m}^{-3}\right]$ & 534 & 968 & 862 & 7140 & 1738 & 1550 & 2700 \\
\hline Metal cost [USD kg $\left.{ }^{-1}\right]$ & 19.2 & 3.1 & 13.1 & 2.2 & 2.2 & 2.28 & 1.9 \\
\hline Abundance ${ }^{a}$ ) & 33 & 6 & 7 & 25 & 8 & 5 & 3 \\
\hline
\end{tabular}

a) Ranking based on the abundance of all elements on earth.

simulated the urgent demands for the next-generation electrochemical energy storage devices for grid-scale applications. ${ }^{[13]}$

\subsection{Aqueous Rechargeable Multivalent Ion Batteries: The Promising Alternatives}

Other metal-ion batteries in non-aqueous electrolyte, such as sodium-ion batteries (SIBs) and potassium-ion batteries (KIBs), are widely studied as alternatives for LIBs, because of their similar chemical properties to lithium and relatively higher abundance. ${ }^{[1-18]}$ Nevertheless, similar to LIBs, the mainstream SIBs and KIBs cannot avoid the adoption of highly toxic and flammable organic electrolyte (e.g., dimethyl carbonate (DMC), ethylene carbonate (EC), propylene carbonate $(\mathrm{PC})$ ), thus resulting in the severe security concerns and considerable fabrication costs. ${ }^{[14,19]}$ Compared with non-aqueous systems, aqueous batteries are equipped with tremendous competitiveness for largescale energy storage applications, due to several merits such as: a) the adoption of non-toxic, low-volatile, and non-flammable aqueous electrolytes minimizes the potential risks; b) convenient and low-cost fabrication process (e.g., $\approx \$ 25$ per $\mathrm{kWh}$ for aqueous zinc-ion batteries in the laboratory, which is around a sixth of that for commercial LIBs) by excluding oxygen-free and drying manufacturing lines; c) the higher ionic conductivity $\left(\approx 1 \mathrm{~S} \mathrm{~cm}^{-1}\right)$ compared with organic electrolytes $\left(\approx 10^{-3} \mathrm{~S} \mathrm{~cm}^{-1}\right)$, offers high power densities and allows the fast charging; d) non-existence of solid electrolyte interphase (SEI) layer; e) high tolerance against electrical and mechanical mishandling. ${ }^{[20-22]}$

Although there are few studies based on the monovalent ions and aqueous electrolytes since 1994, they were failed to present a charming electrochemical performances and commercial prospects. ${ }^{[23]}$ One of the major challenges is their energy density $\left(<70 \mathrm{Wh} \mathrm{kg}^{-1}\right)$ cannot compare with commercial LIBs $\left(\approx 100-265 \mathrm{Wh} \mathrm{kg}^{-1}\right)$, owning to the narrow electrochemical stable potential window (ESPW) of aqueous electrolytes. ${ }^{[2,25]}$ An ingenious solution to compensate the reduced energy density due to the low operation potential is to use multivalent ion as charge carriers in aqueous batteries. As illustrated from Table 1, owning to the multi-electron transfer capability, aqueous rechargeable multivalent ion batteries (AMVIBs) present more energy storage capability, thus providing higher theoretical gravimetric and volumetric energy densities compared with monovalent ions. ${ }^{[20]}$
Therefore, recent years have witnessed increasing focus on the development of different types of AMVIBs, for example, aqueous zinc-ion batteries (AZIBs), ${ }^{[26-29]}$ aqueous calcium-ion batteries (ACIBs), ${ }^{[30]}$ aqueous magnesium-ion batteries (AMIBs) ${ }^{[31]}$ and aqueous aluminum-ion batteries (AAIBs). ${ }^{[32]}$

Figure 1 demonstrates the major development of the cathode for AMVIBs in the past two decades. Although the first rechargeable AIB and MIB were reported in the 1970s and 2000 respectively, it is disappointing that there were few breakthroughs between 2000 and 2010. Early MIBs were mainly based on non-aqueous electrolytes; however, the aqueous systems have received more attention in recent years due to the advantages such as the non-existence of SEI layer. Similarly, research on AIBs based on ionic liquids and aqueous electrolytes has gradually increased since 2011. Rechargeable AZIBs and AMIBs were first reported in 2011 and 2015, respectively. They have developed rapidly, benefiting from comprehensive studies dedicated to cathode development. In addition, the emergence of "water-in-salt" (WIS) aqueous electrolyte in 2015 brings new vitality to the AMVIB field. ${ }^{[33]}$

\subsection{Overview to the Challenges and Opportunities of Extensively Studied Materials}

The AMVIBs not only have similar materials design strategies for cathodes, but also share similar challenges and opportunities (Figure 2). Although the past 5 years have witnessed the rapid development and numerous breakthroughs of eight mainstream cathode candidates for AMVIBs, several substantial challenges still exist and hinder the further development of AMVIBs. These challenges can be mainly summarized in two aspects: a) the innovation of suitable cathode materials and structures, and b) the discovery of adequate electrolytes. First, for liquid-state electrolytes, it is widely known that the narrow ESPW of water $(\approx 1.23 \mathrm{~V})$ limited the output voltage of batteries using aqueous electrolytes (Figure 3a). The use of WIS aqueous electrolytes successfully broaden the output voltage window to $\approx 2-3 \mathrm{~V}$, however, it is still lower than organic or ionic liquid electrolytes $(\approx 2-4 \mathrm{~V})$, gel polymer electrolytes $(\approx 2-6 \mathrm{~V})$ and solid-state electrolytes (up to $\approx 6.5 \mathrm{~V}$ ). ${ }^{[34]}$ Second, the capacity retention of state-of-art cathode candidates in the laboratory are insufficient to meet the requirements for practical application (Figure 3b). 


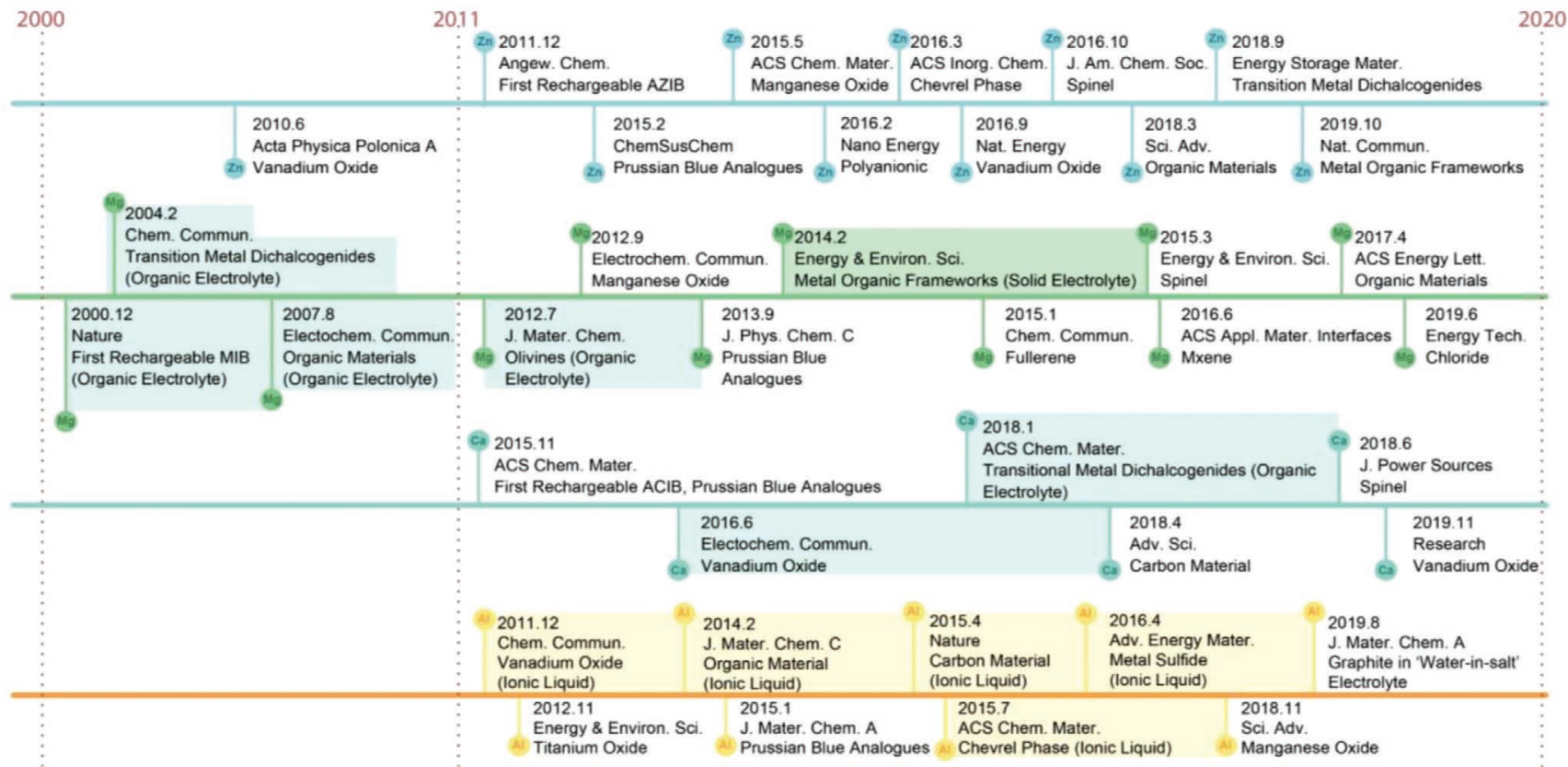

Figure 1. Major achievements of cathodes for rechargeable multivalent ion batteries in the last 20 years.

Currently, there is no commercial AMVIBs, and only a handful of researches based on manganese oxides and vanadium oxides maintain over $90 \%$ capacity retention after 2000 charge/discharge cycles in the laboratory. Furthermore, the multivalent ions $\left(\mathrm{Zn}^{2+}, \mathrm{Mg}^{2+}, \mathrm{Al}^{3+}\right)$ have much higher polarization strength and charge density compared with monovalent ions $\left(\mathrm{Li}^{+}, \mathrm{Na}^{+}\right.$, $\mathrm{K}^{+}$), which results in the diffusion kinetics (or diffusivity) of multivalent ions being significantly lower than the monovalent ions in the similar cathode materials (Figure 3c). Additionally, for systems using zinc metal as the anode, stable cathode candidates and aqueous electrolytes are hard to find, because the standard potential for zinc-ion deposition is more negative than that for hydrogen evolution in aqueous electrolytes. ${ }^{[35]}$

To achieve further improvement to AMVIBs, nine main methodologies have been identified to enhance the performance of these batteries, including: WIS electrolyte, ${ }^{[35,36]}$ electrolyte additives, ${ }^{[2,37]}$ pre-intercalation, ${ }^{[38,39]}$ defect engineering, ${ }^{[40,41]}$ heteroatom doping, ${ }^{[42,43]}$ size regulation, ${ }^{[44,45]}$ composites and freestanding configurations of cathodes, ${ }^{[46,47]}$ advanced characterization, ${ }^{[48]}$ and theoretical investigations. ${ }^{[6,49]}$ These strategies have been extensively studied and used individually or in combination. Although some strategies are adopted in cathode materials based on organic or ionic liquid electrolytes, they could still effectively inspire the development of AMVIBs.

\subsection{Highlights of this Review}

Although the number of publications for AMVIBs continues to increase rapidly, there are few focused reviews that systematically discussed anodes, cathodes, electrolytes, and the mechanisms of AMVIBs. A comparison and summary of recent reviews is listed in Table $2 .^{[50-58]}$ To inspire new research directions, this work has made several improvements that fill gaps in existing reviews, including the combination of: a) focus on recent developments in cathode materials for AMVIBs ( $\mathrm{Zn}, \mathrm{Mg}, \mathrm{Ca}, \mathrm{Al}$ ), and providing general approaches for the design of the different types of cathodes; b) clearly and systematically summarizing common challenges, widely investigated materials, and promising strategies to optimize the cathode candidates; c) establishing the inherent relationships among promising strategies and common challenges and pointing out the conflicting conclusions from the literature, thus inspiring follow-on research.

\section{Aqueous Rechargeable Zinc-Ion Batteries}

As demonstrated in Table 1, among the various charge carriers, AZIBs possess particularly attractive features in the following aspects. 1) High abundance in the Earth's crust and the low cost of zinc facilitate their mass production; 2) high redox potential (versus SHE, $-0.763 \mathrm{~V}$ ) allowing AZIBs to work in both aqueous and non-aqueous electrolytes; 3) zinc anodes offer high theoretical volumetric energy density $\left(5855 \mathrm{mAh} \mathrm{cm}^{-3}\right.$ compared to 2061

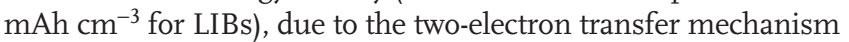
and the high density of $\mathrm{Zn}\left(7.140 \mathrm{~g} \mathrm{~cm}^{-3}\right)$; and 4) the reduced toxicity and improved safety characteristics compared to LIBs. ${ }^{[21,22,59]}$

Similar to the energy storage mechanism of LIBs, AZIBs experience the $\mathrm{Zn}^{2+}$ transfer between anodes and cathodes. Generally, at the anode surface, $\mathrm{Zn}^{2+}$ executes electrochemical plating/stripping during the charge and discharge process. However, the cathode reactions are different depending on the different types of materials used; for example, intercalation or conversion reactions for metal oxides (e.g., $\mathrm{MnO}_{2}$ and $\mathrm{V}_{2} \mathrm{O}_{5}$ ), and redox reactions for organic cathodes (e.g., polyaniline). There are a series of substantial challenges for ZIBs in practical scenarios. First, inhomogeneous electrodeposition will result in the formation of $\mathrm{Zn}$ dendrites and a passivation layer, which will lead to capacity fade, shorter cycle life, and safety issues associated with short-circuiting. ${ }^{[27,60]}$ Meanwhile, the formation 


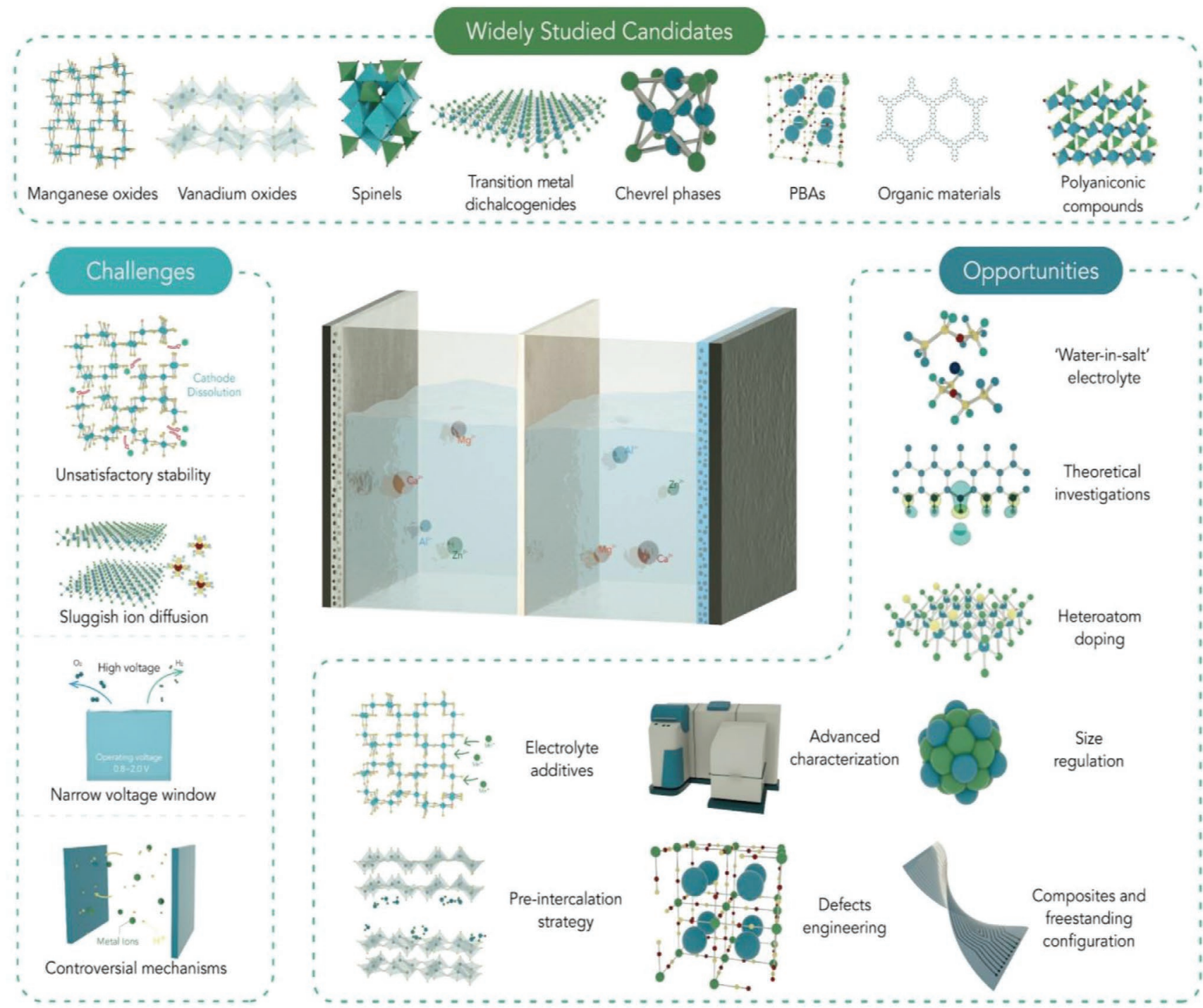

Figure 2. Summary of the materials, challenges and opportunities.

of inactive by-products (e.g., $\mathrm{ZnO}$ ) at the anode caused by the side reactions (e.g., hydrogen evolution and self-corrosion), will lead to the poor Coulombic efficiency. Second, each $\mathrm{Zn}^{2+}$ ion will coordinate with six water molecules and possess a strong electrostatic interaction with cathode materials in AZIBs, thus limiting its diffusion kinetics and increasing the difficulties in identifying suitable cathode materials. ${ }^{[21,61]}$ Then, the standard potential of the $\mathrm{Zn}^{2+}$ ion deposition is more negative than that of hydrogen evolution reaction in aqueous electrolytes, which make it harder to develop stable aqueous electrolytes. ${ }^{[62]}$ In addition, the dissolution of active materials is another major issue and inhibits the durability of AZIBs.

To address the above challenges and further improve the performance of AZIBs, many materials and strategies have been proposed. A summary of cathode materials for AZIBs is given in Table 3. Generally, the widely studied types of cathode materials include manganese-based materials, vanadium-based materials, Prussian blue analogs (PBAs), and other types, which will be discussed as follows.

\subsection{Mn-based Materials}

To date, Mn-based materials are the most commonly studied cathode for AZIBs, because of the low cost and environmentally friendly feature. ${ }^{[26,27]}$ Meanwhile, manganese oxides present a remarkable diversity in crystal structures, nano/micro morphology and porosity, due to the variety in the valence states of $\mathrm{Mn}: \mathrm{Mn}^{2+}, \mathrm{Mn}^{3+}, \mathrm{Mn}^{4+}$, and $\mathrm{Mn}^{7+}$. In recent years, a diverse types of Mn-based materials, including $\alpha-\mathrm{MnO}_{2},{ }^{[2,46,63-65]} \beta$ $\mathrm{MnO}_{2},{ }^{[38,39]} \gamma-\mathrm{MnO}_{2},{ }^{[66]} \varepsilon-\mathrm{MnO}_{2},{ }^{[42]} \delta-\mathrm{MnO}_{2},{ }^{[67]} \mathrm{Mn}_{2} \mathrm{O}_{3},{ }^{[68]}$ and $\mathrm{Mn}_{3} \mathrm{O}_{4},{ }^{[4,47,69]}$ have been received varying degrees of attention. This part of the review focuses on the major challenges and potential solutions summarized from the state-of-the-art work, including: 1) manganese dissolution; 2) controversial mechanistic issues; 3) phase transformation and structural collapse; and 4) emerging strategies.

The first obstacle is the continuous dissolution of manganese into the electrolyte. Liu et al. observed the capacity of $\alpha-\mathrm{MnO}_{2}$ nanofibers significantly decreases in the initial 10 cycles; then, 
(a)

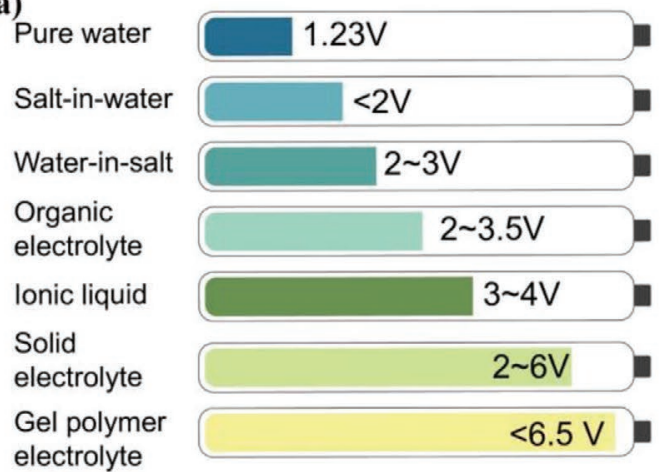

(b) $100 \%$

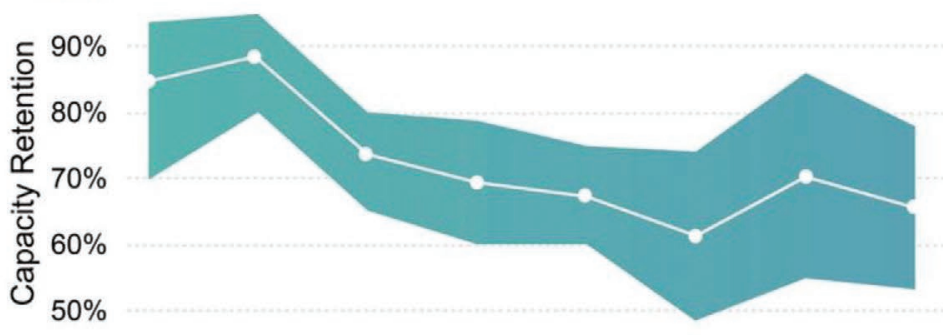

$40 \%$

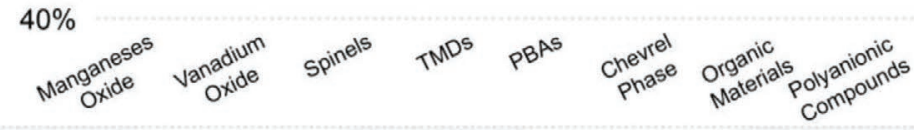

(c) $10^{-5}$
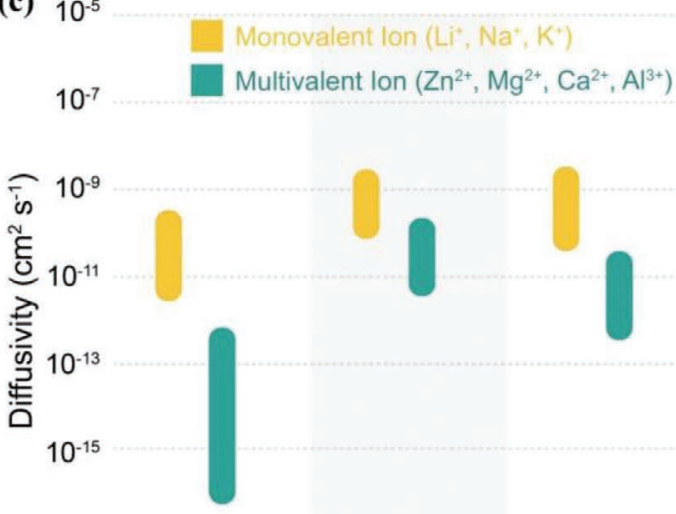

$10^{-17}$

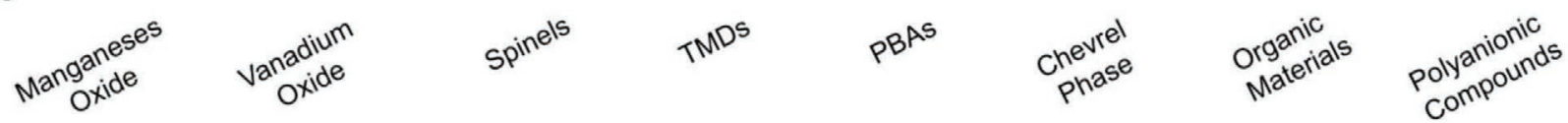

Figure 3. The challenges of AMVIBs. a) The comparison of the output voltage of AMVIBs using different electrolyte; b) capacity retention per 2000 cycles of state-of-art cathode candidates in each type of material. Data collected from Tables 3-6; c) the diffusivity of monovalent $\left(\mathrm{Li}^{+}, \mathrm{Na}^{+}, \mathrm{K}^{+}\right)$and multivalent $\left(\mathrm{Zn}^{2+}, \mathrm{Mg}^{2+}, \mathrm{Ca}^{2+}, \mathrm{Al}^{3+}\right)$ ions in the cathode materials, which is summarized via the results from galvanostatic intermittent titration technique (GITT). The manganese oxide corresponds to $\mathrm{Li}^{+}$and $\mathrm{Zn}^{2+}$ in $\alpha-\mathrm{MnO}_{2} \cdot{ }^{[193,194]}$ The vanadium oxide corresponds to $\mathrm{Li}^{+}$in $\mathrm{NaVO}_{3},{ }^{[195]}$ and $\mathrm{Zn}^{2+}$ in $\mathrm{V}_{2} \mathrm{O}_{5}$ and $\mathrm{H}_{2} \mathrm{~V}_{3} \mathrm{O}_{8} \cdot{ }^{[7,95]}$ The spinels correspond to $\mathrm{Li}^{+}$in $\mathrm{Li}_{2}\left(\mathrm{M}_{1 / 16} \mathrm{Mn}_{11 / 16}\right) \mathrm{O}_{4},{ }^{[196]}$ and $\mathrm{Zn}^{2+}$ in $\mathrm{ZnMn}_{2} \mathrm{O}_{4} \cdot{ }^{[40]}$ The TMDs correspond to $\mathrm{Li}^{+}$and $\mathrm{Zn}^{2+}$ in $\mathrm{MoS}_{2}{ }^{[61,197]}$ The PBAs correspond to $\mathrm{Na}^{+}$in FeHCF, ${ }^{[198]}$ and $\mathrm{Al}^{3+}$ in NiHCF${ }^{[10]}$ The Chevrel phase corresponds to $\mathrm{Li}^{+}$in $\mathrm{Mo}_{6} \mathrm{~S}_{8},{ }^{[199]}$ and $\mathrm{Mg}^{2+}$ in $\mathrm{Cu}_{0.09} \mathrm{Mo}_{6} \mathrm{~S}_{8}{ }^{[200]} \mathrm{The}^{2}$ organic materials correspond to monovalent and multivalent ions in the organic materials. ${ }^{[56,201]}$ The polyanionic compounds correspond to $\mathrm{Na}^{+}$in NASICON-Na $\mathrm{V}_{2}\left(\mathrm{PO}_{4}\right)_{3},{ }^{[194]}$ and $\mathrm{Zn}^{2+}$ in $\mathrm{Na}_{3} \mathrm{~V}_{2}\left(\mathrm{PO}_{4}\right)_{2} \mathrm{~F}_{3}{ }^{[202]}$

through the inductively coupled plasma (ICP) technique, they found that the $\mathrm{Mn}^{2+}$ in the electrolyte can inhibit the dissolution of $\mathrm{Mn}$ in the cathode. ${ }^{[2]}$ Hence, they proposed the pre-addition strategy and added $0.1 \mathrm{M} \mathrm{Mn}^{2+}$ into the pristine electrolyte, thus improving the stability of the electrode and achieving high capacity retention of $92 \%$ after 5000 cycles at 5 C (Figure 4a). Similarly, Chen and co-workers further studied the underlying mechanism of the pre-addition strategy, based on AZIBs with $\beta-\mathrm{MnO}_{2}$ nanorods as the cathode and with $3 \mathrm{M} \mathrm{Zn}\left(\mathrm{CF}_{3} \mathrm{SO}_{3}\right)_{2}$ and $0.1 \mathrm{M} \mathrm{Mn}\left(\mathrm{CF}_{3} \mathrm{SO}_{3}\right)_{2}$ as the electrolyte (Figure $\left.4 \mathrm{~b}\right){ }^{[37]}$ They identified the major merits of the $\mathrm{Mn}^{2+}$ electrolyte additive to be: 1) accommodating/compensating the dissolution of active materials; 2) improving initial Coulombic efficiency and ionic conductivity; 3) generating an uniform interconnected porous $\mathrm{MnO}_{x}$ film after charging, thus improving the electrode integrity and charge transfer.

Currently, the functionality and underlying mechanisms of $\mathrm{Mn}^{2+}$ pre-addition are still controversial. For the $\mathrm{MnO}_{2}$ cathodes which are prone to $\mathrm{Mn}^{3+}$ Jahn-Teller instability, a conventional viewpoint suggested that the pre-addition of $\mathrm{Mn}^{2+}$ inhibits the disproportionate reaction $\left(2 \mathrm{Mn}_{(\mathrm{s})}^{3+} \leftrightarrow \mathrm{Mn}_{(\mathrm{aq})}^{2+}+\mathrm{Mn}_{(\mathrm{aq})}^{4+}\right)$, thus alleviating the dissolution of active materials. However, the $\mathrm{Mn}^{2+}$ in aqueous electrolyte is not stable, which may be redeposited on the $\mathrm{MnO}_{2}$ cathode and contribute to the extra capacity during the cycling. Recently, Xia and colleagues found the $\mathrm{Mn}^{2+}$ preaddition may not be able to inhibit the dissolution of $\mathrm{MnO}_{2}{ }^{[6]}$ As shown in Figure 4f, they proposed the electro-oxidation of $\mathrm{Mn}^{2+}$ in the electrolyte formed the $\mathrm{ZnMn}_{2} \mathrm{O}_{4}$, which would contribute to the extra capacity and influence the evaluation of capacity due to the $\mathrm{MnO}_{2}$ phase change and dissolution. However, the mechanism they proposed is mainly based on the observation of the phase transformation via ex situ XRD. To obtain a clearer mechanism, it is an important route to combine various in situ characterization techniques to provide a more diversified information of the electrode materials. For instance, in situ Raman spectra of $\mathrm{MnO}_{2}$-loaded carbon felt during the continuous discharge and charge process (Figure 4c) indicated the reversible deposition/dissolution mechanism of $\mathrm{MnO}_{2} \cdot{ }^{[70]}$ During the discharge process, the $\mathrm{MnO}_{2}$ peaks $\left(500-600 \mathrm{~cm}^{-1}\right)$ almost remained unchanged as the discharge voltage between 
Table 2. Recent reviews published in related areas. ${ }^{[50-58]}$

\begin{tabular}{|c|c|c|c|c|c|}
\hline $\begin{array}{l}\text { Published } \\
\text { journal }\end{array}$ & $\begin{array}{l}\text { Page } \\
\text { number }\end{array}$ & Title & Types of batteries & Highlight point & Reference \\
\hline $\begin{array}{l}\text { Small } \\
\text { Methods }\end{array}$ & $\begin{array}{l}3(2019) \\
1800272\end{array}$ & $\begin{array}{l}\text { Recent progress of rechargeable } \\
\text { batteries using mild aqueous } \\
\text { electrolytes }\end{array}$ & $\begin{array}{l}\text { Aqueous metal ion batteries } \\
\text { (Li, Na, K, Mg, Ca, Zn, Al) }\end{array}$ & $\begin{array}{c}\text { Recent development of anodes, cathodes } \\
\text { and electrolytes in aqueous metal ion } \\
\text { batteries ( } \mathrm{Li}, \mathrm{Na}, \mathrm{K}, \mathrm{Mg}, \mathrm{Ca}, \mathrm{Zn}, \mathrm{Al} \text { ). }\end{array}$ & {$[50]$} \\
\hline Sci. Adv. & $\begin{array}{c}16(2020) \\
21, \text { eaba4098 }\end{array}$ & $\begin{array}{l}\text { Roadmap for advanced aqueous } \\
\text { batteries: From design of } \\
\text { materials to applications }\end{array}$ & $\begin{array}{l}\text { Aqueous metal ion batteries } \\
\text { (Li, } \mathrm{Na}, \mathrm{K}, \mathrm{Mg}, \mathrm{Ca}, \mathrm{Zn}, \mathrm{Al})\end{array}$ & $\begin{array}{l}\text { Roadmap starting with materials design } \\
\text { and ending with the commercialization of } \\
\text { next-generation reliable aqueous batteries. }\end{array}$ & {$[51]$} \\
\hline $\begin{array}{l}\text { J. Mater. } \\
\text { Chem. A }\end{array}$ & $\begin{array}{c}7 \text { (2019), } \\
20519-20539\end{array}$ & $\begin{array}{l}\text { Rechargeable aqueous electrolyte } \\
\text { batteries: from univalent to } \\
\text { multivalent cation chemistry }\end{array}$ & $\begin{array}{l}\text { Aqueous metal ion batteries } \\
\qquad(\mathrm{Li}, \mathrm{Na}, \mathrm{Zn})\end{array}$ & $\begin{array}{c}\text { Recent development of anodes and } \\
\text { cathodes in aqueous metal ion batteries } \\
(\mathrm{Li}, \mathrm{Na}, \mathrm{Zn}) .\end{array}$ & [52] \\
\hline Small & $\begin{array}{l}15 \text { (2019), } \\
15,1805061\end{array}$ & $\begin{array}{l}\text { Recent progress in multivalent } \\
\text { metal (Mg, } \mathrm{Zn}, \mathrm{Ca} \text {, and } \mathrm{Al}) \text { and } \\
\text { metal-ion rechargeable batteries } \\
\text { with organic materials as } \\
\text { promising electrodes }\end{array}$ & AMVIBs (Zn, Mg, Ca, Al) & $\begin{array}{c}\text { Development and perspectives of organic } \\
\text { electrodes for aqueous rechargeable } \\
\text { multivalent ion batteries. }\end{array}$ & [53] \\
\hline $\begin{array}{l}\text { Nat. Rev. } \\
\text { Mater. }\end{array}$ & $\begin{array}{l}5(2020) \\
276-294\end{array}$ & $\begin{array}{l}\text { Design strategies for non- } \\
\text { aqueous multivalent-ion and } \\
\text { monovalent-ion battery anodes }\end{array}$ & $\begin{array}{l}\text { Non-aqueous multivalent-ion } \\
\text { and monovalent-ion batteries } \\
\qquad(\mathrm{Li}, \mathrm{Na}, \mathrm{K}, \mathrm{Mg}, \mathrm{Ca}, \mathrm{Al})\end{array}$ & $\begin{array}{c}\text { Development of anodes in non-aqueous } \\
\text { multivalent-ion and monovalent-ion } \\
\text { batteries ( } \mathrm{Li}, \mathrm{Na}, \mathrm{K}, \mathrm{Mg}, \mathrm{Ca}, \mathrm{Al}) \text {. }\end{array}$ & {$[54]$} \\
\hline $\begin{array}{l}\text { Adv. Energy } \\
\text { Mater. }\end{array}$ & $\begin{array}{c}10(2020) \\
1904199\end{array}$ & $\begin{array}{l}\text { Covalent-organic frameworks: } \\
\text { advanced organic electrode } \\
\text { materials for rechargeable } \\
\text { batteries }\end{array}$ & $\begin{array}{l}\text { Monovalent-ion batteries ( } \mathrm{Li} \text {, } \\
\mathrm{Na}, \mathrm{K} \text { ) and aqueous zinc ion } \\
\text { batteries }\end{array}$ & $\begin{array}{c}\text { The challenges and perspectives of COF } \\
\text { electrode materials for rechargeable } \\
\text { batteries ( } \mathrm{Li}, \mathrm{Na}, \mathrm{K}, \mathrm{Zn}) .\end{array}$ & [55] \\
\hline $\begin{array}{l}\text { Energy } \\
\text { Environ. Sci. }\end{array}$ & $\begin{array}{l}13(2020) \\
3950-3992\end{array}$ & $\begin{array}{l}\text { Recent advances in developing } \\
\text { organic electrode materials for } \\
\text { multivalent rechargeable batteries }\end{array}$ & $\begin{array}{l}\text { Multivalent-ion batteries (Zn, } \\
\qquad \mathrm{Mg}, \mathrm{Ca}, \mathrm{Al})\end{array}$ & $\begin{array}{c}\text { Development and perspectives of organic } \\
\text { electrodes for rechargeable multivalent ion } \\
\text { batteries. }\end{array}$ & {$[56]$} \\
\hline $\begin{array}{l}\text { Mater. Today } \\
\text { Energy }\end{array}$ & $\begin{array}{l}18(2020) \\
100547\end{array}$ & $\begin{array}{c}\text { Recent progress in aqueous } \\
\text { monovalent-ion batteries with } \\
\text { organic materials as promising } \\
\text { electrodes }\end{array}$ & $\begin{array}{l}\text { Aqueous batteries with } \\
\text { monovalent-ion charge carrier } \\
\left(\mathrm{Li}^{+}, \mathrm{Na}^{+}, \mathrm{K}^{+}, \mathrm{H}^{+}, \mathrm{H}_{3} \mathrm{O}^{+}, \mathrm{NH}_{4}^{+}\right)\end{array}$ & $\begin{array}{c}\text { Development and perspectives of organic } \\
\text { electrodes for aqueous rechargeable } \\
\text { multivalent ion batteries. }\end{array}$ & [57] \\
\hline $\begin{array}{l}\text { Angew. Chem., } \\
\text { Int. Ed. }\end{array}$ & $\begin{array}{c}59(2020) \\
18322-18333\end{array}$ & $\begin{array}{c}\text { Progress of organic electrodes } \\
\text { in aqueous electrolyte for energy } \\
\text { storage and conversion }\end{array}$ & $\begin{array}{l}\text { Aqueous organic batteries } \\
\left(\mathrm{Li}, \mathrm{Na}, \mathrm{K}, \mathrm{Zn}, \mathrm{Mg}, \mathrm{Ca}, \mathrm{H}_{3} \mathrm{O}^{+}\right. \\
\left.\mathrm{NH}_{4}^{+}\right)\end{array}$ & $\begin{array}{l}\text { Development and perspectives of organics } \\
\text { containing carbonyls for energy storage } \\
\text { and conversion in aqueous electrolytes. }\end{array}$ & [58] \\
\hline This review & & $\begin{array}{l}\text { The cathode design for aqueous } \\
\text { rechargeable multivalent } \\
\text { ion batteries: challenge and } \\
\text { opportunities }\end{array}$ & AMVIBs (Zn, Mg, Ca, Al) & $\begin{array}{l}\text { The clear and systematic summary } \\
\text { of general challenges, materials, and } \\
\text { promising strategies for the cathodes of } \\
\text { AMVIBs ( } \mathrm{Zn}, \mathrm{Mg}, \mathrm{Ca}, \mathrm{Al}) \text {; } \\
\text { The establishment of the inherent } \\
\text { relationships among promising strategies } \\
\text { and common challenges } \\
\text { The illustration and comparison of the } \\
\text { features for each technology }\end{array}$ & - \\
\hline
\end{tabular}

2.78-2.62 V, suggesting the presence of $\mathrm{MnO}_{2}$. However, the disappearance of $\mathrm{MnO}_{2}$ peaks and the emerging peaks related to D $\left(1354 \mathrm{~cm}^{-1}\right)$ and $\mathrm{G}\left(1598 \mathrm{~cm}^{-1}\right)$ bands of carbon at the end of the discharge indicated the removal of $\mathrm{MnO}_{2}$. Finally, the carbon peaks vanished rapidly and $\mathrm{MnO}_{2}$ peaks reappearing at the beginning of the charge process revealed the deposit of $\mathrm{MnO}_{2}$.

The surface modification and coating is another widely studied strategy to suppress Mn dissolution issue. Through coating a multilayer reduced graphene oxide (rGO) with a thickness of $5 \mathrm{~nm}$ on the $\mathrm{MnO}_{2}$ nanowire, Mai et al. successfully synthesized $\alpha-\mathrm{MnO}_{2} /$ graphene scrolls (Figure 4d,e). ${ }^{[71]}$ The rGO scrolls alleviate the manganese dissolution during cycling and demonstrate a remarkable capacity $\left(362.2 \mathrm{mAh} \mathrm{g}^{-1}\right.$ at $\left.0.3 \mathrm{~A} \mathrm{~cm}^{-2}\right)$ and durability $\left(94 \%\right.$ retention at $3 \mathrm{~A} \mathrm{~g}^{-1}$ after
3000 cycles). Other methodologies, such as the incorporation of metal ions and lattice defects, provide new strategies for addressing this challenge and still need further research and development. Very recently, Liang and colleagues developed an oxygen-defect $\mathrm{K}_{0.8} \mathrm{Mn}_{8} \mathrm{O}_{16}$ (KMO), which demonstrates an impressive durability $\left(\approx 100 \%\right.$ capacity retention at $\left.1 \mathrm{~A} \mathrm{~g}^{-1}\right)$ over 1000 cycles. ${ }^{[72]}$ Through ICP-OES analysis, they proposed that $\mathrm{K}^{+}$ions steadily intercalated into the tunnels of KMO and bonded with the Mn polyhedrons could alleviate the dissolution of Mn, thus enhancing the stability of KMO.

Besides the mechanisms for the $\mathrm{Mn}^{2+}$ pre-addition strategy, the energy storage mechanism of Mn-based cathodes is somewhat controversial, which includes three major possible mechanisms: a) $\mathrm{Zn}^{2+}$ intercalation/deintercalation, b) conversion 
Table 3. Representative cathode materials of rechargeable AZIBs in recent years.

\begin{tabular}{|c|c|c|c|c|c|c|c|c|}
\hline Materials & $\begin{array}{l}\text { Free- } \\
\text { standing } \\
(\mathrm{Y} / \mathrm{N})\end{array}$ & Electrolyte & $\begin{array}{l}\text { Working } \\
\text { potential } \\
\text { [V] }\end{array}$ & $\begin{array}{l}\text { Specific capacity } \\
{\left[\mathrm{mAh} \mathrm{g}^{-1}\right] \text { at }} \\
\quad \mathrm{x} \mathrm{A} \mathrm{g}^{-1}\end{array}$ & $\begin{array}{l}\text { Capacity retention } \\
\text { at y } \mathrm{Ag}^{-1} \text { after } \mathrm{n} \text { cycles }\end{array}$ & $\begin{array}{l}\text { Rate capability } \\
\text { (capacity } \\
\text { retention } \\
\text { at } z \times x \mathrm{Ag}^{-7} \text { ) }\end{array}$ & Strategies & Reference \\
\hline \multicolumn{9}{|l|}{ Mn-based materials } \\
\hline$\alpha-\mathrm{MnO}_{2}$ & $\mathrm{~N}$ & Gelatin + PAM & $0.8-2.0$ & $306(x=0.0616)$ & $97 \%(n=1000, y=2.772)$ & $40.2 \%(z=6)$ & - & [203] \\
\hline$\alpha$ - $\mathrm{MnO}_{2}$ /graphene scrolls & $\mathrm{N}$ & $\begin{array}{l}2 \mathrm{M} \mathrm{ZnSO}_{4}+ \\
0.2 \mathrm{M} \mathrm{MnSO}_{4}\end{array}$ & $1.0-1.9$ & $362.2(x=0.3)$ & $94 \%(n=3000, y=3)$ & $55.1 \%(z=30)$ & $B, G, H$ & [71] \\
\hline$\alpha-\mathrm{MnO}_{2}$ nanofiber & $\mathrm{N}$ & $\begin{array}{l}2 \mathrm{M} \mathrm{ZnSO}_{4}+ \\
0.1 \mathrm{M} \mathrm{MnSO}_{4}\end{array}$ & $1.0-1.8$ & $255(x=0.0616)$ & $92 \%(n=5000, y=1.54)$ & - & $\mathrm{B}, \mathrm{H}$ & [2] \\
\hline$\beta-\mathrm{MnO}_{2}$ nanorod & $\mathrm{N}$ & $\begin{array}{l}3 \mathrm{~m} \mathrm{Zn}(\mathrm{TFSI})_{2}+ \\
0.1 \mathrm{~m} \mathrm{Mn}(\mathrm{TFSI})_{2}\end{array}$ & $0.8-1.9$ & $225(x=0.2)$ & $94 \%(n=2000, y=2)$ & $38.7 \%(z=50)$ & $\mathrm{A}, \mathrm{H}$ & [37] \\
\hline$\beta-\mathrm{MnO}_{2}$ & $\mathrm{~N}$ & $\begin{array}{l}3 \mathrm{M} \mathrm{ZnSO}_{4}+ \\
0.1 \mathrm{M} \mathrm{MnSO}_{4}\end{array}$ & $0.8-1.8$ & $302(x=0.05)$ & $94 \%(n=300, y=0.1)$ & - & $B, E$ & [75] \\
\hline$\gamma-\mathrm{MnO}_{2}$ & N & $1 \mathrm{M} \mathrm{ZnSO}_{4}$ & $1.0-1.8$ & $285(x=0.5)$ & $64 \%(n=45, \gamma=0.5)$ & - & $\mathrm{H}$ & [66] \\
\hline La-Ca co-doped $\varepsilon-\mathrm{MnO}_{2}$ & N & $\begin{array}{l}1 \mathrm{M} \mathrm{ZnSO}_{4}+ \\
0.4 \mathrm{M} \mathrm{MnSO}_{4}\end{array}$ & $0.8-s s 1.9$ & $300(x=0.25)$ & $76 \%(n=200, y=0.1)$ & - & $B, D$ & [42] \\
\hline$\delta-\mathrm{MnO}_{2}$ & $\mathrm{~N}$ & $\begin{array}{l}2 \mathrm{M} \mathrm{ZnSO}_{4}+ \\
0.1 \mathrm{M} \mathrm{MnSO}_{4}\end{array}$ & $1.0-1.8$ & $266(x=0.1)$ & $40 \%(n=5000, y=2)$ & $42.5 \%(z=30)$ & B & [67] \\
\hline PANI intercalated $\alpha-\mathrm{MnO}_{2}$ & $\mathrm{~N}$ & $\begin{array}{l}2 \mathrm{M} \mathrm{ZnSO}_{4}+ \\
0.1 \mathrm{M} \mathrm{MnSO}_{4}\end{array}$ & $1.0-1.8$ & $280(x=0.2)$ & $\approx 90 \%(n=200, y=0.2)$ & $33 \%(z=15)$ & $\begin{array}{l}\mathrm{B}, \mathrm{C} \\
\mathrm{C}, \mathrm{H}\end{array}$ & [76] \\
\hline $\mathrm{Mn}_{2} \mathrm{O}_{3}$ & $\mathrm{~N}$ & $\begin{array}{l}2 \mathrm{M} \mathrm{ZnSO}_{4}+ \\
0.1 \mathrm{M} \mathrm{MnSO}_{4}\end{array}$ & $1.0-1.9$ & $148(x=0.1)$ & $87 \%(n=2000, y=0.1)$ & $22.2 \%(z=20)$ & B & [68] \\
\hline $\mathrm{Mn}_{3} \mathrm{O}_{4}$ & $\mathrm{~N}$ & $2 \mathrm{M} \mathrm{ZnSO}_{4}$ & $0.8-1.9$ & $239.2(x=0.1)$ & $72 \%(n=300, y=0.5)$ & $50 \%(z=20)$ & $\mathrm{F}, \mathrm{H}$ & [204] \\
\hline $\mathrm{Na}_{0.44} \mathrm{MnO}_{2}$ & $\mathrm{~N}$ & $\begin{array}{l}1 \mathrm{M} \mathrm{Na}_{2} \mathrm{SO}_{4}+ \\
0.5 \mathrm{MnSO}_{4}+ \\
0.05 \mathrm{M} \mathrm{MnSO}_{4}\end{array}$ & $1.0-1.9$ & $340(x=0.1)$ & $100 \%(n=150, y=0.1)$ & $33 \%(z=6)$ & B & [205] \\
\hline $\mathrm{Na}_{0.44} \mathrm{MnO}_{2} \cdot 1.5 \mathrm{H}_{2} \mathrm{O}$ & $\mathrm{N}$ & $\begin{array}{l}2 \mathrm{M} \mathrm{ZnSO}_{4}+ \\
0.2 \mathrm{M} \mathrm{MnSO}_{4}\end{array}$ & $0.9-1.9$ & $278(x=1 C)$ & $98 \%(n=10000, y=20 \mathrm{C})$ & $34 \%(z=20)$ & $B, C$ & [77] \\
\hline $\mathrm{K}_{0.8} \mathrm{Mn}_{8} \mathrm{O}_{16}$ & $\mathrm{~N}$ & $\begin{array}{l}2 \mathrm{M} \mathrm{ZnSO}_{4}+ \\
0.1 \mathrm{M} \mathrm{MnSO}_{4}\end{array}$ & $1.0-1.8$ & $300(x=0.1)$ & $100 \%(n=1000, y=1)$ & $30 \%(z=20)$ & $B, E$ & [72] \\
\hline $\mathrm{ZnMn}_{2} \mathrm{O}_{4} / \mathrm{C}$ & $\mathrm{N}$ & $3 \mathrm{~m} \mathrm{Zn}(\mathrm{TFSI})_{2}$ & $0.8-2.0$ & $150(x=0.05)$ & $94 \%(n=500, y=0.5)$ & - & $A, E, G$ & {$[40]$} \\
\hline$\alpha-\mathrm{MnO}_{2}$ nanorod & Y & $\begin{array}{c}\mathrm{PVA} / \mathrm{ZnCl}_{2} / \\
\mathrm{MnSO}_{4}\end{array}$ & $1.0-1.8$ & $353(x=0.5)$ & $93.6 \%(n=1000, y=0.5)$ & - & $\mathrm{F}, \mathrm{G}$ & [63] \\
\hline$\alpha-\mathrm{MnO}_{2}$ nanowires & Y & $\begin{array}{l}2 \mathrm{M} \mathrm{ZnSO}_{4}+ \\
0.2 \mathrm{M} \mathrm{MnSO}_{4}\end{array}$ & $0.9-1.8$ & $348(x=0.1)$ & $58.3 \%(n=300, y=0.5)$ & $33 \%(z=20)$ & $\mathrm{B}, \mathrm{G}, \mathrm{H}$ & [64] \\
\hline$\alpha-\mathrm{MnO}_{2} @$ PEDOT & Y & $\begin{array}{c}\mathrm{PVA} / \mathrm{ZnCl} 2 / \\
\mathrm{MnSO}_{4}\end{array}$ & $1.0-1.8$ & $366.6(x=0.74)$ & $83.7 \%(n=300, y=1.11)$ & $55.6 \%(z=5.3)$ & G & [46] \\
\hline$\alpha-\mathrm{MnO}_{2} / \mathrm{rGO}$ & Y & $\begin{array}{l}2 \mathrm{M} \mathrm{ZnSO}_{4}+ \\
0.1 \mathrm{M} \mathrm{MnSO}_{4}\end{array}$ & $1.0-2.0$ & $332(x=0.3)$ & $96 \%(n=500, y=6)$ & $54.5 \%(z=20)$ & $B, F, C$ & [65] \\
\hline $\begin{array}{l}\mathrm{Mn}_{3} \mathrm{O}_{4} @ \text { nitrogen-doped } \\
\text { carbon }\end{array}$ & Y & $\begin{array}{l}2 \mathrm{M} \mathrm{ZnSO}_{4}+ \\
0.1 \mathrm{M} \mathrm{MnSO}_{4}\end{array}$ & $1.0-1.8$ & $280(x=0.1)$ & $100 \%(n=500, y=0.5)$ & $43.6 \%(z=10)$ & $B, C$ & [69] \\
\hline $\mathrm{Mn}_{3} \mathrm{O}_{4}$ nanoflower & Y & $\begin{array}{l}2 \mathrm{M} \mathrm{ZnSO}_{4}+ \\
0.1 \mathrm{M} \mathrm{MnSO}_{4}\end{array}$ & $1.0-1.8$ & $300(x=0.5)$ & $98 \%(n=50, \gamma=0.5)$ & - & $B, C$ & [47] \\
\hline \multicolumn{9}{|l|}{ V-based materials } \\
\hline $\mathrm{V}_{2} \mathrm{O}_{5}$ & $\mathrm{~N}$ & $3 \mathrm{M} \mathrm{Zn}(\mathrm{TFSI})_{2}$ & $0.2-1.6$ & $470(x=0.2)$ & $91.1 \%(n=4000, \gamma=5)$ & $84.4 \%(z=50)$ & $A, C$ & [78] \\
\hline $\mathrm{V}_{2} \mathrm{O}_{5} \cdot n \mathrm{H}_{2} \mathrm{O} /$ graphene & $\mathrm{N}$ & $3 \mathrm{~m} \mathrm{Zn}(\mathrm{TFSI})_{2}$ & $0.2-1.6$ & $381(x=0.06)$ & $71 \%(n=900, y=6)$ & $26.2 \%(z=50)$ & $\mathrm{A}, \mathrm{C}, \mathrm{G}, \mathrm{H}$ & [82] \\
\hline $\mathrm{VO}_{2}$ & $\mathrm{~N}$ & $3 \mathrm{~m} \mathrm{Zn}(\mathrm{TFSI})_{2}$ & $0.3-1.5$ & $375(x=0.1)$ & $85 \%(n=2000, y=5)$ & - & $A, E, H$ & [81] \\
\hline $\mathrm{V}_{2} \mathrm{O}_{3}$ & $\mathrm{~N}$ & $2 \mathrm{~m} \mathrm{Zn}(\mathrm{TFSI})_{2}$ & $0.2-1.6$ & $625(x=0.1)$ & $100 \%(n=10000, y=10)$ & $75.8 \%(z=200)$ & $A, F$ & [38] \\
\hline $\mathrm{H}_{2} \mathrm{~V}_{3} \mathrm{O}_{8}$ & $\mathrm{~N}$ & $3 \mathrm{~m} \mathrm{Zn}(\mathrm{TFSI})_{2}$ & $0.2-1.6$ & $423.8(x=0.1)$ & $94.3 \%(n=1000, y=5)$ & $26.2 \%(z=50)$ & A & [85] \\
\hline $\mathrm{V}_{6} \mathrm{O}_{13} \cdot n \mathrm{H}_{2} \mathrm{O}$ & $\mathrm{N}$ & $3 \mathrm{~m} \mathrm{Zn}(\mathrm{TFSI})_{2}$ & $0.2-1.4$ & $395(x=0.1)$ & $87 \%(n=1000, y=5)$ & $24.3 \%(z=200)$ & $A, C, F$ & [206] \\
\hline
\end{tabular}


Table 3. Continued.

\begin{tabular}{|c|c|c|c|c|c|c|c|c|}
\hline Materials & $\begin{array}{l}\text { Free- } \\
\text { standing } \\
(\mathrm{Y} / \mathrm{N})\end{array}$ & Electrolyte & $\begin{array}{c}\text { Working } \\
\text { potential } \\
{[\mathrm{V}]}\end{array}$ & $\begin{array}{c}\text { Specific capacity } \\
{\left[\mathrm{mAh} \mathrm{g}^{-1}\right] \text { at }} \\
\quad \mathrm{xA} \mathrm{g}^{-1}\end{array}$ & $\begin{array}{l}\text { Capacity retention } \\
\text { at } \mathrm{A} \mathrm{g} \mathrm{g}^{-1} \text { after } \mathrm{n} \text { cycles }\end{array}$ & $\begin{array}{l}\text { Rate capability } \\
\text { (capacity } \\
\text { retention } \\
\text { at } z \times x \mathrm{~A} \mathrm{~g}^{-1} \text { ) }\end{array}$ & Strategies & Reference \\
\hline $\mathrm{Na}_{0.33} \mathrm{~V}_{2} \mathrm{O}_{5}$ & $\mathrm{~N}$ & $3 \mathrm{~m} \mathrm{Zn}(\mathrm{TFSI})_{2}$ & $0.2-1.6$ & $367(x=0.1)$ & $93 \%(n=1000, y=1)$ & $26.3 \%(z=20)$ & $A, C$ & [79] \\
\hline $\mathrm{CaV}_{6} \mathrm{O}_{16} \cdot 2.7 \mathrm{H}_{2} \mathrm{O}$ & N & $3 \mathrm{~m} \mathrm{Zn}(\mathrm{TFSI})_{2}$ & $0.2-1.6$ & $265(x=0.1)$ & $100 \%(n=300, y=0.5)$ & $46.2 \%(z=20)$ & $A, C$ & {$[87]$} \\
\hline$\delta-\mathrm{Ni}_{0.25} \mathrm{~V}_{2} \mathrm{O}_{5} \cdot n \mathrm{H}_{2} \mathrm{O}$ & $\mathrm{N}$ & $3 \mathrm{~m} \mathrm{Zn}(\text { TFSI })_{2}$ & $0.3-1.7$ & $402(x=0.2)$ & $98 \%(n=1200, y=5)$ & $35.9 \%(z=25)$ & $\mathrm{A}, \mathrm{C}, \mathrm{H}$ & [48] \\
\hline $\mathrm{NaV}_{3} \mathrm{O}_{8} \cdot 1.5 \mathrm{H}_{2} \mathrm{O}$ & $\mathrm{N}$ & $1 \mathrm{M} \mathrm{ZnSO}_{4}$ & $0.3-1.2$ & $380(x=0.5)$ & $82 \%(n=1000, y=4)$ & - & C & [95] \\
\hline $\mathrm{NH}_{4} \mathrm{~V}_{4} \mathrm{O}_{10}(3 \mathrm{D}-\mathrm{NVO})$ & N & $1 \mathrm{~m} \mathrm{Zn}(\mathrm{TFSI})_{2}$ & $0.3-1.5$ & $485(x=0.1)$ & $90 \%(n=3000, y=10)$ & $38.1 \%(z=100)$ & $A, F, H$ & [83] \\
\hline PANI intercalated $\mathrm{V}_{2} \mathrm{O}_{5}$ & N & $3 \mathrm{~m} \mathrm{Zn}(\text { TFSI })_{2}$ & $0.2-1.6$ & $405(x=0.1)$ & $97.6 \%(n=2000, y=20)$ & $43.2 \%(z=300)$ & $\mathrm{A}, \mathrm{C}, \mathrm{G}, \mathrm{H}$ & [84] \\
\hline PANI intercalated $\mathrm{V}_{2} \mathrm{O}_{5}$ & N & $3 \mathrm{~m} \mathrm{Zn}(\mathrm{TFSI})_{2}$ & $0.4-1.5$ & $372(x=0.5)$ & $60 \%(n=2000, y=5)$ & $56.4 \%(z=20)$ & $\mathrm{A}, \mathrm{C}, \mathrm{G}, \mathrm{H}$ & [92] \\
\hline PEDOT- $\mathrm{NH}_{4} \mathrm{~V}_{3} \mathrm{O}_{8}$ & $\mathrm{~N}$ & $3 \mathrm{~m} \mathrm{Zn}(\text { TFSI })_{2}$ & $0.2-1.6$ & $356.8(x=0.05)$ & $94.1 \%(n=5000, y=10)$ & $49.5 \%(z=200)$ & $\begin{array}{c}\mathrm{A}, \mathrm{C}, \mathrm{E} \\
\mathrm{C}, \mathrm{H}\end{array}$ & [91] \\
\hline $\mathrm{rCO} / \mathrm{Na}_{2} \mathrm{~V}_{3} \mathrm{O}_{8}$ & Y & $\begin{array}{l}1 \mathrm{M} \mathrm{ZnSO} O_{4}+ \\
1 \mathrm{M} \mathrm{Na}_{2} \mathrm{SO}_{4}\end{array}$ & $0.3-1.2$ & $410(x=0.1)$ & $94 \%(n=2000, y=5)$ & - & $B, C$ & [86] \\
\hline $\mathrm{NVO} / \mathrm{rGO} / \mathrm{CNT}$ composite & Y & $3 \mathrm{~m} \mathrm{Zn}(\mathrm{TFSI})_{2}$ & $0.2-1.6$ & $459.1(x=0.5)$ & $83.1 \%(n=1800, y=10)$ & $79.6 \%(z=20)$ & $A, C$ & [73] \\
\hline \multicolumn{9}{|l|}{ Prussian blue analogues } \\
\hline $\mathrm{ZnHCF}$ & $\mathrm{N}$ & $1 \mathrm{M} \mathrm{ZnSO}_{4}$ & $0.8-1.9$ & $65.4(x=0.06)$ & $81 \%(n=100, y=0.3)$ & - & $\mathrm{H}$ & [97] \\
\hline CuHCF & $\mathrm{N}$ & $0.02 \mathrm{M} \mathrm{ZnSO}_{4}$ & $1.3-2.1$ & $53(x=0.06)$ & $96.3 \%(n=50, y=0.1)$ & $80.9 \%(z=10)$ & - & [89] \\
\hline $\mathrm{FeHCF}$ & $\mathrm{N}$ & $\begin{array}{c}1 \mathrm{M} \mathrm{Zn}(\mathrm{OAc})_{2} \text { in } \\
\text { choline acetate } \\
\text { with } 30 w t \% \text { of } \\
\text { water }\end{array}$ & $0.5-1.8$ & $54\left(x=0.1 \mathrm{~mA} \mathrm{~cm}^{-2}\right)$ & $\begin{array}{c}99 \%\left(\begin{array}{c}n=50, y=0.1 \mathrm{~mA} \\
\left.\mathrm{~cm}^{-2}\right)\end{array}\right.\end{array}$ & - & - & [98] \\
\hline $\mathrm{NiHCF}$ & $\mathrm{N}$ & $\begin{array}{c}0.05 \mathrm{M} \mathrm{ZnSO}_{4}+ \\
0.5 \mathrm{M} \mathrm{Na}_{2} \mathrm{SO}_{4}\end{array}$ & $0.9-1.9$ & $76.2(x=0.1)$ & $81 \%(n=1000, y=0.5)$ & $59.1 \%(z=100)$ & B & [99] \\
\hline $\mathrm{ZnHCF} @ \mathrm{MnO}_{2}$ & $\mathrm{~N}$ & $0.5 \mathrm{M} \mathrm{ZnSO}_{4}$ & $1.4-1.9$ & $118(x=0.1)$ & $77 \%(n=1000, y=0.5)$ & $59.3 \%(z=100)$ & G & [207] \\
\hline $\mathrm{FeFe}(\mathrm{CN})_{6}$ & $\mathrm{~N}$ & $\begin{array}{c}1 \mathrm{~m} \mathrm{Zn}(\mathrm{OAc})_{2} \\
\text { in }[\mathrm{Ch}] \mathrm{OAc}+ \\
\text { water }\end{array}$ & $1.0-2.0$ & $112(x=0.01)$ & $99 \%(n=50, y=0.01)$ & $25.8 \%(z=6)$ & B & [100] \\
\hline $\mathrm{Na}_{2} \mathrm{MnFe}(\mathrm{CN})_{6}$ & $\mathrm{~N}$ & $\begin{array}{c}1 \mathrm{M} \mathrm{ZnSO}_{4}+1 \mathrm{M} \\
\mathrm{Na}_{2} \mathrm{SO}_{4}\end{array}$ & $0.2-1.2$ & $170(x=0.5 \mathrm{C})$ & $75 \%(n=2000, y=0.5 \mathrm{C})$ & $61.8 \%(z=60)$ & $\mathrm{B}, \mathrm{H}$ & [101] \\
\hline \multicolumn{9}{|l|}{ Other materials } \\
\hline PANI & Y & $1 \mathrm{~m} \mathrm{Zn}(\mathrm{TFSI})_{2}$ & $0.5-1.5$ & $200(x=0.05)$ & $92 \%(n=3000, y=5)$ & $45 \%(z=100)$ & A & [104] \\
\hline $\begin{array}{l}\text { Pyrene-4,5,9,10-tetraone } \\
\text { (PTO) }\end{array}$ & Y & $2 \mathrm{M} \mathrm{ZnSO}_{4}$ & $0.4-1.5$ & $336(x=0.04)$ & $70 \%(n=1000, y=0.2)$ & - & - & [106] \\
\hline $\begin{array}{l}\text { Tetrachloro-1,4-benzoquinone } \\
\text { (p-chloranil) }\end{array}$ & $\mathrm{N}$ & $1 \mathrm{~m} \mathrm{Zn}(\text { TFSI })_{2}$ & $0.8-1.4$ & $205(x=0.217)$ & $62.4 \%(n=200, y=0.217)$ & - & $\mathrm{A}, \mathrm{H}$ & [208] \\
\hline Quinone (C4Q) & N & $3 \mathrm{~m} \mathrm{Zn}(\mathrm{TFSI})_{2}$ & $0.2-1.8$ & $335(x=0.02)$ & $87 \%(n=1000, y=0.5)$ & - & A & [105] \\
\hline $\begin{array}{l}\text { Ladder-like Polymer (PDB, } \\
\left.\left(\mathrm{C}_{6} \mathrm{O}_{2} \mathrm{~S}_{2}\right)_{n}\right)\end{array}$ & $\mathrm{N}$ & $4 \mathrm{~m} \mathrm{Zn}(\mathrm{TFSI})_{2}$ & $0.2-1.6$ & $205(x=0.05)$ & $75.3 \%(n=10000, y=20)$ & - & $\mathrm{A}, \mathrm{H}$ & [107] \\
\hline $\mathrm{Cu}_{3}(\mathrm{HHTP})_{2}$ & $\mathrm{~N}$ & $3 \mathrm{~m} \mathrm{Zn}(\mathrm{TFSI})_{2}$ & $0.6-1.3$ & $228(x=0.05)$ & $75 \%(n=4000, y=4)$ & - & $\mathrm{A}, \mathrm{H}$ & [109] \\
\hline $\mathrm{MoS}_{2}$ with O-doping & N & $3 \mathrm{~m} \mathrm{Zn}(\mathrm{TFSI})_{2}$ & $0.2-1.4$ & $232(x=0.1)$ & - & $38.7 \%(z=10)$ & $\mathrm{A}, \mathrm{C}, \mathrm{H}$ & [61] \\
\hline $\mathrm{MoS}_{2}$ with defects & $\mathrm{N}$ & $3 \mathrm{~m} \mathrm{Zn}(\mathrm{TFSI})_{2}$ & $0.2-1.2$ & $128.23(x=0.1)$ & $87.8 \%(n=1000, y=1)$ & $50.8 \%(z=20)$ & $A, E, H$ & [41] \\
\hline $\mathrm{Co}(\mathrm{III})$ rich- $-\mathrm{Co}_{3} \mathrm{O}_{4}$ & $\mathrm{~N}$ & $\begin{array}{l}2 \mathrm{M} \mathrm{ZnSO}_{4}+ \\
0.2 \mathrm{M} \mathrm{CoSO}_{4}\end{array}$ & $0.8-2.2$ & $158(x=1)$ & $92 \%(n=5000, \gamma=1)$ & $31.6 \%(z=8)$ & $B, G, H$ & [113] \\
\hline $\mathrm{CoSe}_{2-x} @ \mathrm{C} / \mathrm{CC}$ & Y & $\begin{array}{c}(\mathrm{PANa})-\mathrm{KOH} / \\
\mathrm{Zn}(\mathrm{Ac})_{2}\end{array}$ & $0.75-2.05$ & $\begin{array}{c}112 \mathrm{mAh} \mathrm{cm}-2 \\
\left(x=0.004 \mathrm{~A} \mathrm{~cm}^{-2}\right)\end{array}$ & $\begin{array}{l}80 \%(n=10000 \\
\left.y=0.01 \mathrm{~A} \mathrm{~cm}^{-2}\right)\end{array}$ & - & $\mathrm{D}, \mathrm{G}$ & [1יו1] \\
\hline $\mathrm{Ni}-\mathrm{NiO}$ nanosheets & N & $1 \mathrm{~m} \mathrm{KOH}$ & $1.5-2.0$ & - & $\begin{array}{c}96.6 \%(n=10000 \\
y=22.2)\end{array}$ & - & G & [112] \\
\hline
\end{tabular}

*For the strategies employed: A ("water-in-salt" electrolyte), B (electrolyte additives), C (pre-intercalation strategy), D (heteroatom doping), E (defects engineering), F (size regulation), G (composites and free-standing configuration), $\mathrm{H}$ (advanced characterization and theoretical study). 
(a)

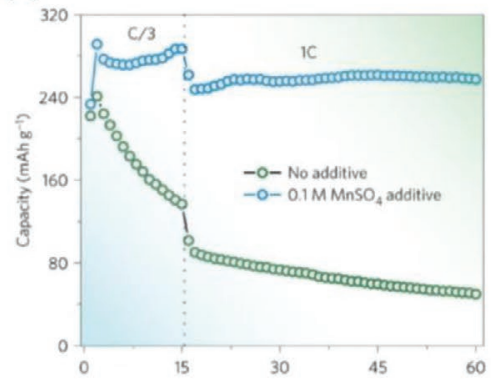

(b)

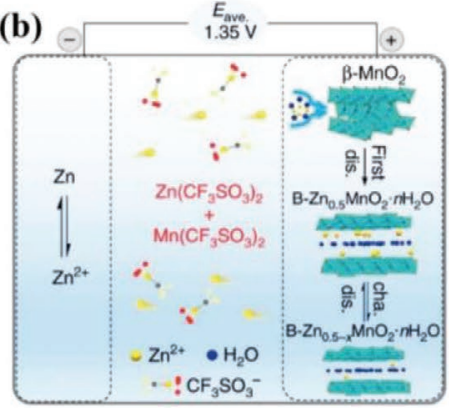

(f)

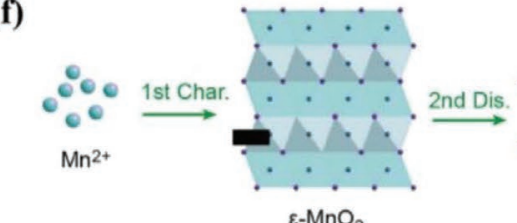

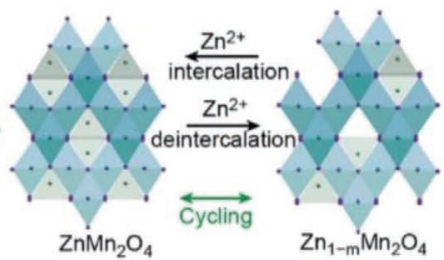

$M n(+3,+4) \bullet Z n(+2)$

- $M n(+2)$ (c)

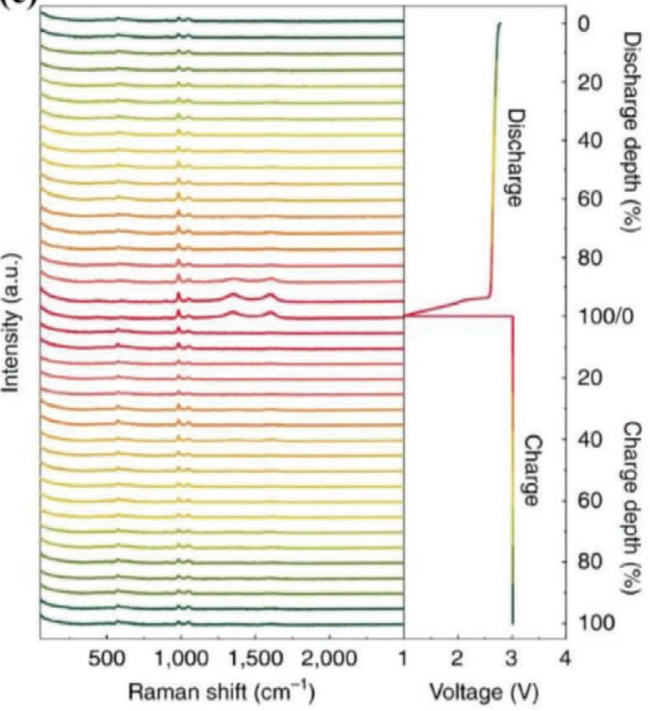

(e)
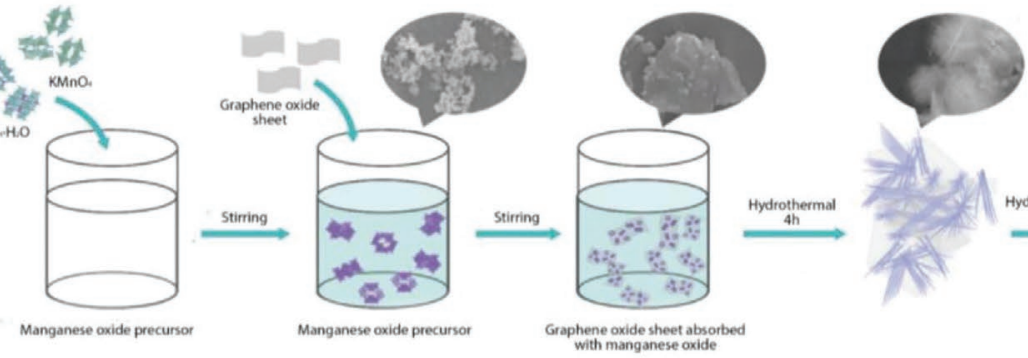

(d)

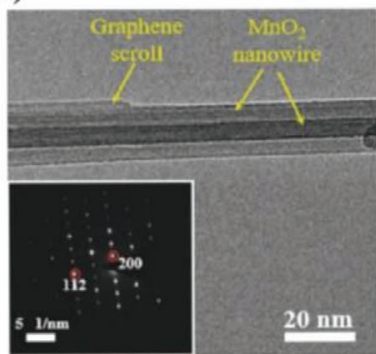

(g)

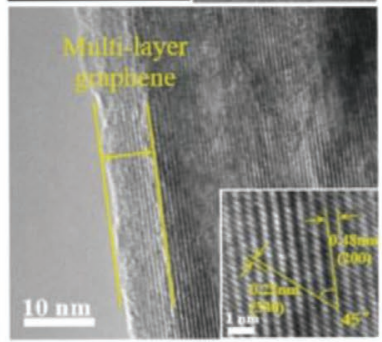

(h)
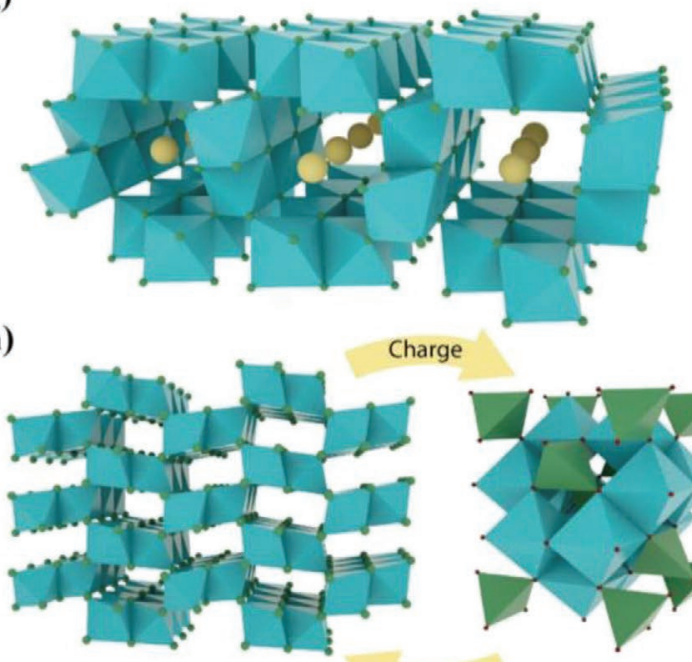

Charge

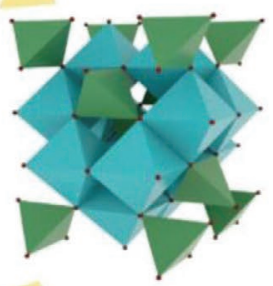

(i)

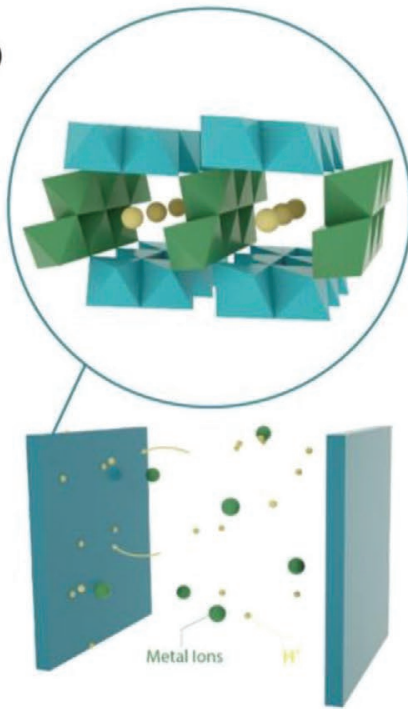

Discharge

Figure 4. $\mathrm{Mn}$-based cathode candidates for AZIBs. a) Cycling performance of $\mathrm{MnO}_{2}$ electrodes with and without $0.1 \mathrm{M} \mathrm{MnSO}_{4}$ additive in 2 M ZnSO aqueous electrolyte at the current densities of C/3 and 1 C, respectively; Reproduced with permission. ${ }^{[2]}$ Copyright 2016, Nature Springer. b) Schematic diagram of $\mathrm{Zn}-\mathrm{MnO}_{2} \mathrm{AZIB}$ using $\mathrm{CF}_{3} \mathrm{SO}_{3}$ electrolyte; Reproduced under the terms of CC-BY license. ${ }^{[37]}$ Copyright 2017, Nature Springer. C) In situ Raman spectra of the $\mathrm{MnO}_{2}$ electrode under decoupled $\mathrm{Zn}-\mathrm{MnO}_{2}$ battery (DZMB). Reproduced with permission. ${ }^{[70]}$ Copyright 2020, Nature Springer. d) Schematic diagram of the synthesize route of $\alpha-\mathrm{MnO}_{2}$ /graphene scrolls (MGS); e) SAED and HRTEM of MGS. Reproduced with permission. [7] Copyright 2018, Wiley. f) Schematic diagram of structural evolutions to spinel $\mathrm{ZnMn}_{2} \mathrm{O}_{4}$ during cycling. Reproduced with permission. ${ }^{[6]}$ Copyright 2020, Elsevier. Schematic diagram of mechanisms of g) $\mathrm{Zn}^{2+}$ insertion/extraction, and h) conversion reaction mechanism, and i) $\mathrm{Zn}^{2+} / \mathrm{H}^{+} \mathrm{co}^{-i n s e r t i o n}$. 
reaction, and c) $\mathrm{H}^{+} / \mathrm{Zn}^{2+}$ co-insertion. Currently, the dominant view is the reversible intercalation/deintercalation mechanism (Figure $4 \mathrm{~g}$ ) of $\mathrm{Zn}^{2+}$ during the redox of manganese oxides, which is widely reported..$^{[43,44,71]}$ However, Liu et al. observed that the $\alpha-\mathrm{MnO}_{2}$ will react with $\mathrm{H}^{+}$to form the $\mathrm{MnOOH}$ phase during the discharge process, and the products further react with $\mathrm{ZnSO}_{4}$ and $\mathrm{H}_{2} \mathrm{O}$ forming $\mathrm{ZnSO}_{4}\left[\mathrm{Zn}(\mathrm{OH})_{2}\right]_{3}$ and reaching the charge balance. ${ }^{[2]}$ Also, some researches have observed that $\mathrm{Zn}^{2+}$ intercalation will trigger structural transformation to layered $\mathrm{Zn}_{x} \mathrm{MnO}_{2}$ and/or $\mathrm{ZnMn}_{2} \mathrm{O}_{4}$ at different depths of the discharge (Figure $4 \mathrm{~h}) \cdot{ }^{[38,40]}$ Other investigations have indicated that the co-insertion mechanism of $\mathrm{Zn}^{2+}$ and $\mathrm{H}^{+}$exits in cathode materials of AZIBs (Figure 4i) ${ }^{[64,73]}$ Through electrochemical and structural analysis, Wang and co-workers first proposed the co-insertion of $\mathrm{Zn}^{2+}$ and $\mathrm{H}^{+}$mechanism based on the Akhtenskite $\mathrm{MnO}_{2}$, and confirmed that the insertion of $\mathrm{H}^{+}$happens before the $\mathrm{Zn}^{2+}$ insertion. ${ }^{[7]}$ Additionally, it is noteworthy that most of the AZIBs involved in the $\mathrm{H}^{+}$and $\mathrm{Zn}^{2+}$ co-insertion mechanism present better rate capability and capacity retention, when compared with those only involving $\mathrm{Zn}^{2+}$ (de)intercalation mechanisms. ${ }^{[42,50]}$ Further exploration of the energy storage mechanism of Mn-based cathodes is needed and will facilitate further development of AZIBs.

The third issue for Mn-based cathode materials is the phase transformation and structural collapse during the charge/ discharge process. Defect engineering is a widely recognized strategy to solve this issue, which includes two categories (cation vacancy and oxygen vacancy) for manganese oxides (Figure 5a). Chen et al. reported the cation-defective $\mathrm{ZnMn}_{2} \mathrm{O}_{4}$ spinel as the cathode for AZIBs, in which the defects effectively enhance the structural stability. ${ }^{[40]}$ The spinel structure is well maintained during the (de)insertion processes, as evidenced by the only signals $\left(\mathrm{ZnMn}_{2} \mathrm{O}_{4}\right)$ from the XRD profile. Then, they suggested that the mobility of $\mathrm{Zn}^{2+}$ in this particular structure (a)

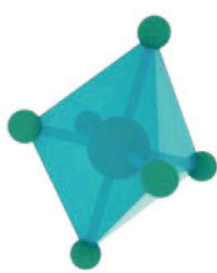

Perfect Structure
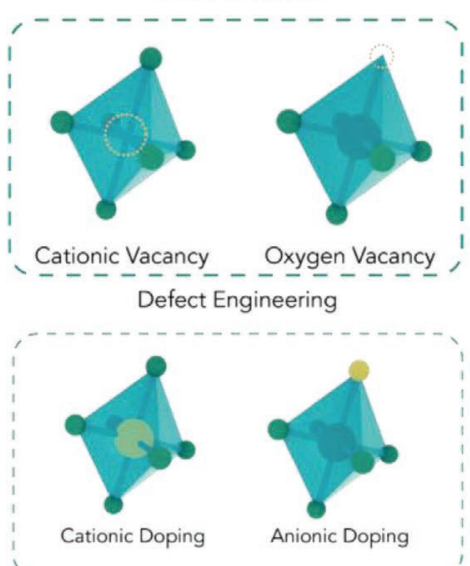

Substitutional Doping

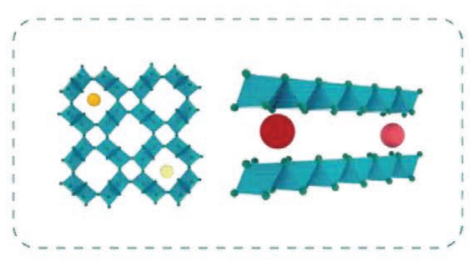

Pre-intercalation (b)

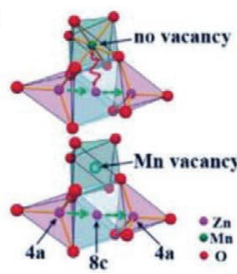

(e)

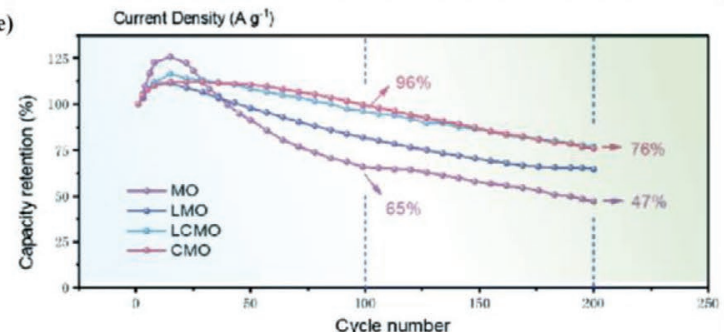

(g)

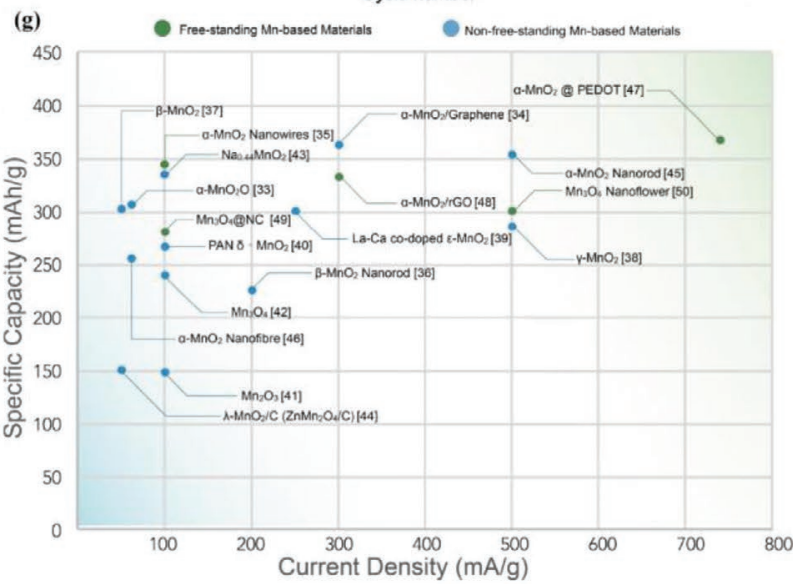

(c)
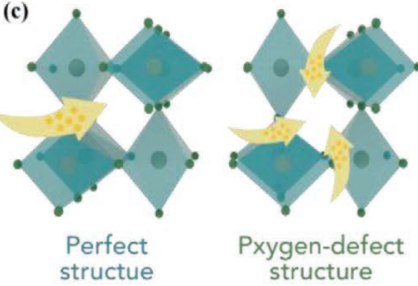

Pxygen-defect

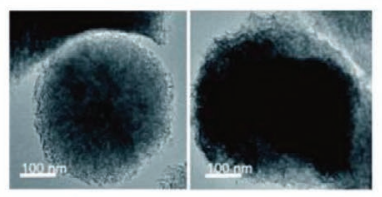

(h)

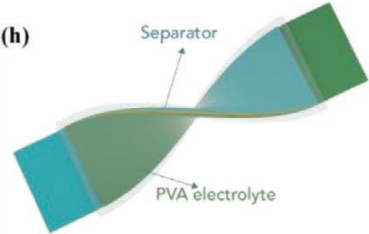

(i)

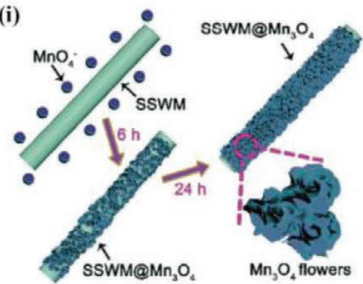

Figure 5. Mn-based cathode candidates for AZIBs. a) Schematic illustration of defect engineering, heteroatom doping, and pre-intercalation strategy of manganese oxides; b) schematic diagram of $\mathrm{Zn}^{2+}$ diffusion pathway in $\mathrm{ZMO}$ spinel without and with $\mathrm{Mn}$ vacancies. Reproduced with permission. ${ }^{400}$ Copyright 2016, American Chemical Society. c) schematic illustration of $\mathrm{H}^{+}$diffusion paths in pristine $\beta-\mathrm{MnO}_{2}$ and defect-rich $\beta$ - $\mathrm{MnO}_{2}$. Reproduced with permission. ${ }^{[75]}$ Copyright 2020, Elsevier. d) discharge capacities and e) cycling performance of the pristine $\varepsilon$ - $\mathrm{MnO}_{2}(\mathrm{MO})$, La-doped $\varepsilon$-MnO ${ }_{2}$ cathode (LMO), Ca-doped $\varepsilon-\mathrm{MnO}_{2}$ cathode (CMO), and La-Ca co-doped $\varepsilon-\mathrm{MnO}_{2}$ cathode (LCMO); f) TEM images of La-Ca co-doped $\varepsilon$-MnO $\mathrm{M}_{2}$ materials. Reproduced with permission. ${ }^{[42]}$ Copyright 2020, Royal Society of Chemistry. g) Comparison of electrochemical performance between the up-to-date free-standing and non-free-standing cathode materials; h) schematic illustration of $\mathrm{Zn}-\mathrm{MnO}_{2} @$ PEDOT battery. Reproduced with permission. ${ }^{[46]}$ Copyright 2017, Wiley. i) Schematic diagram of synthesize of SSWM@ $\mathrm{Mn}_{3} \mathrm{O}_{4}$. Reproduced with permission. ${ }^{[4]}$ Copyright 2018, Royal Society of Chemistry. 
is free from the large electrostatic repulsion (Figure 5b), thus facilitating the faster electrode kinetics and enhancing the electrochemical properties. Very recently, Liang and co-workers introduced oxygen defects in the $\beta-\mathrm{MnO}_{2}$ cathode, which successfully enhanced the $\mathrm{Zn}^{2+}$ insertion kinetics and achieved remarkable stability (94\% retention, 300 cycles at $\left.0.1 \mathrm{~A} \mathrm{~g}^{-1}\right)$. ${ }^{\text {75] }}$ Coupling density functional theory (DFT) calculations with diffusion coefficient measurements, they proposed that the oxygen defects opened up the $\left[\mathrm{MnO}_{6}\right]$ polyhedron walls and created extra ion diffusion channels, and thus facilitated the kinetics of $\mathrm{H}^{+} / \mathrm{Mg}^{2+}$ ion insertion (Figure $5 \mathrm{c}$ ).

In addition to defects engineering, the heteroatom doping strategy has been applied to Mn-based cathodes with promising consequences. Generally, there are two types of substitutional doping: a) cationic doping; b) anionic doping (cationic and anionic). Lu and colleagues successfully synthesized a La-Ca codoped $\varepsilon-\mathrm{MnO}_{2}$ (LCMO) cathode by simply mixing the precursor solutions $\left(\mathrm{MnSO}_{4}, \mathrm{CaCl}_{2}, \mathrm{La}\left(\mathrm{NO}_{3}\right)_{3}\right)$, leading to impressive enhancement in both specific capacity (Figure $5 \mathrm{~d}$ ) and stability (Figure $5 \mathrm{e}$ ) compared with pristine $\varepsilon$ - $\mathrm{MnO}_{2}{ }^{[42]}$ This enhancement is primarily the result of two contributions: a) the unique urchin-like structure of LCMO offers more active sites for $\mathrm{Zn}^{2+}$ accommodation (Figure 5f), and b) La-Ca doping strategy enlarges the tunnel diameter and facilitates the $\mathrm{Zn}^{2+}$ diffusion kinetics. Theoretically, the anionic doping substitute oxygen with lower electronegativity elements (e.g., S, Se, and N), thus reducing the diffusion barriers for $\mathrm{Zn}^{2+}$ in the cathode materials. However, there is no research based on anionic doping manganese oxides, which offer an opportunity for future research.

Another effective methodology to address this issue is the pre-intercalation strategy (as known as the interstitial doping), which is mainly implemented by the introduction of polymers, anions or water molecule. Xia and colleagues unprecedently synthesized a polyaniline pre-intercalated layered $\mathrm{MnO}_{2}$ and achieved a remarkable stability $(\approx 90 \%$ capacity retention) of 200 cycles with a high specific capacity of $280 \mathrm{mAh} \mathrm{g}^{-1}$ at $200 \mathrm{~mA} \mathrm{~g}^{-1}$. $^{76]}$ Recently, Zhi et al. fabricated a quasi-solid-state AZIB based on a $\mathrm{Na}_{0.44} \mathrm{Mn}_{2} \mathrm{O}_{4} \cdot \mathrm{H}_{2} \mathrm{O}$ electrode synthesized by the pre-intercalation of $\mathrm{Na}^{+}$and water molecules into the $\delta$ $\mathrm{MnO}_{2}{ }^{[77]}$ Due to the pre-intercalation, the interlayer spacing of the as-prepared $\mathrm{Na}_{0.44} \mathrm{Mn}_{2} \mathrm{O}_{4} \cdot \mathrm{H}_{2} \mathrm{O}$ cathode increases from 0.55 to $0.72 \mathrm{~nm}$, which leads to a remarkable enhancement in cycling stability $(98 \%$ capacity retention after 10000 cycles at $20 \mathrm{C})$ compared to the pristine $\delta-\mathrm{MnO}_{2}$ electrode $(79.6 \%$ capacity retention after 2000 cycles at $6.67 \mathrm{C}$ ).

The current challenges to further improve the performance of AZIBs have involved the development of free-standing cathodes. As shown in Figure 5g, without using additives and a metallic current collector, the state-of-the-art freestanding Mn-based cathodes demonstrate superior performance in specific capacity than non-free-standing cathodes. Tong et al. synthesized the core-shell structure of $\mathrm{MnO}_{2} @$ poly(3,4-ethylenedioxythiophene) (PEDOT) as free-standing cathodes for the quasi-solid-state AZIBs, using a facial electrodeposition method on flexible carbon cloth (Figure 5h). ${ }^{[46]}$ The as-synthesized free-standing material achieved remarkable specific capacity (366.6 $\mathrm{mAh} \mathrm{g}^{-1}, 0.74 \mathrm{~A} \mathrm{~g}^{-1}$ ) among all the Mn-based cathode materials. Additionally, the free-standing strategy can also improve cathode stability to some extent.
Liang and co-workers synthesized binder-free stainless steel welded mesh@flower-like $\mathrm{Mn}_{3} \mathrm{O}_{4}$ via a one-step hydrothermal method (Figure 5i). ${ }^{[4]}$ The stainless steel welded mesh (SSWM) provides stable support for $\mathrm{Mn}_{3} \mathrm{O}_{4}$, thus improving the electrochemical performance compared to the pristine $\mathrm{Mn}_{3} \mathrm{O}_{4}$ and achieving long-term stability up to 500 cycles at $0.5 \mathrm{~A} \mathrm{~g}^{-1}$.

In general, Mn-based cathodes face three major challenges: contentious mechanism, manganese dissolution, and phase transformation or structural collapse. These issues could be addressed through strategies such as electrolyte optimization, surface modification and coating, $\mathrm{Mn}^{2+}$ pre-addition, freestanding cathodes and heteroatom doping. Moreover, a detailed investigation and comparison of $\mathrm{Mn}$-based cathode materials (such as phases, electrolytes, potential windows, etc.) need to be carried out to further clarify the mechanisms.

\subsection{V-based Materials}

Vanadium-based components have received tremendous attention, owning to their the extensive mineral reserves, low cost, preferable stability, and diversity of chemistry. ${ }^{[28,78,79]}$ Generally, the variety in valence states of V-based materials can facilitate achieving local electroneutrality, and thus alleviate the polarization issue of $\mathrm{Zn}^{2+}$ ions. ${ }^{[80]}$ In recent years, research had focused on (summarized in Table 3): $\mathrm{VO}_{2}$, ${ }^{[81]}$ $\mathrm{V}_{2} \mathrm{O}_{5},{ }^{, 78,82,83]} \quad \mathrm{M}_{x} \mathrm{~V}_{2} \mathrm{O}_{5} \cdot n \mathrm{H}_{2} \mathrm{O},{ }^{[48,73,79,84]} \quad \mathrm{H}_{2} \mathrm{~V}_{3} \mathrm{O}_{8} \cdot n \mathrm{H}_{2} \mathrm{O},{ }^{[38,85]}$ $\mathrm{M}_{x} \mathrm{~V}_{3} \mathrm{O}_{8} \cdot n \mathrm{H}_{2} \mathrm{O},{ }^{[86]}$ and $\mathrm{M}_{x} \mathrm{~V}_{6} \mathrm{O}_{16} \cdot n \mathrm{H}_{2} \mathrm{O}$, ${ }^{[87]}$ etc. However, V-based materials usually suffer from three major issues: toxicity, low operation voltages (typically $0.2-1.6 \mathrm{~V}$ ) and relatively low $\mathrm{Zn}^{2+}$ diffusion kinetics. Many methodologies are proposed to solve these issues and improve the battery performance, such as pre-intercalation strategy, WIS electrolyte, defects engineering and size regulation.

It is widely reported that exploring materials with large interlayer spacing is an effective strategy to improve the stability of AZIBs. ${ }^{[38,62,88]}$ Mai et al. synthesized layered structure of $\mathrm{H}_{2} \mathrm{~V}_{2} \mathrm{O}_{3}$ as a cathode material with high performance and proposed that the large interlayer spacing will improve the electrochemical stability during the insertion/extraction of $\mathrm{Zn}^{2+}{ }^{\left[{ }^{[38]}\right.}$ In recent years, many researchers have focused on preintercalation strategies and introduced structural water, cations, and other substances into the host materials to elevate interlayer spacing and the stability of the materials. ${ }^{[82,84,89]}$ Based on $\mathrm{V}_{2} \mathrm{O}_{5} \cdot \mathrm{nH}_{2} \mathrm{O}$ /graphene (VOG), Yang and co-workers found the interlayer increases from 10.4 to $13.5 \AA$ after the intercalation of $\mathrm{Zn}^{2+}$, which is contradicted with the lattice contraction reported previously. ${ }^{[2]}$ Through structural evolution characterization and electrochemical kinetic analyses, they proposed the "lubricating" effect that the water-based shielding layer could reduce the $\mathrm{Zn}^{2+}$ effective charge and increase the interlayer distance, thus promoting the diffusion of $\mathrm{Zn}^{2+}$ (Figure 6a). As illustrated in Figure 6b, Nazar et al. reported that the water molecule will be intercalated into the $\mathrm{Zn}_{0.25} \mathrm{~V}_{2} \mathrm{O}_{5} \cdot \mathrm{H}_{2} \mathrm{O}$ before the discharge and removed during the insertion of $\mathrm{Zn}^{2+}{ }^{290]}$ The "pillar" effect of the indigenous $\mathrm{Zn}^{2+}$ stabilizes the framework, while the water molecule enables the reversible expansion and contraction of the layered galleries, thus enhancing the diffusion kinetics and performances. 
(a)

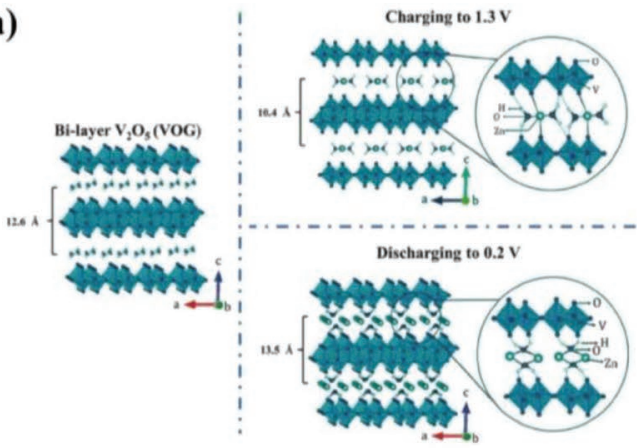

(b)

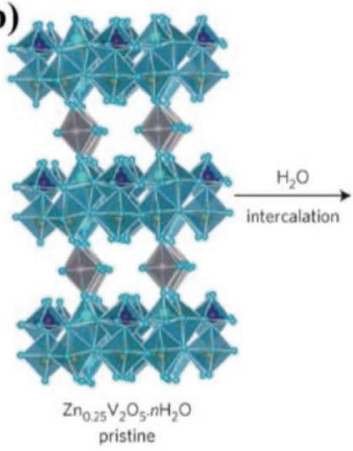

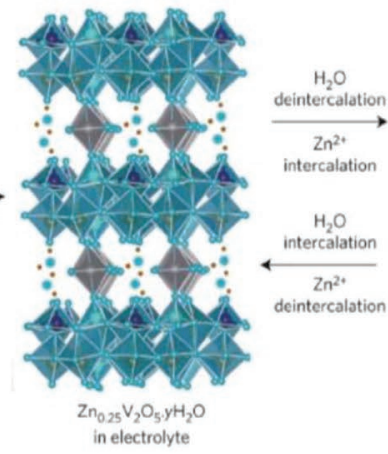

(c)

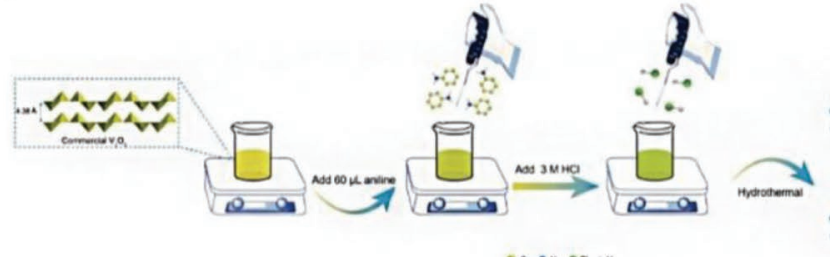

(f)
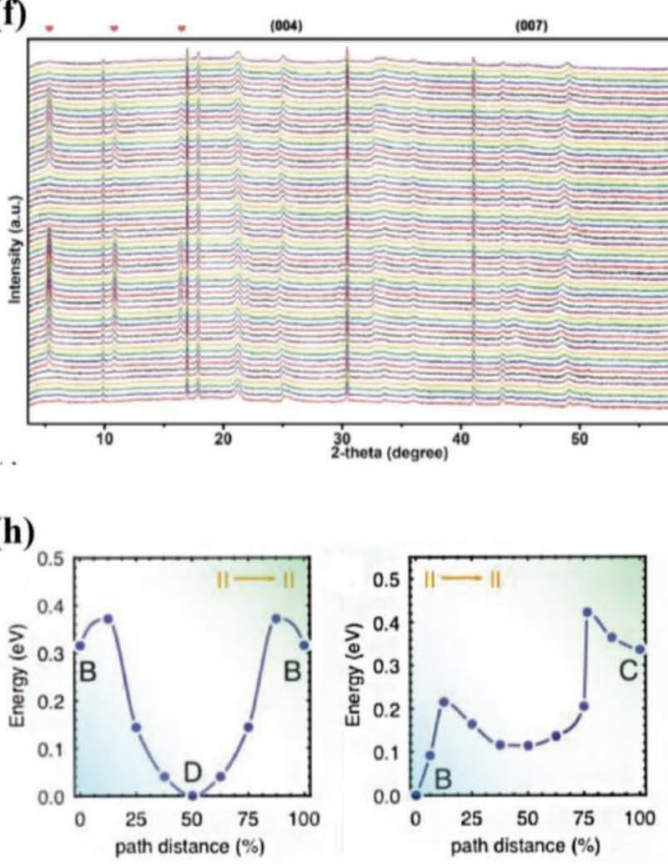

(1007)

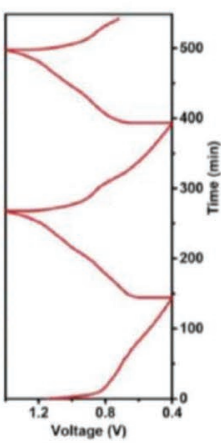

2 2.theta (dogrroe) (d)

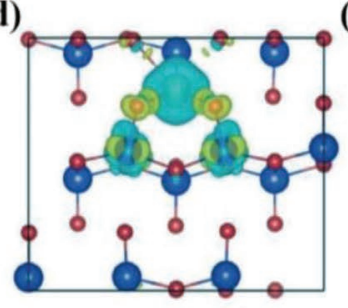

(e)

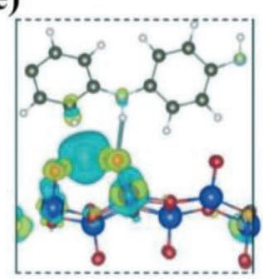

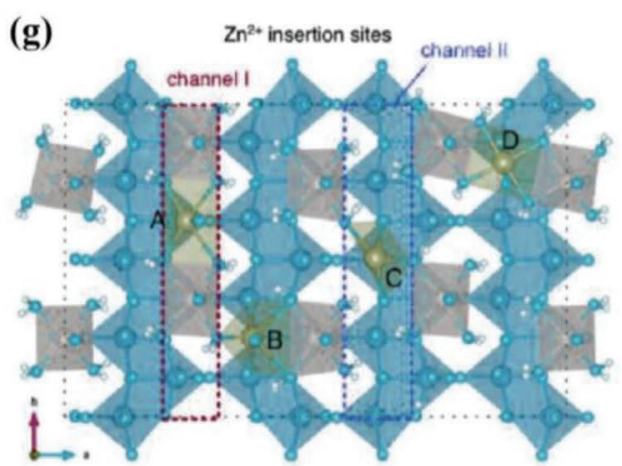

(i)
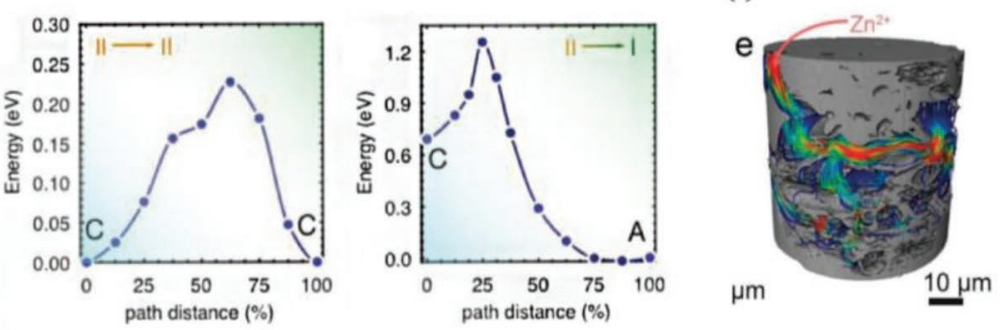

Figure 6. V-based cathode candidates for AZIBs. a) The proposed pristine $\mathrm{V}_{2} \mathrm{O}_{5} \cdot n \mathrm{H}_{2} \mathrm{O}$ /graphene (VOG) crystal structures, VOG after charging to $1.3 \mathrm{~V}$, and discharging to $0.2 \mathrm{~V}$. Reproduced with permission. ${ }^{[82]}$ Copyright 2017, Wiley. b) schematic diagram of reversible water (de) intercalation into $\mathrm{Zn}_{0.25} \mathrm{~V}_{2} \mathrm{O}_{5} \cdot \mathrm{nH}_{2} \mathrm{O}$. Reproduced with permission. ${ }^{\text {90] }}$ Copyright 2016, Nature Springer. c) schematic diagram of synthetic process of PANI-intercalated $\mathrm{V}_{2} \mathrm{O}_{5}$ nanosheets; differential charge density with $\mathrm{Zn}^{2+}$ intercalation in d) pristine $\mathrm{V}_{2} \mathrm{O}_{5}$, and e) PANI- $\mathrm{V}_{2} \mathrm{O}_{5}$; f) in situ XRD characterization; g) intercalation sites $\mathrm{A}, \mathrm{B}, \mathrm{C}$, and $\mathrm{D}$ for $\mathrm{Zn}^{2+}$ in $\mathrm{Zn}_{0.125} \mathrm{Ni}_{0.25} \mathrm{~V}_{2} \mathrm{O}_{5} \cdot \mathrm{H}_{2} \mathrm{O}$; h) migration pathways along channel I, from channel I to channel II, and along channel II; and i) reconstructed pore morphology. Reproduced with permission. ${ }^{[48,84]}$ Copyright 2020, Wiley.

Very recently, Xia et al. successfully enlarged the interlayer spacing of $\mathrm{NH}_{4} \mathrm{~V}_{3} \mathrm{O}_{8}$ from 7.8 to $10.8 \AA$ via the pre-intercalation of a conductive PEDOT, which demonstrates a high specific capacity of $356.8 \mathrm{mAh} \mathrm{g}^{-1}$ and enhanced stability $(94.1 \%$ capacity retention after 5000 cycles at $\left.10 \mathrm{~A} \mathrm{~g}^{-1}\right) \cdot{ }^{[1]}$ Similarly, Li and colleagues have in situ intercalated the polyaniline (PANI) into the layered $\mathrm{V}_{2} \mathrm{O}_{5}$ and significantly increased its interlayer spacing to $13.80 \AA$ (Figure 6c), thus achieving $97.6 \%$ retention after 2000 cycles at $20 \mathrm{~A} \mathrm{~g}^{-1} \cdot{ }^{[8]}$ Moreover, they performed DFT calculations to uncover the intrinsic effect of PANI intercalations on the diffusion kinetics of $\mathrm{Zn}^{2+}$. Compared to pristine $\mathrm{V}_{2} \mathrm{O}_{5}$ (Figure 6d), the notable redistribution could be observed around the nearest $\mathrm{C}-\mathrm{H}$ bond of PANI in PANI- $\mathrm{V}_{2} \mathrm{O}_{5}$ materials (Figure 6e) due to the repulsion between $\mathrm{Zn}^{2+}$ and $\mathrm{H}^{+}$ions. 
Almost at the same time, Zhang et al. reported PANI intercalated $\mathrm{V}_{2} \mathrm{O}_{5}$ and achieved similar performance to Li's group. ${ }^{\text {92] }}$ Through in situ XRD (Figure 6f), they found that new diffraction peaks appeared at $5.5^{\circ}, 11.1^{\circ}$, and $16.6^{\circ}$, which suggested that the interlayer spacing increased from 1.42 to $1.62 \mathrm{~nm}$ as the $\mathrm{Zn}^{2+}$ accumulation. In addition, they observed that the $\mathrm{pH}$ value of the electrolyte significantly increased during the discharge and gradually decreased during the charge, indicating that the pre-intercalation of PANI could realize the reversible (de)insertion of $\mathrm{Zn}^{2+}$ and $\mathrm{H}^{+}$.

Although many materials based on the "lubricating" and "pillar" effects have been investigated, such as $\mathrm{Zn}_{0.25} \mathrm{~V}_{2} \mathrm{O}_{5}$, $\mathrm{Na}_{0.33} \mathrm{~V}_{2} \mathrm{O}_{5},{ }^{[79]}$ and $\mathrm{Mg}_{0.34} \mathrm{~V}_{2} \mathrm{O}_{5},{ }^{, 93]}$ the challenges in crystallographic complexity and the evaluation of the functions of the pre-intercalated ions have hindered the further design of this type of cathode material. Through coupled theoretical and experimental methods, self-templated porous hydrated $\delta-\mathrm{Ni}_{0.25} \mathrm{~V}_{2} \mathrm{O}_{5}$ have been reported, the importance of initial intercalated cations was comprehensively clarified and energy storage mechanisms based on multi-scale investigations were discussed. ${ }^{[48]}$ Through atomic-level DFT simulation, two $\mathrm{Zn}^{2+}$ ionic migration channels and four intercalation sites (Figure $6 \mathrm{~g}, \mathrm{~h}$ ) have been proposed, and the mitigation pathways along the channel I, from the channel I to channel II, and along the channel II were identified. In addition, the diffusion flux from the electrode scale based on the pore structure reconstructed by nano-CT (Figure 6i) has been simulated, leading to the suggestion that the reactant transport capability of the material is much better than that for LIBs. ${ }^{[94]}$

Electrolyte optimization is the second mainstream strategy to improve the performances of AZIBs. Chen and co-workers observed that the $1 \mathrm{~m} \mathrm{ZnSO}_{4}$ electrolyte results in the rapid dissolution of $\mathrm{NaV}_{3} \mathrm{O}_{8}$ (NVO) and the formation of harsh/ vertical dendrites. ${ }^{\left[{ }^{95}\right]}$ Hence, they optimized the electrolyte by adding $1 \mathrm{M} \mathrm{Na}_{2} \mathrm{SO}_{4}$ to improve the cycling stability, because the addition of $\mathrm{Na}^{+}$a) alleviate the continuous dissolution of
NVO, via changing its dissolution equilibrium; b) restricts the growth of $\mathrm{Zn}$ dendrites owning to the electrostatic shield effect (reduction potential of $\mathrm{Na}^{+}$lower than $\mathrm{Zn}^{2+}$ ). By employing $3 \mathrm{~m} \mathrm{Zn}\left(\mathrm{CF}_{3} \mathrm{SO}_{3}\right)_{2}$ electrolyte, Liu et al. reported an aqueous $\mathrm{Zn}-\mathrm{V}_{2} \mathrm{O}_{5}$ battery with the highest specific capacity $\left(470 \mathrm{mAh} \mathrm{g}{ }^{-1}\right.$ at $0.2 \mathrm{~A} \mathrm{~g}^{-1}$ ) among all V-based cathode materials and remarkable durability (91.1\% retention over 4000 cycles at $\left.5 \mathrm{~A} \mathrm{~g}^{-1}\right)$. ${ }^{[78]}$ Their work also suggested that the application of WIS electrolyte exhibited the following merits: 1) expanding the electrochemical stability window; 2) coupling with pseudocapacitive behavior and synergistically accelerating the mass diffusion; and 3) enabling higher active material utilization. However, the cost of $\mathrm{Zn}\left(\mathrm{CF}_{3} \mathrm{SO}_{3}\right)_{2}$ electrolyte (589.8 USD per $100 \mathrm{~g}$ ) is much higher than the most commonly used aqueous electrolyte (e.g., $\mathrm{ZnSO}_{4}, 45.7$ USD per 100 g), which may hinder its application for large-scale energy storage. ${ }^{[38,78,86]} \mathrm{Ji}$ et al. proposed a low-cost WIS electrolyte with an ultrahigh concentration $\mathrm{ZnCl2}{ }^{[60]}$ When increasing the concentration of the $\mathrm{ZnCl} 2$ electrolyte from 1 to $30 \mathrm{~m}$, there are significant enhancements in both specific capacity (from 296 to $496 \mathrm{mAh} \mathrm{g}^{-1}$ ) and stability (from $8.4 \%$ to $51.1 \%$ retention over 100 cycles) for $\mathrm{Ca}_{0.20} \mathrm{~V}_{2} \mathrm{O}_{5} \cdot 0.8 \mathrm{H}_{2} \mathrm{O}$ (Figure $7 \mathrm{a}$ ). The improvement in specific capacity is mainly attributed to the application of the more concentrated electrolytes raises the onset potential of oxygen evolution reaction, thus allowing the higher cutoff potential. In addition, the use of high-concentration electrolytes effectively alleviated the vanadium dissolution and improve the cycling stability. However, the high concentration salt-in-water electrolyte may bring serval drawbacks, such as: a) higher concentration would reduce the ionic conductivity (e.g., $12.7 \mathrm{mS} \mathrm{cm}^{-1}$ for $30 \mathrm{M} \mathrm{ZnCl}_{2}$, while $101 \mathrm{mS} \mathrm{cm}{ }^{-1}$ for $1 \mathrm{M} \mathrm{ZnCl}_{2}$ ); b) the solubility of metal salt will generally decrease with the decrease of the temperature, which limit the temperature range in the practical scenarios; c) the high concentration solution will enhance the interaction between anions and cations, thus bringing high viscosity and resulting in detrimental mass transfer process; d) it (a)

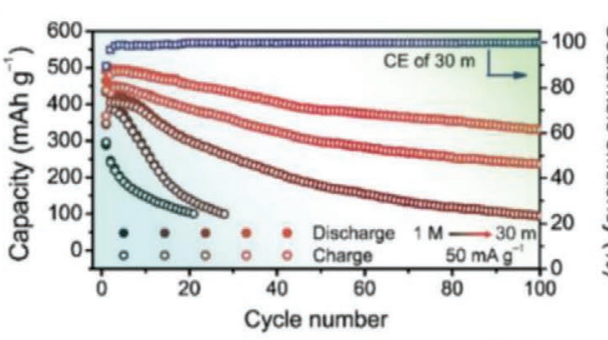

(c)

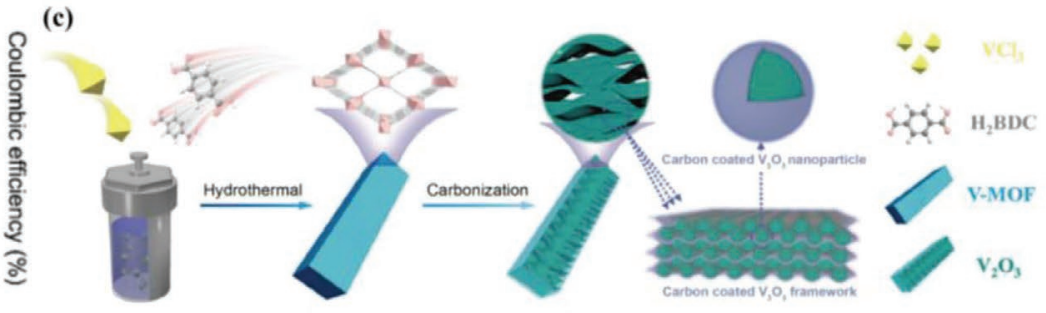

(b)

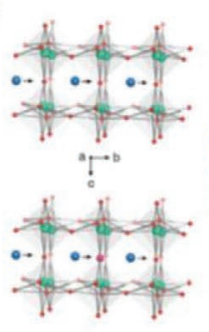

(d)

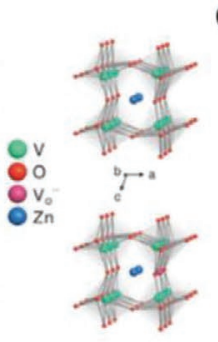

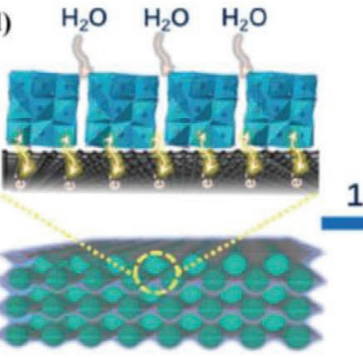

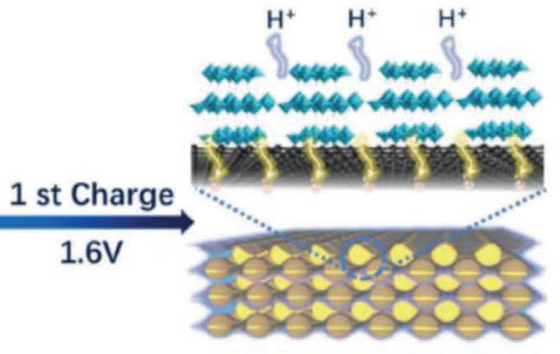

Figure 7. V-based cathode candidates for AZIBs. a) cycling stability and $C E$ at $59 \mathrm{~mA} \mathrm{~g}^{-1}$ in different concentration of $\mathrm{ZnCl}_{2}$ solutions. Reproduced with permission. ${ }^{[60]}$ Copyright 2019, Wiley. b) $\mathrm{Zn}^{2+}$ diffusion pathways along the tunnel in b direction in $\mathrm{VO}_{2}$ and $\mathrm{VO}_{1.75}$; c) the synthetic process of $\mathrm{V}_{2} \mathrm{O}_{3}$; d) the schematic diagram of the oxidation of $\mathrm{V}_{2} \mathrm{O}_{3}$ during the first full charging. Reproduced with permission. ${ }^{[38,81]}$ Copyright 2020, American Chemical Society. 
would increase the weight of the device and reduce the energy density. ${ }^{[96]}$

Defect engineering and size regulation are also effective approaches. Cao and co-workers investigated the impacts of oxygen vacancies on $\mathrm{Zn}^{2+}$ intercalation in $\mathrm{VO}_{2}$ and found that oxygen vacancies $\left(\mathrm{V}_{\mathrm{O}} \cdot{ }^{\prime \prime}\right)$ in $\mathrm{VO}_{2}(\mathrm{~B})$ could improve the electrical conductivity and expand ion diffusion tunnels. ${ }^{[1]}$ Then, DFT calculations (Figure 7b) were conducted and confirmed that the existence of $\mathrm{V}_{\mathrm{O}} \cdot{ }^{*}$ expanded the ion diffusion tunnels along the $b$-axis and reduced the migration energy of $\mathrm{Zn}^{2+}$. Generally, the materials with long diffusion pathway and low specific surface area (e.g., low-valent $\mathrm{V}_{2} \mathrm{O}_{3}$ ) are not suitable for $\mathrm{Zn}^{2+}$ hosts; while regulating the size and morphology of them can effectively address this issue. Very recently, Dou et al. reported a hollow-carved carbon-coated $\mathrm{V}_{2} \mathrm{O}_{3}$ microcuboids-based cathode with high surface area and short diffusion pathway (Figure 7c), which exhibits a record high specific capacity of $625 \mathrm{mAh} \mathrm{g}^{-1}$ at $0.1 \mathrm{~A} \mathrm{~g}^{-1}$ and an impressive $100 \%$ capacity retention over 10000 cycles at $10 \mathrm{~A} \mathrm{~g}^{-1} \cdot{ }^{[38]}$ Through in situ electrochemical oxidation, almost all $\mathrm{V}_{2} \mathrm{O}_{3}$ achieved a phase transition to $\mathrm{V}_{2} \mathrm{O}_{5-x} \cdot \mathrm{nH}_{2} \mathrm{O}$ or fully changed to $\mathrm{V}_{2} \mathrm{O}_{5} \cdot n \mathrm{H}_{2} \mathrm{O}$, thus providing a reversible 1.75 electron transfer. Meanwhile, the oxidation of $\mathrm{V}_{2} \mathrm{O}_{3}$ and $\mathrm{H}_{2} \mathrm{O}$ happened simultaneously in $2 \mathrm{M}$ $\mathrm{Zn}(\mathrm{TFSI})_{2}$, and delivers $1420 \mathrm{mAh} \mathrm{g}^{-1}$ capacity during the first charge (Figure 7d). However, it is worth noting that the specific capacity was slightly overestimated because calculation is based on $\mathrm{V}_{2} \mathrm{O}_{3}$ rather than formed $\mathrm{V}_{2} \mathrm{O}_{5-x} \cdot \mathrm{nH}_{2} \mathrm{O}$ during charge storage processes.

Another interesting viable approach is the construction of hierarchical porous composites by low-dimensional nanostructures. Yang et al. designed and prepared free-standing, hierarchical, and porous composite consisting of hybrid 1D NVO nanobelts and 3D rGO/CNT scaffolds via one-pot hydrothermal self-assembly and vacuum filtration. ${ }^{[73]}$ This unique structure demonstrates excellent electrochemical performance (459.1 $\mathrm{mA} \mathrm{g}^{-1}$ at $0.5 \mathrm{~A} \mathrm{~g}^{-1}$ and $83.1 \%$ retention after 1800 cycles at $10 \mathrm{~A} \mathrm{~g}^{-1}$ ) owing to several advantages, including faster ion (de)intercalation, enhanced electron transportation, and capability to buffer the large volume change during charge/discharge processes. Moreover, with a similar strategy, Huang and co-workers fabricated flower-like 3D-NVO via $1 \mathrm{D} \quad \mathrm{NH}_{4} \mathrm{~V}_{4} \mathrm{O}_{10}$ nanobelts, which delivered a remarkable reversible capacity of $485 \mathrm{mAh} \mathrm{g}^{-1}$ at $0.1 \mathrm{~A} \mathrm{~g}^{-1}$. 83$]$

In summary, compared with Mn-based materials, the energy density and stability of V-based cathodes are usually higher, due to the larger capacitive contribution and inherent stable structures. To further improve the performance of V-based materials, it is suggested that future research should pay particular attention to effective methodologies that include electrolyte optimization, design of novel composites, and more in-depth study of the underlying pre-intercalation mechanisms (e.g., initial mass change of active materials, and in situ monitor of pre-intercalated ions).

\subsection{PBAs}

Compared with Mn-based and V-based materials, although the PBA-based cathodes do not show advantages in terms of energy density and durability, it has attracted particular attention in recent years due to its remarkable power density, extremely low cost, and simple synthesize routes. ${ }^{[3]}$ The nominal formula of PBAs is $\mathrm{A}_{x} \mathrm{M}_{A}\left[\mathrm{M}_{B}(\mathrm{CN})_{6}\right]_{z} \cdot w \mathrm{H}_{2} \mathrm{O}$, where $\mathrm{A}$ represents an alkali metal and $\mathrm{M}$ represents metal. As shown in Figure 8a, the large interstitial sites and channels in PBAs' open-framework structures allow the (de)insertion of various metal (a)

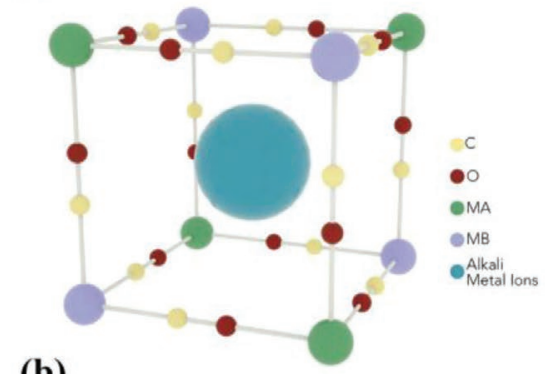

(b)

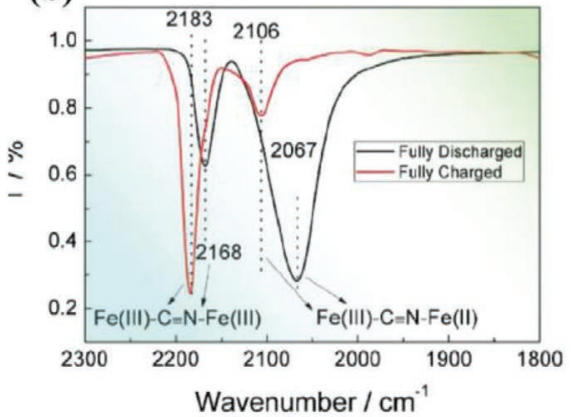

(c)
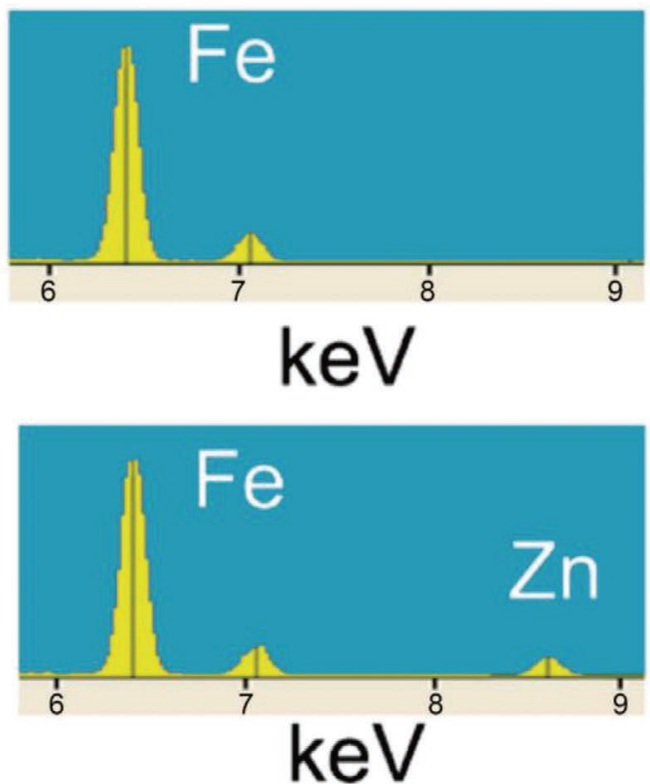

Figure 8. Prussian blue analog cathode candidates for AZIBs. a) schematic diagram of Prussian blue analogs; b) FT-IR spectra of fully charged/discharged FeHCF; c) EDX of as-prepared FeHCF and fully discharged FeHCF. Reproduced with permission. ${ }^{[100]}$ Copyright 2016, American Chemical Society. 
ions. Recently, research has focused on materials including $\mathrm{ZnHCF},{ }^{[97]} \mathrm{CuHCF},{ }^{[89]} \mathrm{FeHCF},{ }^{[98]} \mathrm{NiHCF},{ }^{[99]} \mathrm{FeFe}(\mathrm{CN})_{6}{ }^{[100]}$ and $\mathrm{Na}_{2} \mathrm{MnFe}(\mathrm{CN})_{6},{ }^{[101]}$ etc. At present, unitary and binary charged transition metal PBAs have been widely studied, but to the best of our knowledge, there are only a few publications based on ternary transition metal PBAs.

Usually, the presence of a transition metal increases the weight of pristine PBA-based cathode materials, which leads to a decreased specific capacity. One viable strategy is to introduce metal ions with redox behavior at both $\mathrm{M}_{A}$ and $\mathrm{M}_{B}$ sites; thus the 2 or more electron reaction could elevate the specific capacity. Endres and colleagues prepared $\mathrm{FeFe}(\mathrm{CN})_{6}$ nanoparticles cathode and studied the electrochemical (de)insertion of $\mathrm{Zn}^{2+}$ in this material. ${ }^{[100]}$ According to the FT-IR results at fully charged and discharged states (Figure $8 \mathrm{~b}$ ), the peak wavenumber shifts from 2168 to $2067 \mathrm{~cm}^{-1}$ during the fully discharged states, which indicates that the Fe(III) in the material is reduced to $\mathrm{Fe}(\mathrm{II})$ when $\mathrm{Zn}^{2+}$ is inserted. Meanwhile, the EDX (Figure $8 \mathrm{c}$ ) reveals the molar ratio between $\mathrm{Zn}$ and $\mathrm{Fe}$ is $\approx 1: 3$ during the fully discharged state, which also provided evidence for the $\mathrm{Zn}^{2+}$ insertion process.

Another issue is the dissolution and the phase change of PBA in the aqueous electrolyte, which results in capacity loss and poor durability. Zhou et al. prepared cubic and rhombic ZnHCF without coordinated water via a typical co-precipitation method at 25 and $100{ }^{\circ} \mathrm{C}$ respectively and performed the comparison between these two materials. ${ }^{[102]}$ The results proved that the cubic analogs are more soluble than the non-cubic phases, and non-cubic phases will slowly transform back to the cubic phase when immersed in the electrolyte.

Similar to the Mn-based and V-based materials, electrolyte optimization is one possible methodology to improve the stability of the PBA frameworks. Although the transformation and the dissolution of $\mathrm{ZnHCF}$ can be delayed by adding excess $\mathrm{Zn}^{2+}$ into the electrolyte, further studies revealed that the higher $\mathrm{Zn}^{2+}$ concentration will accelerate the phase-transformationmediated aging process, thus reducing the stability of cathode materials. ${ }^{[103]}$ Recently, Qian et al. added sodium dodecyl sulfate into the aqueous electrolyte of the AZIB system with $\mathrm{Na}_{2} \mathrm{MnFe}(\mathrm{CN})_{6}$ nanocubes cathode and achieved $75 \%$ retention after 2000 cycles. ${ }^{[101]}$ Meanwhile, the coating and surface modification is another effective methodology to prevent the deformation of the PBA frameworks, but more research is needed to explore this approach fully.

Although PBA cathodes have a higher voltage range compared with other materials, the high voltage may degrade the performance of AZIBs. Mantia et al. reported a zinc-ion battery system based on copper hexacyanoferrate (CuHCF) with a high average discharge potential $(1.73 \mathrm{~V})$, which is the highest among all AZIBs to date. ${ }^{[89]}$ However, the high charging voltage $(2 \mathrm{~V})$ of the system will oxidize the aqueous electrolyte, resulting in $\mathrm{O}_{2}$ evolution on the cathodes and $\mathrm{H}_{2}$ evolution and the formation of $\mathrm{ZnO}$ on the surface of the zinc foil, causing the slow diffusion of $\mathrm{Zn}^{2+}$ and poor Coulombic efficiency (95\%) at $0.1 \mathrm{~A} \mathrm{~g}^{-1}$.

Overall, PBA-based cathodes are one of the most widely studied cathode materials, but there is still a long way for their development. At present, the most substantial challenges are their poor stability and insufficient specific capacity, which greatly limits their practical application. To date, there are three relatively less investigated directions worthy of future efforts: a) further electrolyte optimization to alleviate the active material loss and accommodate the high voltage; b) ternary transition metal PBAs for the cathodes of AZIBs; and c) coating and surface modification to boost the performance.

\subsection{Other Materials}

Research has mainly focused on inorganic materials; however, recent years have seen an increasing focus on organic cathodes. Organic cathodes possess several unique merits, they are a) lightweight; b) environmental friendly; c) ease of ion (de)intercalation, owning to the weak intermolecular van der Waals forces; and are d) resilient to structural variations, thus improving the cycle life. ${ }^{[6]}$ Combining $\mathrm{Zn}^{2+}$ insertion and dualion mechanisms, Niu's group developed an aqueous Zn-organic battery using polyaniline/carbon felts (PANI/CFs) cathode. ${ }^{[104]}$ Through the XPS spectra, they proposed a different energy storage mechanisms (Figure 9b) compared with conventional inorganic host materials: a) during the discharge, the doped $\left(=\mathrm{NH}^{+}\right)$and undoped $(=\mathrm{N}-)$ nitrogen in the initial PANI will be reduced to $-\mathrm{NH}-$ and $-\mathrm{N}^{-}-$respectively, thus removing the anions $\left(\mathrm{Cl}^{-}\right.$and $\left.\mathrm{CF}_{3} \mathrm{SO}_{3}{ }^{-}\right)$and interacting with $\mathrm{Zn}^{2+}$; b) during the charge process, the $-\mathrm{NH}-$ and $-\mathrm{N}^{-}-$will be oxidized to $=$ $\mathrm{NH}^{+}-$and $=\mathrm{N}-$ respectively, thus removing the $\mathrm{Zn}^{2+}$ and interacting with $\mathrm{CF}_{3} \mathrm{SO}_{3}{ }^{-}$. Based on "ion-coordination" mechanism, Chen et al. introduced a quinone (C4Q) electrode with a high capacity $\left(335 \mathrm{mAh} \mathrm{g}^{-1}\right.$ at $\left.0.02 \mathrm{~A} \mathrm{~g}^{-1}\right)$, where $\mathrm{Zn}^{2+}$ can be stored through the coordination with oxygen atoms in the reduced carbonyl groups (Figure 9a). ${ }^{[105]}$ The assembled AZIB has a flat voltage plateau and good durability $(87 \%$ capacity retention after 1000 cycles at $0.5 \mathrm{~A} \mathrm{~g}^{-1}$ ), however, its further application is limited by issues such as the dissolution of discharged products, the use of expensive fluorine-containing membrane (Nafion film), and the poisoning effect of the quinone on the $\mathrm{Zn}$ anode. To address these issues, Wang and colleagues proposed a pyrene-4,5,9,10-tetraone (PTO) cathode with a high specific capacity of $336 \mathrm{mAh} \mathrm{g}^{-1}\left(0.04 \mathrm{~A} \mathrm{~g}^{-1}\right)$ and long-term lifespan (over 1000 cycles). ${ }^{[106]}$ As exhibited in Figure 9c, $\mathrm{Zn}^{2+}$ ions pass across the electrolyte and are stored by PTO cathodes via the coordination reaction during the discharge. And the charge process reverses discharge.

Very recently, Zhang et al. proposed a ladder-like polymer poly(2,3-dithiino-1,4-benzoquinone) (PDB, $\left.\mathrm{C}_{6} \mathrm{~S}_{2} \mathrm{O}_{2}\right)_{n}$ cathode, and demonstrated a novel irreversible electrolyte anion-doping strategy for the first time. ${ }^{[107]}$ Combining various spectroscopic characterizations along with DFT calculations, they suggested a detailed mechanism for PDB during the cycling (Figure 9d): a) during the initial charge, an irreversible anion-doping $\left(\mathrm{A}^{-}\right)$ occurs and leads to the formation of intermolecular S...S interactions on the heterocyclic thioether group $(\mathrm{C}-\mathrm{S}-\mathrm{C})$; b) during the following discharge, a maximum of one $\mathrm{Zn}^{2+}$ ion can be stored through the adjacent carbonyl groups on PDB molecules, or via the coordination/linkage between two PDB molecules. In addition, to alleviate the dissolution of organic electrodes and enhance the stability of the aqueous Zn-organic batteries, their group proposed an aqueous eutectic electrolyte by coupling $\mathrm{Zn}\left(\mathrm{ClO}_{4}\right)_{2} \cdot 6 \mathrm{H}_{2} \mathrm{O}$ with a neutral ligand ( $\mathrm{SN}$, 
(a)

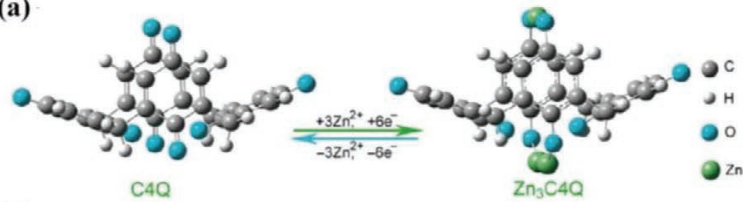

(c)

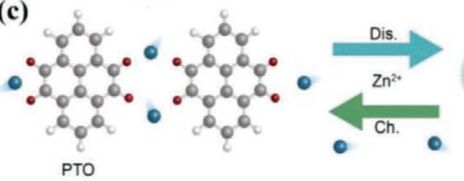

(d)

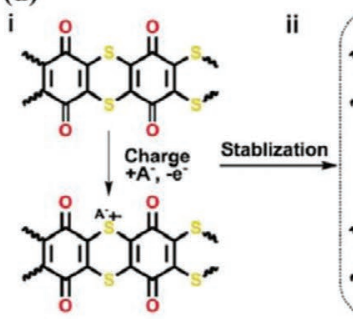

Irreversible doping ii

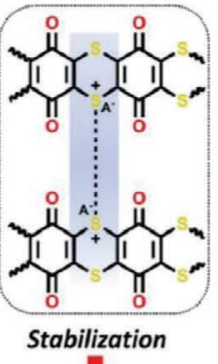

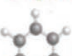

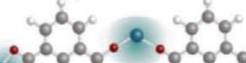

0.000 .0 .0 .0

0.0 .0 .000

PTO-Zn ${ }^{2 *}$ (b)

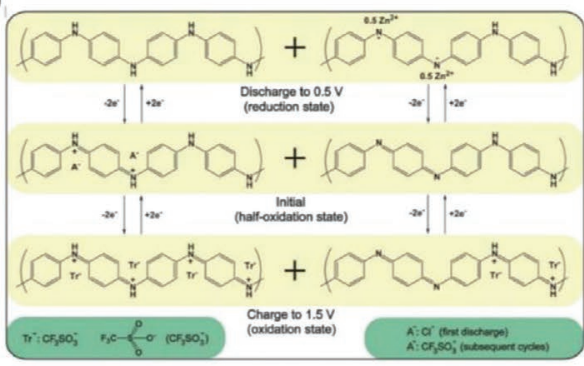

(i)

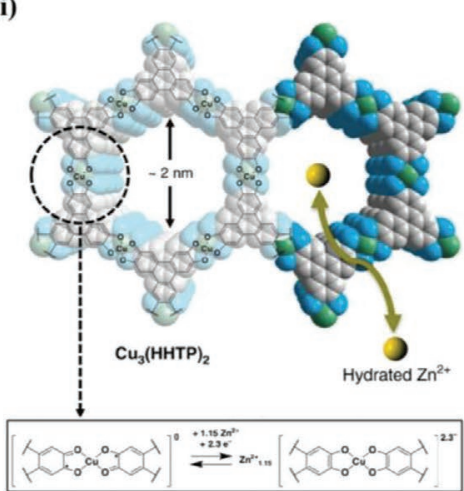

(e)

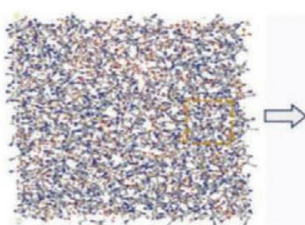

(g)

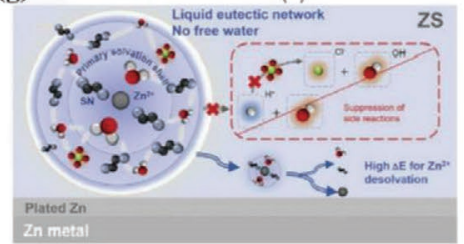

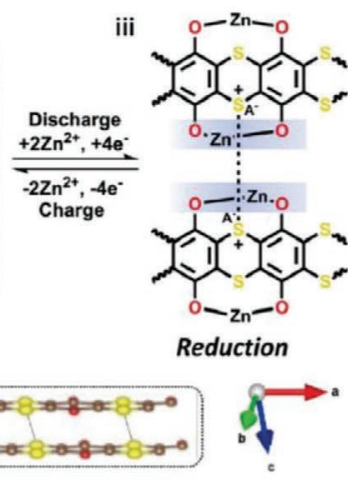

(f) (j)

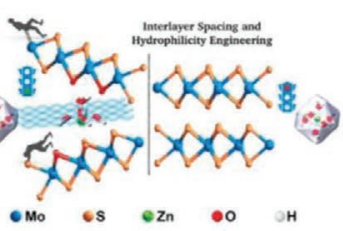

(I)

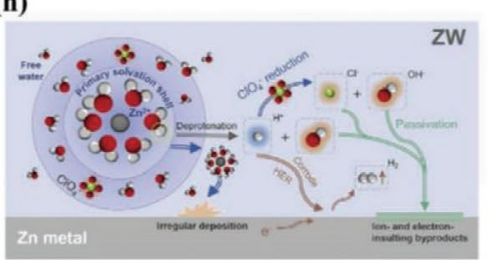

(h)

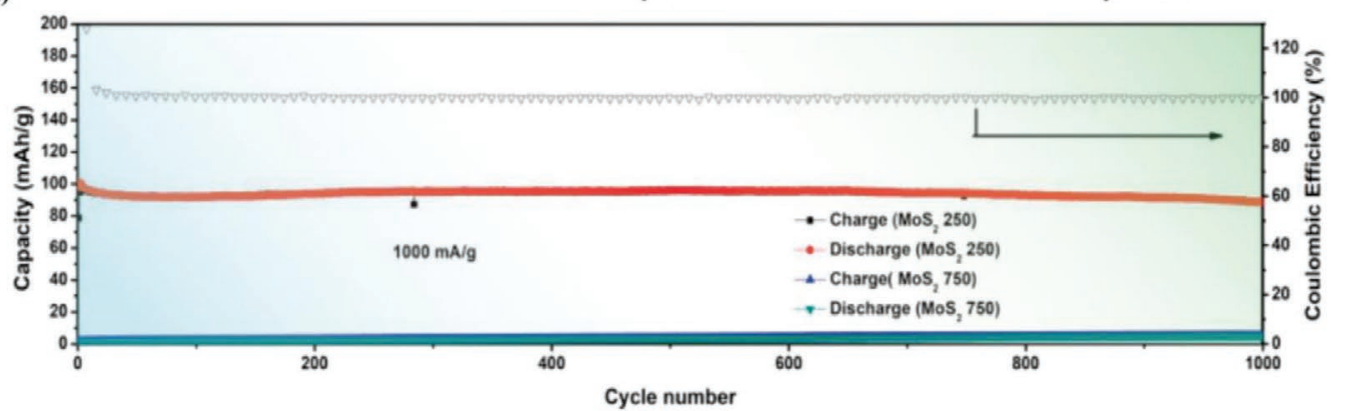

Figure 9. Other cathode candidates for AZIBs a) Configurations of C4Q before and after $\mathrm{Zn}^{2+}$ insertion. Reproduced with permission. ${ }^{\text {[105] }}$ Copyright 2018, American Association for the Advancement of Science. The schematic diagram of proposed mechanism of b) PANI/CFs, and c) PTO cathode. Reproduced with permission. ${ }^{[104,106]}$ Copyright 2018, Wiley. d) The schematic diagram of proposed mechanism of PDB cathode during the charge and discharge process. Reproduced with permission. ${ }^{[107]}$ Copyright 2020, Elsevier. e) 3D snapshot obtained by molecular dynamics (MD) simulation and representative $\mathrm{Zn}^{2+}$ solvation structure in the ZS electrolyte. f) radial distribution functions (RDFs) for $\mathrm{Zn}^{2+}-\mathrm{N}$ and $\mathrm{Zn}^{2+}-\mathrm{O}$ (water) from MD simulations of ZS. Schematic diagram of $\mathrm{Zn}^{2+}$ solvation structure and corresponding interfacial reactions in g) $\mathrm{ZW}\left(\mathrm{Zn}\left(\mathrm{ClO}_{4}\right)_{2} \cdot 6 \mathrm{H}_{2} \mathrm{O}: \mathrm{H}_{2} \mathrm{O}=1: 8\right)$ electrolyte and $\left.\mathrm{h}\right) \mathrm{ZS}\left(\mathrm{Zn}(\mathrm{ClO})_{2} \cdot 6 \mathrm{H}_{2} \mathrm{O}: \mathrm{SN}=1: 8\right)$ electrolyte. Reproduced with permission. ${ }^{[108]}$ Copyright 2020, Elsevier. i) structure and the electrochemical reaction of $\left.\mathrm{Cu}_{3}(\mathrm{HHTP})_{2} ; \mathrm{j}\right) \mathrm{Changes}$ of electron density during the reduction of $\mathrm{Cu}_{3}(\mathrm{HHTP})_{2}$. Reproduced under the terms of CC-BY license. ${ }^{[109]}$ Copyright 2019, Nature Springer. k) Interlayer spacing and hydrophilicity engineering of $\mathrm{MoS}_{2}$. Reproduced with permission. ${ }^{[6]]}$ Copyright 2019, American Chemical Society. I) Long-term cycling performance at $1000 \mathrm{~mA} \mathrm{~g}^{-1}$. Reproduced with permission. ${ }^{[4]]}$ Copyright 2018, Elsevier. 
succinonitrile). ${ }^{[108]}$ Based on molecular dynamic (MD) simulation, Figure 9e exhibits a typical solvation structure of $\mathrm{Zn}^{2+}$ in a $\mathrm{ZS}\left(\mathrm{Zn}\left(\mathrm{ClO}_{4}\right)_{2} \cdot 6 \mathrm{H}_{2} \mathrm{O}: \mathrm{SN}=1: 8\right)$ electrolyte, where a four-coordinated $\mathrm{Zn}^{2+}$ complexes are formed by $\mathrm{Zn}^{2+}$ coordinating with two water molecules and two SN molecules. The additional evidence of $\mathrm{Zn}^{2+}$ coordinating with both $\mathrm{SN}$ and $\mathrm{H}_{2} \mathrm{O}$ is provided by the radial distribution functions (RDFs) (Figure 9f). Due to the presence of the fragile $\mathrm{Zn}\left[\mathrm{OH}_{2}\right]_{6}{ }^{2+}$ in the conventional electrolyte (Figure 9g), the side reactions including passivation, corrosion and hydrogen evolution compete with the $\mathrm{Zn} /$ $\mathrm{Zn}^{2+}$ redox processes. While in the $\mathrm{ZS}$ electrolyte, the primary solvation shell of $\mathrm{Zn}^{2+}$ is mostly occupied by the $\mathrm{SN}$ molecules (Figure 9h), which enhanced the interfacial stability by suppressed perchlorate decomposition.

Aside from PBAs, other conductive metal-organic frameworks (MOFs) are also potentially excellent cathode candidates to solve the dissolution of active materials challenge, due to the coordinate covalent bonds between the active organic species and metal-ligands. In these MOFs, the porous structure and conductive properties enable fast electron and ion transport. Stoddart and colleagues reported a $2 \mathrm{D}$ conductive MOF, $\mathrm{Cu}_{3}(\mathrm{HHTP})_{2}$, which presented high specific capacity $\left(228 \mathrm{mAh} \mathrm{g}^{-1}\right.$ at $50 \mathrm{~mA} \mathrm{~g}^{-1}$ ) and stability (75\% after 4000 cycles at $4 \mathrm{~A} \mathrm{~g}^{-1}$ ) as the cathode material for AZIBs (Figure 9i). ${ }^{[109]}$ Through DFT calculations, the copper atom and the linkers were found to participate in the reduction reaction and take off the additional electron when supplying 6.9 extra electrons (Figure 9j).

Another widely studied strategy is to use transition metals other than V/Mn-based compounds as electrode materials, such as Mo, ${ }^{[41,110]} \mathrm{Co},{ }^{[111]}$ and Ni. ${ }^{[112]}$ With the open-crystal structures and rigid frameworks, $\mathrm{MoS}_{2}$ can be reversibly (de)intercalated with monovalent ions $\left(\mathrm{Li}^{+}\right.$and $\left.\mathrm{Na}^{+}\right)$; however, it is hard for the $\mathrm{Zn}^{2+}$ (de)intercalation due to the higher valence states and large ion radius. ${ }^{[61]}$ This can be solved by interlayer spacing and defect engineering. Liang et al. found that the small amount of incorporated oxygen (5\%) can increase the interlayer spacing from 6.2 to $9.5 \AA$ and enhance the hydrophilicity due to the reduced van der Waals interaction caused by the shorter $\mathrm{Mo}-\mathrm{O}$

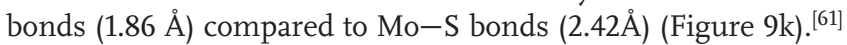
As a result, the diffusivity and storage capacity of $\mathrm{Zn}^{2+}$ has been increased significantly by 3-orders of magnitude and ten times, respectively. Combining theoretical and experimental studies, Wang and co-workers proposed that the existence of numerous edges, boundaries, and defects will significantly facilitate the diffusion of $\mathrm{Zn}^{2+} \cdot{ }^{241]}$ The defect engineered $\mathrm{MoS}_{2-x}$ nanosheets presents a remarkable enhancement on capacity (128.23 $\mathrm{mAh} \mathrm{g}^{-1}$ at $100 \mathrm{~mA} \mathrm{~g}^{-1}$ ) and durability (87.8\% after 1000 cycles at $1 \mathrm{~A} \mathrm{~g}^{-1}$ ) compared to the defect-free $\mathrm{MoS}_{2}$ electrode (Figure 91).

$\mathrm{Ni}$ and Co-based compounds are promising cathode materials for aqueous battery systems due to the variety in the oxidation states, and high electrochemical activity. ${ }^{[111,112]}$ However, the deterioration of active materials and the formation of dendrites will lead to the poor specific capacity and low Coulombic efficiency for Ni/Co-based AZIBs. Although the $\mathrm{Co}^{3+}$ / $\mathrm{Co}^{4+}$ pair has a higher potential ( $>1.95 \mathrm{~V}$ versus $\mathrm{Zn}$ ) compared to $\mathrm{Co}^{2+} / \mathrm{Co}^{3+}(1.419 \mathrm{~V}$ versus $\mathrm{Zn})$, it faces issues including much more challenging activation and degradative transition of the key species. ${ }^{[113]}$ Based on $\mathrm{CoSe}_{2-x}$ supported on carbon cloth ( $\left.\mathrm{CoSe}_{2-x} @ \mathrm{C} / \mathrm{CC}\right)$ cathode, Li and colleagues proposed the transformation-induced heteroatom doping strategy to address these challenges, which enables the as-assembled AZIB to achieve 10 000-cycle ultralong lifespans with $0.02 \%$ per cycle capacity decay. ${ }^{[111]}$ The $\mathrm{CoSe}_{2-x}$ is transformed into $\mathrm{Co}_{x} \mathrm{O}_{y} \mathrm{Se}_{z}$ (stable Corich state) in the first of several cycles, therefore alleviating the degradative transition of residue $\mathrm{Co}^{3+}$ species to the equilibrium $\mathrm{Co}^{2+}$.

Other materials, such as NASICON-typed polyanionic, ${ }^{[114]}$ Chevrel phase $\mathrm{M}_{x} \mathrm{Mo}_{6} \mathrm{~T}_{8}(\mathrm{~T}=\mathrm{O}, \mathrm{S}, \mathrm{Se}){ }^{[115]}$ Ti-substituted tungsten molybdenum oxide (MTWO), ${ }^{[16]}$ are also promising candidates for AZIBs. Although research on non-Mn/V/PBA-based materials is beginning to emerge, promising performance has been demonstrated and attracted ever-increasing attention.

\subsection{Perspectives}

Overall, AZIBs are still in the early stage of development, but that does not inhibit them from being one of the most promising candidate technologies for large-scale energy storage. Numerous hurdles still need to be overcome to develop cathodes with high specific capacity, large potential window and the required stability, this includes:

1. Comprehensive mechanistic understanding. At present, the debate on the mechanism of Mn-based materials is still in progress and focuses on three possible mechanisms: $\mathrm{Zn}^{2+}$ (de)intercalation, conversion reaction, and co-(de)intercalation of $\mathrm{Zn}^{2+}$ and $\mathrm{H}^{+}$. The functionalities of pre-added $\mathrm{Mn}^{2+}$ species remains controversial. Similarly, the nature of the large capacitive contribution that enables V-based cathodes to present such a high performance, as well as their capacity decay mechanisms, are still not clear. Therefore, there is the need to deploy advanced in situ characterization techniques and precise theoretical study to tackle this challenge.

2. Challenging intrinsic issues. AZIBs have two major challenges: low operating potential and poor $\mathrm{Zn}^{2+}$ diffusivity. Although WIS electrolytes have been introduced to expand the potential window, the prohibitive cost limits their application for most practical scenarios. Strategies such as interlayer spacing and defects engineering are promising to improve the diffusion of $\mathrm{Zn}^{2+}$; however, they do not address the stability issue. Compared with the mature battery chemistries, many efficient strategies and methods have yet to be developed for AZIBs.

3. Further studies on electrode and electrolyte. Electrode and electrolyte optimization is the most urgent task at present; however, relatively few compounds have been studied for AZIB applications. Compared to the $\approx 40$ compounds reported so far, there are hundreds of Mn/V-based compounds that have not been studied and other categories of cathode materials only at the initial stage of development. Meanwhile, a limited number of organic cathode candidates and related mechanisms were reported so far. Hence, further investigations that consider the relationships between performance, morphology, structure, and doping will shorten the process of finding suitable materials and electrolytes. 
4. Capacity balance of anodes and cathodes. Currently, most of the high-performance cathode candidates are operated against the over-sized anodes $(\approx 10-200$ times the capacity of the cathodes), which may lead to poor device performances (e.g., energy and power density) and low utilization rate of the anode materials. The current research is still at an initial stage. Several strategies, such as the control of equilibrium potentials of surface charges (e.g., the introduction of functional groups, charge injection), are effective to facilitate the capacity balance.

\section{Aqueous Rechargeable Magnesium-Ion Batteries}

Over the past two decades, extensive research has focused on the development of magnesium-ion batteries (MIBs) driven by advantages that include environmental and economically attractive features, high energy density, low reduction potential and dendrite-free magnesiation. ${ }^{[3,117]}$ Similar to AZIBs, the mainstream energy storage mechanisms of AMIBs are (de) intercalation and conversion reaction. For (de)intercalation mechanism, although $\mathrm{Mg}^{2+}$ ions possess a similar ionic radius with $\mathrm{Li}^{+}(0.72 \AA$ and $0.76 \AA$, respectively), most of the host cathodes for LIBs are not suitable for AMIBs due to the high charge density of divalent $\mathrm{Mg}^{2+}$. Fortunately, $\mathrm{Mg}^{2+}$ ions possess a series of key properties highly similar to the $\mathrm{Zn}^{2+}$, such as the same coordination number (6), charge density $\left(120 \mathrm{C} \mathrm{mm}^{-3}\right.$ and $112 \mathrm{C} \mathrm{mm}^{-3}$, respectively), ionic radius $(0.72 \AA$ and $0.75 \AA$, respectively), and hydrated ionic radius $(4.28 \AA$ and $4.3 \AA$, respectively); ${ }^{[118]}$ therefore, in theory, the intercalation electrode materials for AZIBs should be also useful for the AMIBs after conducting necessary optimization. However, by comparing Tables 3 and 4, it can be found that there are very limited researches based on these potential high-performance cathode candidates. This is mainly due to the major challenge in the employment of suitable electrolyte. In addition to the intercalation compounds, the electrode materials with conversion reactions have been extensively studied, such as $\alpha-\mathrm{MnO}_{2}$ and ramsdellite $\mathrm{MnO}_{2}$. In contrast to the intercalation compounds, the (de)magnesiation of conversion materials breaks chemical bonds and form new bonds during the insertion and extraction of $\mathrm{Mg}^{2+} \cdot{ }^{[119]}$ The conversion reactions usually occur when the number of inserted ions exceeds the maximum available ion diffusion channels and available sites in the host materials.

One of the substantial challenges for AMIBs is the slow $\mathrm{Mg}^{2+}$ diffusion kinetics. Generally, from the perspective of cathode design, it is mainly determined by three structural factors: a) the size of the intercalated ions and the cavities/channels; b) the strength of the interaction between intercalated ions and host materials; c) the connectivity between sites. However, the narrow potential window elevates difficulties in finding and designing suitable electrolytes and cathode materials. In addition, different from lithium metals, the formation of non-permeable solid electrolyte interphase (SEI) layers on Mg metals restricts both ionic and electronic transport. ${ }^{[120]}$

Extensive investigations of many materials have been trialled (Figure 1), most of which are based on non-aqueous electrolytes. However, the aqueous systems have received more attention in recent years due to several attractive merits and factors, including: 1). no SEI formation; 2). safety considerations; $3)$. potential window $(\approx 2 \mathrm{~V})$ broadened by WIS aqueous electrolyte; 4). Developments in the pre-intercalation strategy. This section will particularly focus on the chalcogenides, V-based, and Mn-based components for AMIBs (Table 4).

\subsection{Chalcogenides}

In general, the strong interaction between $\mathrm{Mg}^{2+}$ and cathode frameworks results in slow diffusion kinetics, while the chalcogenides cathodes with moderate polarities enable weak electrostatic interactions with $\mathrm{Mg}^{2+}$ and thus have received tremendous attention since the birth of rechargeable MIBs in 2000. ${ }^{[117,120]}$ However, the enhanced diffusion dynamics by weak interactions come with a price: the reduced redox potentials of the metals, thus lowering the electrode potential window. In addition, the inherent structural issues of chalcogenides cathodes also lead to an unsatisfactory specific capacity. To date, there are three main categories of widely researched chalcogenides: the Chevrel phase (CP), ${ }^{[4,44,121,122]}$ transition metal dichalcogenides (TMDs), ${ }^{[123-126]}$ and other chalcogenides. ${ }^{[127-130]}$ Although most of the current research is conducted based on non-aqueous electrolytes (e.g., acetonitrile or tetrahydrofuran), a relevant review is still necessary and meaningful due to the following reasons: a). Chalcogenides are by far the most widely investigated materials for rechargeable MIBs; b). According to chalcogenides cathodes in AZIBs, it has great potential for application in aqueous systems. The following will discuss representative $\mathrm{CP}$ and TMDs type chalcogenide cathodes in detail.

Chevrel phase (CP) compounds refer to the ternary molybdenum chalcogenides $\mathrm{M}_{x} \mathrm{Mo}_{6} \mathrm{X}_{8}$ ( $\mathrm{X}=$ chalcogens), which possess an open $3 \mathrm{D}$ framework and enable the stable reversible (de)intercalation of $\mathrm{Mg}^{2+}$ (Figure 10a). However, the high-temperature synthesize process of CP materials is complicated and faces the safety issues such as high-pressure explosion caused by sulfur vapor and the difficulty of precise control of the heating process in a hydrogen atmosphere. ${ }^{[131]}$ To tackle this challenge, Kumta et al. synthesized the CP type materials via high-energy mechanical milling (HEMM) of a stoichiometric mixture of molybdenum and metal chalcogenides, which significantly reduced the reaction temperature and avoided the use of $\mathrm{H}_{2}$ gas or sulfur vapor. ${ }^{[121]}$

Another major challenge for CP cathodes is the relatively low specific capacity $\left(80-100 \mathrm{mAh} \mathrm{g}^{-1}\right)$ and low operating potential (0.9-1.2 V). Mitelman and coworkers studied the $\mathrm{Mg}^{2+}$ diffusion based on $\mathrm{Mg}_{x} \mathrm{Mo}_{6} \mathrm{~T}_{8}(\mathrm{~T}=\mathrm{S}$ or $\mathrm{Se}$ ) and proposed that partially replacing $\mathrm{S}$ with Se could improve the electrochemical kinetics of CP cathodes. ${ }^{[132]}$ According to their research, the substitution of Se distorts the crystal structure and reduces the activation barrier, thus enhancing the $\mathrm{Mg}^{2+}$ transport. Also, incorporating metal ions into the host CP could improve energy density. Although Aurbach et al. discovered that $\mathrm{Cu}$ incorporation could significantly improve the energy density of AMIB, ${ }^{[133]}$ the underlying mechanisms were comprehensively investigated by Choi and colleagues in recent years. ${ }^{[43]}$ As illustrated in Figure 10b,c, the mechanism follows a process whereby during discharge, $\mathrm{Cu}^{2+}$ is extracted and reduced to nanoscaled 
Table 4. Summary of cathode materials used in rechargeable MIBs in recent years.

\begin{tabular}{|c|c|c|c|c|c|c|c|c|}
\hline Materials & $\begin{array}{l}\text { Aqueous } \\
(\mathrm{Y} / \mathrm{N})\end{array}$ & Electrolyte & $\begin{array}{c}\text { Working } \\
\text { potential } \\
\text { [V] }\end{array}$ & $\begin{array}{l}\text { Specific capacity } \\
{\left[\mathrm{mAh} \mathrm{g}^{-1}\right] \text { at } x \mathrm{Ag}^{-1}}\end{array}$ & $\begin{array}{c}\text { Capacity retention } \\
\text { at y } \mathrm{Ag}^{-1} \text { after } n \\
\text { cycles }\end{array}$ & $\begin{array}{c}\text { Rate capability } \\
\text { (capacity } \\
\text { retention at } \\
\mathrm{z} \times x \mathrm{~A} \mathrm{~g}^{-1} \text { ) }\end{array}$ & Strategies & Ref. \\
\hline \multicolumn{9}{|l|}{ Chalcogenides } \\
\hline $\mathrm{Mg}_{x} \mathrm{Cu}_{y} \mathrm{Mo}_{6} \mathrm{Se}_{8}$ & $\mathrm{~N}$ & $0.4 \mathrm{M}(\mathrm{PhMgCl})-\mathrm{AlCl}_{3} / \mathrm{THF}$ & $0.5-1.95$ & $99.1(x=0.006)$ & $\begin{array}{c}97 \%(n=30 \\
y=0.006)\end{array}$ & - & $\mathrm{G}, \mathrm{H}$ & {$[43]$} \\
\hline $\mathrm{Mg}_{x} \mathrm{Mo}_{6} \mathrm{Se}_{8}$ & N & $0.4 \mathrm{M}(\mathrm{PhMgCl})-\mathrm{AlCl}_{3} / \mathrm{THF}$ & $0.5-1.95$ & $93(x=0.005)$ & - & - & $\mathrm{F}$ & {$[44]$} \\
\hline $\mathrm{Cu}_{2} \mathrm{Mo}_{6} \mathrm{Se}_{8}$ & N & $0.4 \mathrm{M}(\mathrm{PhMgCl})-\mathrm{AlCl}_{3} / \mathrm{THF}$ & $0.5-1.75$ & $128(x=0.057)$ & $\begin{array}{c}52.3 \%(n=107 \\
y=0.057)\end{array}$ & - & - & [121] \\
\hline $\mathrm{Cu}_{x} \mathrm{Mo}_{6} \mathrm{Se}_{8}$ & $\mathrm{~N}$ & $0.4 \mathrm{M}(\mathrm{PhMgCl})-\mathrm{AlCl}_{3} / \mathrm{THF}$ & $0.5-1.95$ & $116(x=0.006)$ & $\begin{array}{c}93 \%(n=50 \\
y=0.006)\end{array}$ & - & D & [122] \\
\hline $\mathrm{TiSe}_{2}$ & N & $0.25 \mathrm{M} \mathrm{Mg}\left(\mathrm{PhCl}_{2} \mathrm{EtBu}\right)_{2} / \mathrm{THF}$ & $0.25-1.5$ & $122(x=0.005)$ & $\begin{array}{c}90.2 \%(n=60 \\
y=0.005)\end{array}$ & - & $\mathrm{H}$ & [123] \\
\hline $\mathrm{TiS}_{2}$ & N & All-phenyl complex (APC)/THF & $0.0-1.9$ & $250(C / 10)$ & $\begin{array}{c}56 \%(n=40, \\
C / 10)\end{array}$ & - & - & [124] \\
\hline $\mathrm{NiS}_{x}$ & $\mathrm{~N}$ & $0.4 \mathrm{M}(\mathrm{PhMgCl})-\mathrm{AlCl}_{3} / \mathrm{THF}$ & $0.3-1.9$ & $\begin{array}{c}150 \mathrm{mAh} \mathrm{cm}^{-3} \\
(x=0.01)\end{array}$ & $\begin{array}{c}71.4 \%(n=5000 \\
y=0.05)\end{array}$ & $6.7 \%(z=25)$ & $\mathrm{F}$ & [125] \\
\hline N-CNFs@Mos 2 & Y & $\mathrm{MgCl}_{2}$-LiTFSI & $0.0-1.8$ & $176(x=0.2)$ & $\begin{array}{c}74.4 \%(n=120 \\
y=0.2)\end{array}$ & $28.0 \%(z=25)$ & $A, G$ & [126] \\
\hline $\mathrm{Cu}_{2} \mathrm{Se}$ & N & $0.25 \mathrm{M} \mathrm{Mg}\left(\mathrm{PhCl}_{2} \mathrm{EtBu}\right)_{2} / \mathrm{THF}$ & $0.2-1.8$ & $148(x=0.005)$ & $\begin{array}{c}64.2 \%(n=35 \\
y=0.005)\end{array}$ & - & - & [127] \\
\hline $\mathrm{VS}_{4}$ & N & $0.4 \mathrm{~m}(\mathrm{PhMgCl})-\mathrm{AlCl}_{3} / \mathrm{THF}$ & $0.2-2.2$ & $251(x=0.1)$ & $\begin{array}{c}77 \%(n=800 \\
y=0.5)\end{array}$ & $43.8 \%(z=50)$ & $\mathrm{F}, \mathrm{H}$ & [128] \\
\hline $\mathrm{TiS}_{3}$ & N & $\mathrm{Mg}\left(\mathrm{CB}_{11} \mathrm{H}_{12}\right)_{2} /$ tetraglyme & - & $80(x=0.01)$ & - & - & $\mathrm{H}$ & [129] \\
\hline CuS & N & $\mathrm{Mg}(\mathrm{HMDS})_{2}-\mathrm{AlCl}_{3} /$ diglyme & $-1.0-2.0$ & $175(x=0.05)$ & $\begin{array}{c}75 \%(n=350 \\
y=0.05)\end{array}$ & - & $\mathrm{F}$ & [130] \\
\hline \multicolumn{9}{|l|}{ Mn-based materials } \\
\hline$\alpha-\mathrm{MnO}_{2} / \mathrm{CNTs}$ & Y & $1 \mathrm{M} \mathrm{MgSO}_{4}$ & $-0.6-1.5$ & $144.6(x=0.5)$ & $\begin{array}{c}85 \%(n=1000 \\
y=10)\end{array}$ & - & G & [134] \\
\hline$\delta$ - $\mathrm{MnO}_{2} @ \mathrm{CMS}$ & Y & $0.5 \mathrm{M} \mathrm{MgSO}_{4}$ & $-0.6-0.8$ & $112.2(x=0.05)$ & $\begin{array}{c}46.9 \%(n=100 \\
y=0.05)\end{array}$ & $52.7 \%(z=10)$ & G & [136] \\
\hline$\lambda-\mathrm{MnO}_{2}$ & Y & $1 \mathrm{M} \mathrm{MgCl} 2$ & $-0.8-1.2$ & $545.6(x=0.0136)$ & $\begin{array}{c}28.5 \%(n=300 \\
\gamma=0.156)\end{array}$ & $32.1 \%(z=100)$ & - & [137] \\
\hline$\lambda-\mathrm{MnO} 2 \cdot x \mathrm{H} 2 \mathrm{O}$ & Y & $0.5 \mathrm{M} \mathrm{Mg}\left(\mathrm{ClO}_{4}\right)_{2}$ & $-0.6-0.8$ & $231.1(x=0.1)$ & $\begin{array}{c}62.5 \%(n=10000 \\
y=2.0)\end{array}$ & - & c & [138] \\
\hline Sponge-like $\mathrm{Mn}_{3} \mathrm{O}_{4}$ & N & $0.4 \mathrm{M}(\mathrm{PhMgCl})-\mathrm{AlCl}_{3} / \mathrm{THF}$ & $0.2-2.1$ & $233(C / 10)$ & $\begin{array}{c}93 \%\left(\begin{array}{l}n=1000 \\
C / 10)\end{array}\right.\end{array}$ & - & $\mathrm{F}$ & [139] \\
\hline $\mathrm{MgMn}_{2} \mathrm{O}_{4} @ \mathrm{rGO}$ & Y & $0.5 \mathrm{M} \mathrm{MgCl} 2$ & $-0.5-0.8$ & $140.1(x=1)$ & $\begin{array}{c}85.7 \%(n=1000 \\
y=1)\end{array}$ & $75 \%(z=10)$ & G & [140] \\
\hline Mg-OMS-1 & Y & $0.5 \mathrm{M} \mathrm{MgCl}_{2}$ & $-0.65-0.8$ & $300(x=0.01)$ & $\begin{array}{c}83.7 \%(n=300 \\
y=0.1)\end{array}$ & $10.3 \%(z=100)$ & - & [141] \\
\hline Mg-OMS-2/graphene & Y & $0.5 \mathrm{M} \mathrm{Mg}\left(\mathrm{NO}_{3}\right)_{2}$ & $-0.65-0.75$ & $232.4(x=0.02)$ & $\begin{array}{c}93 \%(n=300 \\
y=0.1)\end{array}$ & - & G & [142] \\
\hline $\mathrm{Mg}_{0.15} \mathrm{MnO}_{2} \cdot 0.9 \mathrm{H}_{2} \mathrm{O} / \mathrm{CC}$ & Y & $0.5 \mathrm{M} \mathrm{Mg}\left(\mathrm{ClO}_{4}\right)_{2}$ & $-0.3-1.3$ & $150(2 \mathrm{C})$ & $30 \%(n=160,2 \mathrm{C})$ & - & $C, \mathrm{G}$ & [209] \\
\hline \multicolumn{9}{|l|}{ V-based materials } \\
\hline $\mathrm{V}_{2} \mathrm{O}_{5}$ xerogel/graphene & N & $0.5 \mathrm{M} \mathrm{Mg}(\mathrm{TFSI})_{2} /$ Acetonitrile & $1.65-3.3$ & $330(x=0.1)$ & $\begin{array}{c}81 \%(n=200 \\
\quad y=1)\end{array}$ & $33.4 \%(z=40)$ & G & [143] \\
\hline $\mathrm{V}_{2} \mathrm{O}_{5}$ xerogel/graphite & Y & $4.7 \mathrm{M} \mathrm{Mg}\left(\mathrm{NO}_{3}\right)_{2}$ & $-1.0-1.2$ & $76.8(x=1)$ & $\begin{array}{c}82.7 \%(n=10 \\
y=1)\end{array}$ & $59.9 \%(z=5)$ & $\mathrm{G}, \mathrm{H}$ & [49] \\
\hline $\mathrm{V}_{2} \mathrm{O}_{5}$ nanoclusters & $\mathrm{N}$ & $0.4 \mathrm{M} \mathrm{Mg}(\mathrm{TFSI})_{2} /$ diglyme & $0.5-2.8$ & $300(x=0.04)$ & $\begin{array}{c}65 \%(n=100 \\
y=0.32)\end{array}$ & - & $\mathrm{F}, \mathrm{G}$ & [45] \\
\hline Amorphous V2O5-P2O5 & $\mathrm{N}$ & $1 \mathrm{M} \mathrm{Mg}\left(\mathrm{ClO}_{4}\right)_{2} /$ Acetonitrile & $0.9-3.5$ & $121(x=0.005)$ & - & - & G & [144] \\
\hline
\end{tabular}


Table 4. Continued.

\begin{tabular}{|c|c|c|c|c|c|c|c|c|}
\hline Materials & $\begin{array}{c}\text { Aqueous } \\
(\mathrm{Y} / \mathrm{N})\end{array}$ & Electrolyte & $\begin{array}{c}\text { Working } \\
\text { potential } \\
{[\mathrm{V}]}\end{array}$ & $\begin{array}{l}\text { Specific capacity } \\
{\left[\mathrm{mAh} \mathrm{g}^{-1}\right] \text { at } x \mathrm{~A} \mathrm{~g}^{-1}}\end{array}$ & $\begin{array}{c}\text { Capacity retention } \\
\text { at y } \mathrm{A} \mathrm{g}^{-1} \text { after } n \\
\text { cycles }\end{array}$ & $\begin{array}{c}\text { Rate capability } \\
\text { (capacity } \\
\text { retention at } \\
\mathrm{z} \times x \mathrm{Ag}^{-1} \text { ) }\end{array}$ & Strategies & Ref. \\
\hline $\mathrm{VO}_{x}$ nanotube & $\mathrm{N}$ & $0.5 \mathrm{M} \mathrm{Mg}\left(\mathrm{ClO}_{4}\right)_{2} /$ Acetonitrile & $1.75-3.0$ & $218(x=0.06)$ & $\begin{array}{c}72.4 \%(n=20 \\
\gamma=0.06)\end{array}$ & - & $\mathrm{F}$ & {$[146$} \\
\hline $\mathrm{Li}_{3} \mathrm{~V}_{2}\left(\mathrm{PO}_{4}\right)_{3}$ & $\mathrm{Y}$ & $4 \mathrm{M} \mathrm{Mg}(\mathrm{TFSI})_{2}$ & $2.4-3.6$ & $55(x=0.1)$ & $\begin{array}{c}92 \%(n=6000, \\
y=0.2)\end{array}$ & $63.6 \%(z=60)$ & A & {$[36]$} \\
\hline $\mathrm{Mg}_{0.1} \mathrm{~V}_{2} \mathrm{O}_{5} \cdot 1.8 \mathrm{H}_{2} \mathrm{O}$ & $\mathrm{N}$ & $0.5 \mathrm{M} \mathrm{Mg}(\mathrm{TFSI})_{2} /$ Acetonitrile & $-1.0-1.2$ & $280(C / 10)$ & $\begin{array}{c}\text { Only } 7 \text { charge/ } \\
\text { discharge cycles } \\
\text { at } C / 10\end{array}$ & - & C & [39] \\
\hline \multicolumn{9}{|l|}{ Other materials } \\
\hline Quinone (C4Q) & $\mathrm{Y}$ & $3 \mathrm{M} \mathrm{Mg}(\text { TFSI })_{2}$ & $1.2-2.0$ & $247.4(x=0.02)$ & - & - & A & {$[105$} \\
\hline PPTO & $\mathrm{Y}$ & $4.5 \mathrm{M} \mathrm{Mg}\left(\mathrm{NO}_{3}\right)_{2}$ & $0.3-1.3$ & $144(x=0.07)$ & $\begin{array}{c}66 \%(n=1000 \\
y=0.07)\end{array}$ & - & - & {$[149$} \\
\hline PTCDA & Y & $4.8 \mathrm{M} \mathrm{Mg}\left(\mathrm{NO}_{3}\right)_{2}$ & $-0.8-0.2$ & $136(x=0.5)$ & $\begin{array}{c}58.8 \%(n=37, \\
\quad y=0.5)\end{array}$ & - & $\mathrm{H}$ & {$[150$} \\
\hline PANI & Y & $2 \mathrm{M} \mathrm{Mg}\left(\mathrm{ClO}_{4}\right)_{2}$ & $1.0-1.6$ & - & - & - & - & {$[151]$} \\
\hline Polyimides@CNT & $\mathrm{Y}$ & $4 \mathrm{M} \mathrm{Mg}(\mathrm{TFSI})_{2}$ & $1.7-2.5$ & $110(x=0.1)$ & $\begin{array}{c}87.3 \%(n=500 \\
y=0.1)\end{array}$ & $55.0 \%(z=40)$ & $\mathrm{A}, \mathrm{G}, \mathrm{H}$ & {$[210$} \\
\hline $\mathrm{NiHCF}$ & $\mathrm{Y}$ & $1 \mathrm{M} \mathrm{MgSO}_{4}$ & $0-1.55$ & $35(x=2)$ & $\begin{array}{c}54.3 \%(n=5000 \\
y=2)\end{array}$ & - & - & {$[211]$} \\
\hline $\mathrm{NiHCF}$ & Y & $1 \mathrm{M} \mathrm{Mg}\left(\mathrm{NO}_{3}\right)_{2}$ & $0-1.6$ & $52(5 \mathrm{C})$ & $\begin{array}{c}65 \%(n=5000 \\
5 \mathrm{C})\end{array}$ & - & - & {$[153$} \\
\hline $\mathrm{NiHCF}$ & $\mathrm{N}$ & $0.5 \mathrm{M} \mathrm{Mg}\left(\mathrm{ClO}_{4}\right)_{2} /$ Acetonitrile & $2.72-2.32$ & $48(x=0.0114)$ & $\begin{array}{c}62.5 \%(n=30 \\
\gamma=0.0114)\end{array}$ & - & $\mathrm{H}$ & {$[212$} \\
\hline Fullerene & $\mathrm{N}$ & $0.5 \mathrm{~m}(\mathrm{PhMgCl})-\mathrm{AlCl}_{3} / \mathrm{THF}$ & $0.8-2.2$ & $47.5\left(75 \mu \mathrm{A} \mathrm{cm}^{-2}\right)$ & $\begin{array}{c}40 \%(n=2000 \\
\left.19 \mu \mathrm{A} \mathrm{cm}^{-2}\right)\end{array}$ & - & - & {$[155$} \\
\hline Fluorinated graphene & $\mathrm{N}$ & $0.75 \mathrm{M} \mathrm{Mg}\left(\mathrm{ClO}_{4}\right)_{2} / \mathrm{DMSO}$ & $0.6-2.75$ & $110(x=0.01)$ & $\begin{array}{c}90 \%(n=30, \\
y=0.01)\end{array}$ & $45.5 \%(z=10)$ & c & {$[156$} \\
\hline
\end{tabular}

*For the strategies employed: A ("water-in-salt" electrolyte), B (electrolyte additives), C (pre-intercalation strategy), D (heteroatom doping), E (defects engineering), F (size regulation), $\mathrm{G}$ (composites and free-standing configuration), $\mathrm{H}$ (advanced characterization and theoretical study).

$\mathrm{Cu}$ crystal; and during charge, the deposited $\mathrm{Cu}^{0}$ is oxidized and reversibly inserted to the host structure. Therefore, the enhancement in specific capacity mainly results from the deposition/dissolution of $\mathrm{Cu}^{0}$. Besides, it is known that decreasing the particle size to the nanoscale will expedite diffusion kinetics and increase the energy density of AMIBs, due to the shortened diffusion paths for $\mathrm{Mg}^{2+}$ and increased specific surface area. ${ }^{[4]}$ Compared with microsized Chevrel $\left(73 \mathrm{mAh} \mathrm{g}^{-1}\right.$ at $5 \mathrm{~mA} \mathrm{~g}^{-1}$ ), the specific capacity of submicrosized Chevrel $\left(93 \mathrm{mAh} \mathrm{g}^{-1}\right.$ at $5 \mathrm{~mA} \mathrm{~g}^{-1}$ ) exhibited $\approx 27.3 \%$ enhancement.

Various TMDs with layered structures and high electron conductivity have been studied as the cathode for AMIBs, including $\mathrm{TiSe}_{2},{ }^{[123]} \mathrm{TiS}_{2},{ }^{[124]} \mathrm{NiS}_{2},{ }^{[125]} \mathrm{MoS}_{2},{ }^{[126]}$ and $\mathrm{Cu}_{2} \mathrm{Se}^{[127]}$ etc. Taniguchi et al. reported a layered $\mathrm{TiSe}_{2}$ as cathode material, which demonstrated a high specific capacity of $250 \mathrm{mAh} \mathrm{g}^{-1}$ at $\mathrm{C} / 10 .{ }^{[124]}$ On the one hand, the van der Waals gap in $\mathrm{TiSe}_{2}$ suppress the effect of Coulomb repulsion between $\mathrm{Mg}^{2+}$, thus facilitating the fast transport kinetics; On the other hand, they proposed that the charge delocalization resulting from the strong d-p orbital hybridization may improve the process of $\mathrm{Mg}^{2+}$ (de) intercalation.
Despite limited research, other chalcogenides are promising for AMIBs, such as $\mathrm{VS}_{4},{ }^{[128]} \mathrm{TiS}_{3},{ }^{[129]}$ and $\mathrm{CuS},{ }^{[130]}$ etc. By the hydrothermal method, Zhong et al. synthesized highly branched $\mathrm{VS}_{4}$ nanodendrites with $1 \mathrm{D}$ atomic-chain structure, which presents a high specific capacity $\left(251 \mathrm{mAh} \mathrm{g}^{-1}\right.$ at $\left.100 \mathrm{~mA} \mathrm{~g}^{-1}\right) \cdot{ }^{[128]}$ It can be seen from the DFT calculations (Figure 10d): 1) that the formation energy tends to decrease when $0.125<x<0.625$, indicating the $\mathrm{Mg}^{2+}$ intercalation is favorable; 2) the formation energy gradually increases along with the increase of $\mathrm{Mg}^{2+}$ content $(0.625<x<0.875)$, but it is still energetically favorable. To the best of our knowledge, there are less than 20 chalcogenides that have been developed for rechargeable MIB cathodes, which means that hundreds of chalcogenides remain un-explored. Further comprehensive and innovative research will be helpful to the design of high-performance electrode materials for rechargeable AMIBs.

Interestingly, chalcogenides based on aqueous electrolytes have made promising progress, which provides new insights and opportunities for chalcogenides in AMIBs. In 2018, Yu et al. reported the electrochemical performance of a N-CNFs@ $\mathrm{MoS}_{2}$ cathode in an aqueous dual-salt electrolyte $\left(\mathrm{MgCl}_{2}\right.$-LiTFSI) 
(a)

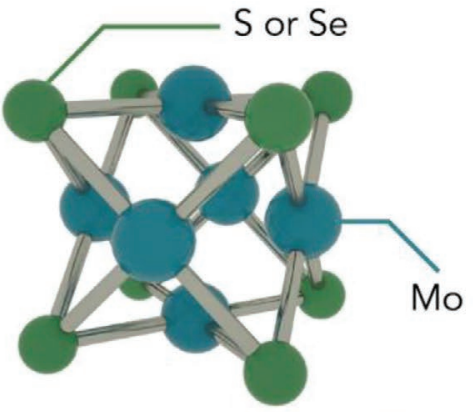

(d)

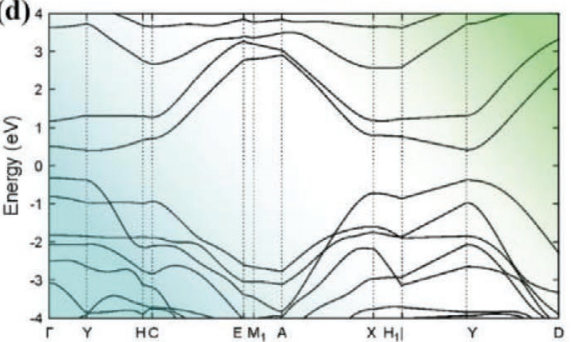

(b)

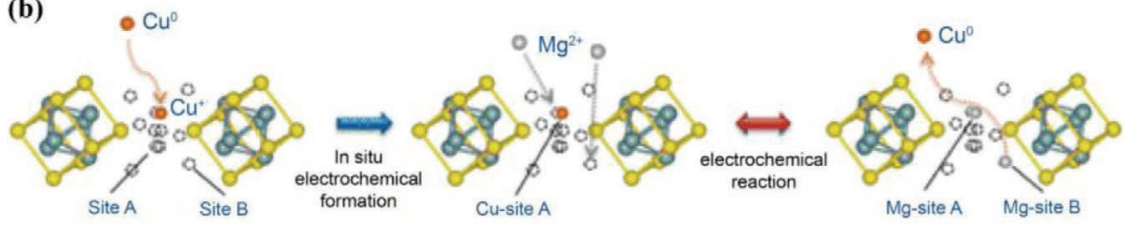

\section{$\mathrm{Mo}_{6} \mathrm{~S}_{8}+\mathrm{Cu}^{0} \rightarrow \mathrm{Cu}_{x} \mathrm{Mo}_{6} \mathrm{~S}_{8}$ $\mathrm{Cu}_{x} \mathrm{Mo}_{6} \mathrm{~S}_{8}+2 \mathrm{Mg}^{2+}+4 \mathrm{e}^{-} \leftrightarrow \mathrm{Mg}^{2} \mathrm{Mo}_{6} \mathrm{~S}_{8}+\mathrm{Cu}^{0}$ \\ (In situ electrochemical formation) \\ (Electrochemical reaction)}

(c)

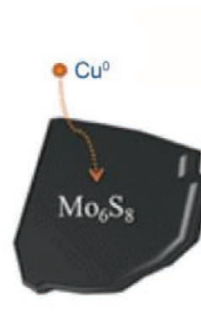

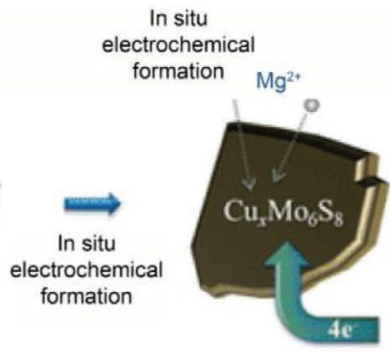

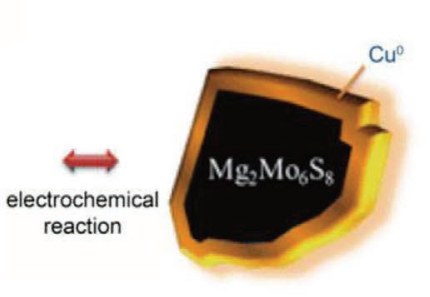

Figure 10. Chalcogenides cathode for MIBs. a) Schematic diagram of Chevrel phase compounds; schematic diagram of b) Cu replacement reaction in the $\mathrm{Mo}_{6} \mathrm{~S}_{8}$, and c) the proposed Cu replacement reaction structure during Mg-ion insertion/extraction; Reproduced with permission. ${ }^{[43]}$ Copyright 2015, American Chemical Society. d) band structure for $\mathrm{TiS}_{3}$. Reproduced with permission. ${ }^{[129]}$ Copyright 2017, American Chemical Society.

and found that it exhibited a specific capacity of $178 \mathrm{mAh} \mathrm{g}^{-1}$ at $0.2 \mathrm{~A} \mathrm{~g} \mathrm{~g}^{-1}$ and stability of $74.4 \%$ retention, after 120 cycles at $0.2 \mathrm{~A} \mathrm{~g}^{-1}$, which is better than most of the chalcogenides in the non-aqueous system. ${ }^{[126]}$ Therefore, it is reasonable to expect that the exciting development of AMIBs will be achieved by coupling the widely-studied chalcogenide cathodes and the innovation of electrolytes in future.

\subsection{Mn-based Materials}

Mn-based cathode materials for AMIBs have received significant attention owing to their low-cost, environmentally friendly nature, fast $\mathrm{Mg}^{2+}$ (de)intercalation properties and higher operation voltage compared to the Chevrel phase. Similar to AZIBs, many Mn-based materials have been studied for rechargeable AMIBs, including $\beta-\mathrm{MnO}_{2},{ }^{[134]} \gamma-\mathrm{MnO}_{2},{ }^{[135]} \delta-\mathrm{MnO}_{2},{ }^{[136]}$ $\lambda$ - $\mathrm{MnO}_{2},{ }^{[137,138]} \mathrm{Mn}_{3} \mathrm{O}_{4},{ }^{[139]}$ spinel-type $\mathrm{MgMn}_{2} \mathrm{O}_{4},{ }^{, 140]}$ and magnesium octahedral molecular sieves (Mg-OMS). ${ }^{[141,142]}$ Although AMIBs possess better intercalation capability than that of AZIBs for the Mn-based system, the crucial challenges for Mnbased cathodes are to further enhance the specific capacity and ion diffusion kinetics without compromising the materials' stability. To improve the stability and performance of Mn-based cathodes, many methods have been proposed recently, such as the introduction of crystal water, defects and morphology engineering, etc.

The introduction of lattice water into the active host can reduce the dissolution energy loss at the electrode-electrolyte interface and effectively shield the charge, thus facilitating $\mathrm{Mg}^{2+}$ diffusion. Based on Birnessite $\mathrm{MnO}_{2}$, Choi et al. systematically studied the function of lattice water on the active host. ${ }^{[38]}$ Their research directly observed the presence and dynamic rearrangements of lattice water during discharge-charge processes
(Figure 11a), via annular bright field-scanning transmission electron microscopy (ABF-STEM). The proposed rearrangements (Figure 11b) not only effectively shield the electrostatic interaction between $\mathrm{Mg}^{2+}$ ions and the active host, but also enhance the structural stability of the cathode material during the (de)intercalation.

Many investigations demonstrate that innovation in morphology could improve the performance of Mn-based cathodes. Vullum-Bruer et al. successfully synthesized sponge-like porous $\mathrm{Mn}_{3} \mathrm{O}_{4}$ nanoparticles with a high content of interconnected mesopores and well-dispersed nanoparticles $(\approx 10 \mathrm{~nm})$ (Figure 11c), which resulted in a remarkable enhancement in Coulombic efficiency and cyclic stability (94\% retention, 1000 cycles at 2C). ${ }^{[139]}$ Besides, the development of nanocomposites is also a feasible methodology. Cao and colleagues incorporated reduced graphene oxide ( $\mathrm{rGO}$ ) with $\mathrm{MgMn}_{2} \mathrm{O}_{4}$ using a sol-gel method, which optimizes the interfacial properties and increases the electric conductivity. ${ }^{[140]}$ Compared with the pristine $\mathrm{MgMn}_{2} \mathrm{O}_{4}$, the $\mathrm{MgMn}_{2} \mathrm{O}_{4} / \mathrm{rGO}$ composite electrode presents a significant enhancement in specific capacity (140.1 $\mathrm{mAh} \mathrm{g}^{-1}$ at $1 \mathrm{~A} \mathrm{~g}^{-1}$ ) and stability $(85.7 \%$ capacity retention after 1000 cycles at $1 \mathrm{~A} \mathrm{~g}^{-1}$ ) (Figure 11d).

In general, Mn-based cathodes are one of the most promising materials for rechargeable AMIBs, but they still need further exploration. For instance, various types of morphologies (nanorods, nanofibers, nanowires, and nanoflowers, etc.) and incorporated substances such as polyaniline (PAN) and poly(3,4-ethylenedioxythiophene) (PEDOT), have been proved as effective strategies for AZIBs, but have not been reported in AMIBs. The current theoretical investigations are not yet sufficient to reveal the underlying mechanisms. For example, it is unclear whether the $\mathrm{H}^{+}$co-intercalation or the conversion reaction mechanisms occur in AMIBs. To the best of our knowledge, there is no research on free-standing Mn-based cathodes, 
(a)
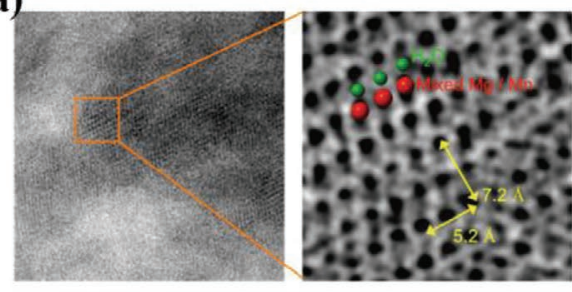

(c) (d)

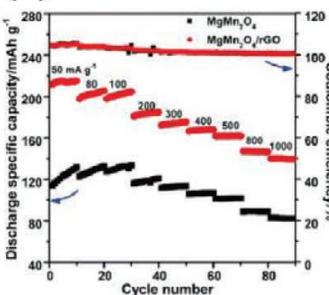

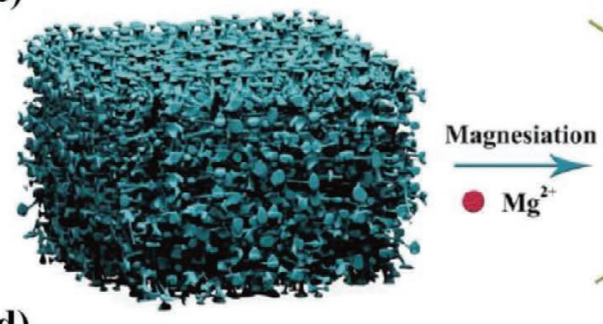

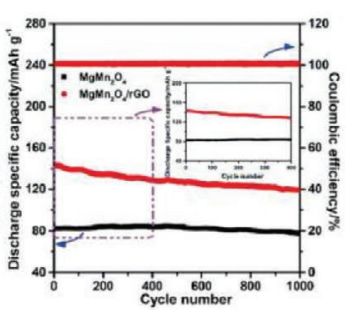

(b)
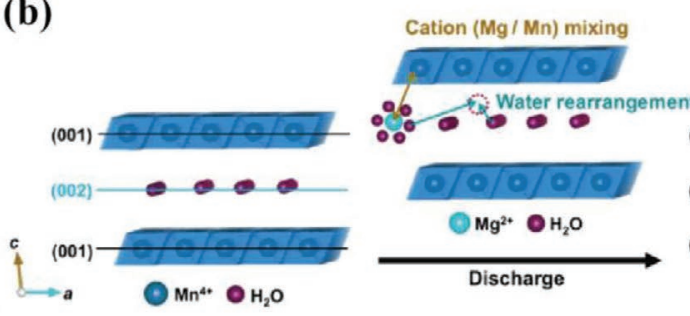

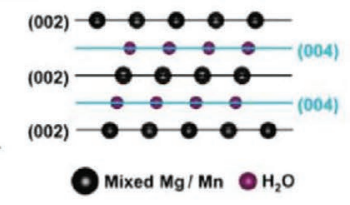

(f)

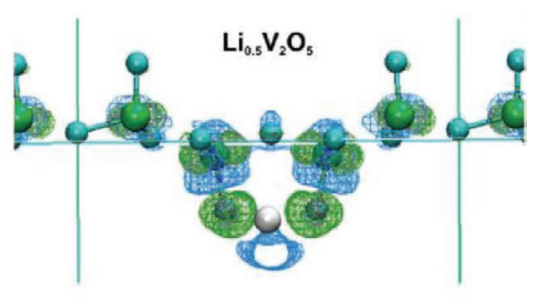

(e)
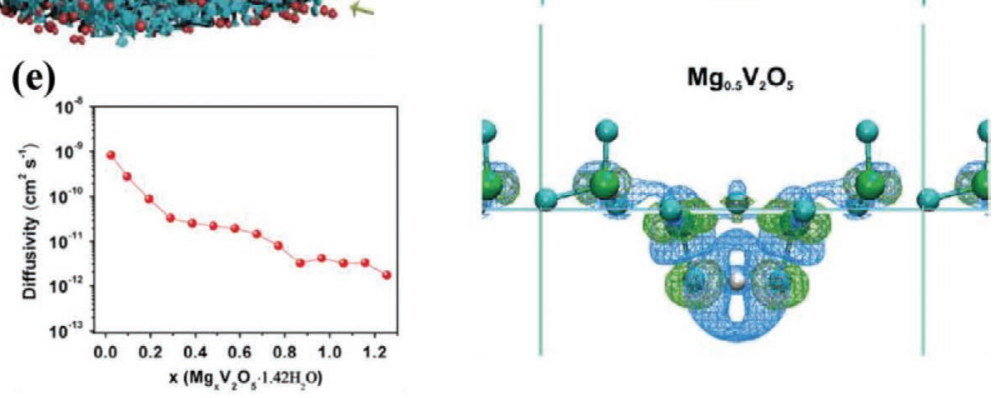

(g)
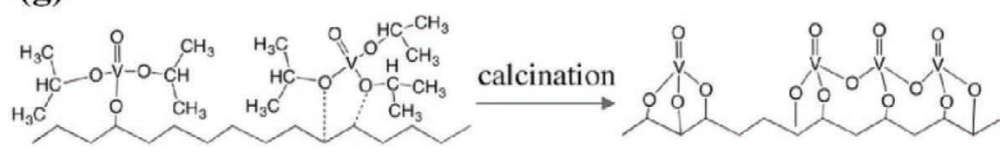

reversible
$\mathrm{Mg}^{2+}$ storage

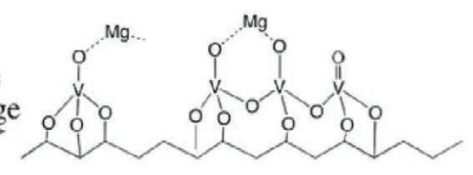

Figure 11. Mn-based and V-based materials for AMIBs a) ABF-STEM images of discharged manganese birnessite cathodes at low and high magnifications; b) schematic diagram of intercalation of hydrated $\mathrm{Mg}^{2+}$ and $\mathrm{Mg} / \mathrm{Mn}$ mixing during discharging; Reproduced with permission. ${ }^{[138]}$ Copyright 2015, American Chemical Society. c) Magnesiation process of sponge-like porous manganese (II, III) oxide. Reproduced with permission. ${ }^{[139]}$ Copyright 2016, American Chemical Society. d) Rate performance and long-term cycling stability of $\mathrm{MgMn}_{2} \mathrm{O}_{4}$ and $\mathrm{MgMn}_{2} \mathrm{O}_{4} / \mathrm{rCO}$. Reproduced with permission. [140] Copyright 2018, Royal Society of Chemistry. e) diffusivity versus state of discharge of $\mathrm{Mg}_{x} \mathrm{~V}_{2} \mathrm{O}_{5} \cdot 1.42 \mathrm{H}_{2} \mathrm{O}$. Reproduced with permission. ${ }^{[143]}$ Copyright 2015, Elsevier. f) Proposed mechanism for the formation of dispersed vanadium oxide nanoclusters on the surface of porous carbon, and the reversible storage of $\mathrm{Mg}^{2+}$. Reproduced with permission. ${ }^{[45]}$ Copyright 2015, Wiley. g) Charge redistribution pattern due to the interaction between $\mathrm{V}_{2} \mathrm{O}_{5}-\mathrm{SL}$ and $\mathrm{Mg} / \mathrm{Li}$. Reproduced with permission. ${ }^{[49]}$ Copyright 2015, Elsevier.

which we believe could be promising to address some of the current obstacles for AMIBs.

\subsection{V-based Materials}

Decades of intensive research have proven that V-based materials are one of the most promising cathode materials for rechargeable batteries, due to their extensive reserves, low price, chemical diversity, and excellent performance. Most of the current widely studied V-based materials, including $\mathrm{V}_{2} \mathrm{O}_{5},{ }^{[45,49,143-145]}$ $\mathrm{Mg}_{x} \mathrm{~V}_{2} \mathrm{O}_{5} \cdot \mathrm{yH}_{2} \mathrm{O},{ }^{[39]} \mathrm{Li}_{3} \mathrm{~V}_{2}\left(\mathrm{PO}_{4}\right)_{3},{ }^{[36]}$ and $\mathrm{VO}_{x}$ nanotubes, ${ }^{[146]}$ are mainly focused on non-aqueous systems. This is because of the compatibility issue between the aqueous electrolyte and metallic magnesium electrodes, as well as the excessive deformation of cathode materials. However, recent developed strategies are to increase lattice water and use WIS electrolytes to alleviate these issues, thus making the realization of similar charge storage behaviors as in aqueous electrolytes. This section focuses on the discussion of WIS electrolytes, lattice water introduction strategy and the current findings from theoretical studies.

As early as 1993, Novák and Desilvestro found that the kinetics of $\mathrm{Mg}^{2+}$ diffusion and specific capacity could be significantly enhanced when adding $1 \mathrm{M} \mathrm{H}_{2} \mathrm{O}$ into the $\mathrm{Mg}\left(\mathrm{ClO}_{4}\right)_{2}$ acetonitrile electrolyte. ${ }^{[147]}$ Furthermore, in 1995, they proposed that this enhancement was due to a charge shielding effect, which resulted from the dipole molecule $\left(\mathrm{H}_{2} \mathrm{O}\right)$ converting $\mathrm{Mg}^{2+}$ into a less polarizing solvated ion. ${ }^{[148]}$ Nevertheless, this strategy faced rapid capacity attenuation, owing to water ejection from the crystal structure of the host material. For example, Lee et al. synthesized $\mathrm{Mg}_{0.1} \mathrm{~V}_{2} \mathrm{O}_{5} \cdot 1.8 \mathrm{H}_{2} \mathrm{O}$ showing the $280 \mathrm{mAh} \mathrm{g}{ }^{-1}$ discharge capacity at $0.1 \mathrm{~A} \mathrm{~g}^{-1}$ via the sol-gel method, however, the as-assembled battery was stable for only 7 cycles. ${ }^{[39]}$ To address this challenge, Mai and coworkers reported the graphene decorated hydrated vanadium oxide nanocomposite (VOG-1) as the cathode material, which possesses a specific capacity of $330 \mathrm{mAh} \mathrm{g}^{-1}\left(0.1 \mathrm{~A} \mathrm{~g}^{-1}\right)$ and $81 \%$ retention after 200 cycles at $1 \mathrm{~A} \mathrm{~g}^{-1} \cdot[143]$ Then, informed by the galvanostatic intermittent 
titration technique (GITT), they noticed that $\mathrm{Mg}$ diffusivity decreases from $9 \times 10^{-10}$ to $1 \times 10^{-12} \mathrm{~cm}^{2} \mathrm{~s}^{-1}$ as the $\mathrm{Mg}^{2+}$ concentration increases due to charge repulsion effect (Figure 11e). Meanwhile, the unique nanocomposite architecture alleviates water ejection from the host and provides efficient electron transport pathways.

Nevertheless, the introduction of lattice water faces several substantial issues: a) excessive structural deformations of host materials due to the large effective radius of the intercalated moieties; b) poor compatibility between the water and magnesium anodes. To address these challenges, Wang et al. used $4 \mathrm{M} \mathrm{MgTSFI}_{2}$ aqueous electrolyte to inhibit water activity and expand the electrochemical stability window. ${ }^{[36]}$ Although the electrolyte exhibits a wide potential window of $2 \mathrm{~V}$, as well as excellent safety and corrosion resistance properties, its high price is inappropriate for cost-sensitive applications. Recently, several research studies have focused on $\mathrm{V}_{2} \mathrm{O}_{5}$ nanoclusters, ${ }^{[45]}$ ultrathin layers of $\mathrm{V}_{2} \mathrm{O}_{5}{ }^{[145]}$ and $\mathrm{V}_{2} \mathrm{O}_{5}-\mathrm{P}_{2} \mathrm{O}_{5}$ powders. ${ }^{[144]}$ This has proven that nanoscaled V-based materials could shorten the $\mathrm{Mg}^{2+}$ diffusion path and provide high voltage reversibility. Based on this strategy, Liu et al. synthesized highly dispersed vanadium oxide $\left(\mathrm{V}_{2} \mathrm{O}_{5}\right)$ nanoclusters supported on porous carbon frameworks, which demonstrates encouraging performance $\left(300 \mathrm{mAh} \mathrm{g}^{-1}\right.$ at $40 \mathrm{~mA} \mathrm{~g}^{-1}, 70 \%$ retention after 100 cycles at $\left.320 \mathrm{~mA} \mathrm{~g}^{-1}\right) \cdot{ }^{[45]}$ Additionally, the rich defective and reactive sites in this composite could react with $\mathrm{Mg}^{2+}$ through reversible chemical binding reactions (Figure 11f) and lead to capacitive behavior with outstanding rate performance.

Further research on unique divalent $\mathrm{Mg}^{2+}$ electrochemistry, especially $\mathrm{Mg}^{2+}$ storage mechanisms and their interaction and transportation with the host material, will provide new insights into the development of AMIBs. Based on amorphous $\mathrm{V}_{2} \mathrm{O}_{5}$ xerogel/graphite composite, Mentus and colleagues compared capacity retention of different inserted ions and found the capacity decreased in the following order: $\mathrm{Mg}^{2+}>\mathrm{Li}^{+}>\mathrm{Na}^{+}>$ $\mathrm{K}^{+} .{ }^{[49]}$ Through DFT calculations, they found that $\mathrm{Mg}^{2+}$ is more likely to generate a strong interaction with four oxygens from the $\mathrm{V}=\mathrm{O}$ groups (vanadyl oxygen) compared with other monovalent ions, therefore strengthening the $\mathrm{V}-\mathrm{O}(3)$ bonds and forming a more stable structure (Figure 11g). This stronger interaction resulted in stronger bonding of $\mathrm{V}-\mathrm{O}(3)$ bonds, thereby inhibiting the dissolution of vanadium ions in the crystal into the electrolyte and enhancing stability. It should be noted that existing mechanistic research is mainly focused on non-aqueous systems, with limited investigations into aqueous systems. As we try to translate the materials for non-aqueous system into the application of AMIBs, more mechanistic studies will be needed to guide materials optimization.

V-based materials for AMIBs are attractive and promising in both performances and development potentials. Although some of the materials discussed are applied to non-aqueous MIBs, it does not prevent them from inspiring AMIB research. Most of these strategies for non-aqueous systems can be adopted in AMIBs, such as defect engineering, size regulation, the introduction of transition metal atoms, etc. It is worth noting that combining the lattice water strategy together with the application of WIS aqueous electrolyte, the performance and feasibility of V-based AMIBs may have significant advances.

\subsection{Other Materials}

Organic cathodes are receiving increasing attention and many compounds are currently being developed as cathode materials for AMIBs, including quinone $(\mathrm{C} 4 \mathrm{Q}),{ }^{[105]}$ poly(pyrene-4,5,9,10tetraone) (PPTO), ${ }^{[149]}$ perylenetetracarboxylic dianhydride (PTCDA), ${ }^{[150]}$ and polyaniline (PANI). ${ }^{[151]} \mathrm{Ji}$ et al. reported that the crystalline 3,4,9,10-perylenetetracarboxylic dianhydride (PTCDA) demonstrated intrinsically superior performance (138 mAh g $\mathrm{m}^{-1}$ at $0.02 \mathrm{~A} \mathrm{~g}^{-1}$ ) in the affinity of divalent metal ions in aqueous electrolyte, due to the van der Waals structure and lack of ionicity. ${ }^{[150]}$ Via ex situ XRD and TEM characterizations, they found the simultaneous contraction and expansion along with different crystallographic directions during "magnesiation." Then, by combining the DFT calculations with XRD analysis of hydronium-inserted PTCDA structures, it was confirmed that the expansion is due to the hydronium insertion. Additionally, they investigated the "magnesiation"induced PTCDA contraction via first-principles calculations and found that the distance between two oxygen atoms chelating with one $\mathrm{Mg}^{2+}$ decreases from 3.93 to $3.42 \AA$ for pristine PTCDA and Mg-PTCDA, respectively (Figure 12a). Therefore, the insertion of $\mathrm{Mg}^{2+}$ alleviates carbonyl/carbonyl repulsion and becomes coordinated by three different carbonyl groups (Figure 12b), which results in the PTCDA molecules rotating in separate directions toward a more linear arrangement (Figure 12c).

PBA-based cathodes have been regarded as promising materials for rechargeable batteries in aqueous systems since 2011, because of their merits including open-frameworks, low-cost and their environmentally friendly nature. ${ }^{[152]} \mathrm{Xia}$ and colleagues reported the first aqueous Mg-ion battery using a nickel hexacyanoferrate (NiHCF) cathode, and polyimide anode, which exhibits an operating voltage $(1.6 \mathrm{~V})$ equivalent to that of MIB using highly unstable organic electrolyte. ${ }^{[153]}$ Meanwhile, the as-assembled aqueous MIB demonstrates impressive durability (65\% after 5000 cycles) and a remarkable power density $\left(45 \mathrm{Wh} \mathrm{kg}^{-1}\right)$, which is close to the requirements for stationary energy storage applications. ${ }^{[154]}$

At present, the search for a metal-free cathodes for MIBs is mainly based on organic electrolytes, such as fullerene and fluorinated graphene. ${ }^{[155,156]}$ Generally, functionalized carbonbased materials could provide redox sites for cations on the surface, thus resulting in pseudocapacitance dominated behavior. ${ }^{[157]}$ In 2007, graphite fluorides $\left(\mathrm{CF}_{x}\right)$ were developed as an effective cathode when coupled with the Mg anode. However, its mechanism was unclear. ${ }^{[158]}$ For fluorinated graphene nanosheets (FGSs), Guo et al. investigated multiple cation or anion (de)intercalation processes during the initial few cycles, and proposed possible mechanisms (Figure 12d): 1) first charge: the insertion of $\mathrm{ClO}_{4}^{-}$, most of which are converted to $\mathrm{Cl}^{-}$based groups; 2) second discharge: the insertion of $\mathrm{Mg}^{2+}$ contained solvate cations; 3) second charge and deeper cycling: shuttle of cations including $\mathrm{MgCl}^{+}, \mathrm{Mg}_{2} \mathrm{Cl}_{3}{ }^{+}$, and $\mathrm{Mg}(\mathrm{DMSO})_{n} \mathrm{ClO}_{4}{ }^{+} \cdot{ }^{[156]}$ Benefiting from abundant surface reactions at fluorinated functional groups, this material possesses many merits, including alleviated structural deformation, negligible voltage polarization and highly reversible pseudocapacitive behavior at a high voltage. 


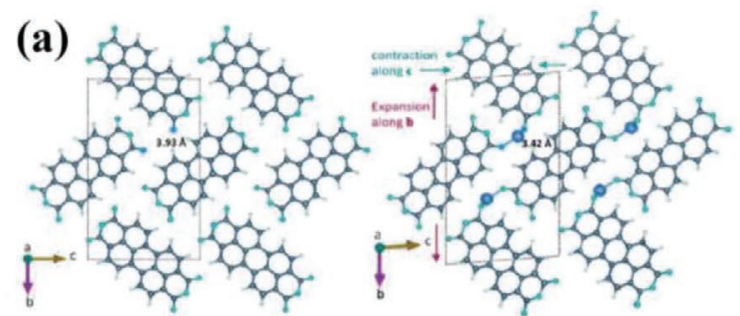

(d)

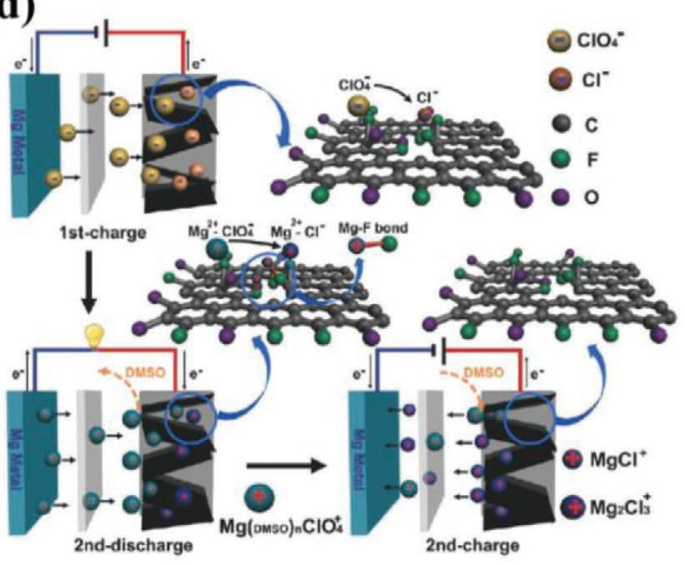

(b)
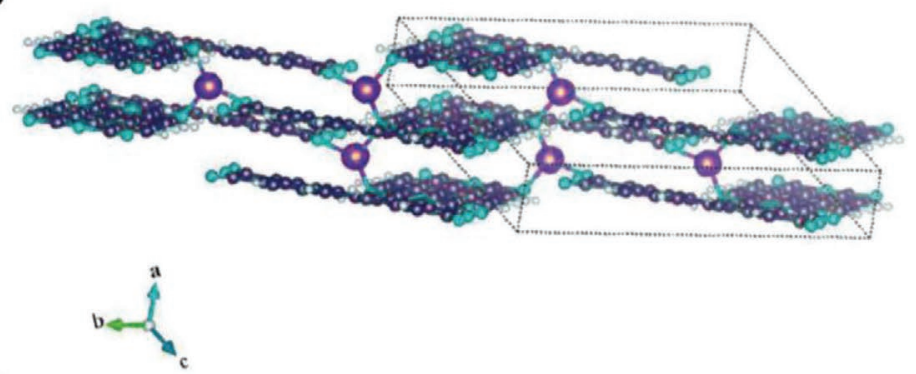

(c)

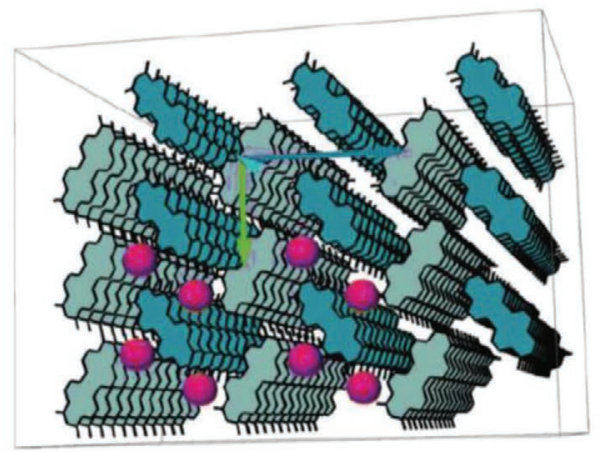

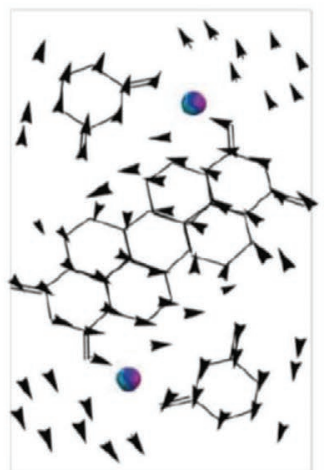

Figure 12. Other cathode candidates for AMIBs. a) PTCDA unit cells simulation before and after magnesiation; b) schematic diagram of the PTCDA crystal lattice (three PTCDA molecules coordinated with one $\mathrm{Mg}^{2+}$; c) schematic diagram of the packing of the PTCDA molecules. Reproduced with permission. ${ }^{[150]}$ Copyright 2017, American Chemical Society. d) schematic diagram of electrochemical reaction mechanisms of a Mg/FGS battery. Reproduced with permission. ${ }^{[156]}$ Copyright 2015, Wiley.

\subsection{Perspectives}

Although it has been 20 years since the first MIB was reported, it is still quite a long way from being used in practical scenarios. In general, AMIBs are still facing the following challenges and opportunities:

1. It is a feasible and promising strategy to convert massive non-aqueous electrolyte based materials studies into aqueous systems. Nevertheless, there may be many challenges in implementing this strategy, such as compatibility issues between the electrode materials and aqueous electrolytes and narrow potential window. Additionally, current studies investigating electrode/electrolyte interphase properties in the aqueous systems are far from sufficient; hence, further studies are urgently needed. Meanwhile, due to the high similarity in many key properties between $\mathrm{Zn}^{2+}$ and $\mathrm{Mg}^{2+}$, the high-performance cathode candidates for AZIBs may be also suitable for AMIBs. After addressing the electrolyte challenges, promising studies on cathode materials are expected.

2. The mechanistic understanding of AMIBs is still in its infancy and many potential possibilities remain unexplored. For example, the $\mathrm{H}^{+}$co-intercalation could provide additional capacity and has been widely reported for AZIBs, however, its existence and mechanism have not been extensively investigated in AMIBs. Therefore, advanced in situ characterization techniques and more comprehensive computational chemistry studies are highly recommended for future research.
3. Compared to commercial LIBs or AZIBs, few state-of-the-art cathode materials for AMIBs exhibit such promising merits in terms of specific capacity and durability. At present, no single strategy can universally solve all problems. For instance, although the introduction of lattice water in the host materials could enhance the $\mathrm{Mg}^{2+}$ diffusion kinetics and stability, it may also face several issues, including excessive structural deformations of host materials and poor compatibility between water and the magnesium anodes. The emergence of WIS aqueous electrolyte may broaden the potential window to $\approx 2 \mathrm{~V}$; however, its current high cost is a barrier to costsensitive applications. Therefore, a reasonable combination of several promising strategies will be an effective solution to further improve the performance of AMIBs.

\section{Aqueous Rechargeable Aluminum-Ion Batteries}

The concept of rechargeable aluminum-ion batteries (AIBs) was proposed in the 1970s; however, the overall electrochemical performance of AIBs is still far from satisfactory compared to LIBs. ${ }^{[8]}$ Although AIBs provide the possibilities of low cost, high safety, and high performance for large-scale electrochemical energy storage, they suffer from substantial challenges including sluggish diffusion kinetics, ${ }^{[159]}$ materials disintegration, ${ }^{160]}$ low discharge voltage $(\approx 0.55 \mathrm{~V}),{ }^{[161]}$ poor durability $(\approx 40-90 \% \text { per } 100 \text { cycles })^{[160,162-168]}$ and the formation of a passivating oxide film. ${ }^{[169]}$ Basically, the energy storage 
Table 5. Representative cathode materials of rechargeable AIBs in recent years.

\begin{tabular}{|c|c|c|c|c|c|c|c|c|}
\hline Materials & $\begin{array}{l}\text { Aqueous } \\
(\mathrm{Y} / \mathrm{N})\end{array}$ & Electrolyte & $\begin{array}{c}\text { Working } \\
\text { potential } \\
{[\mathrm{V}]}\end{array}$ & $\begin{array}{c}\text { Specific capacity } \\
{\left[\mathrm{mAh} \mathrm{g}^{-1}\right]} \\
\text { at } x \mathrm{Ag}^{-1}\end{array}$ & 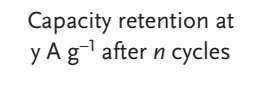 & $\begin{array}{l}\text { Rate capability } \\
\text { (capacity retention } \\
\text { at } z \times \times \mathrm{Ag}^{-1} \text { ) }\end{array}$ & Strategies & Reference \\
\hline 3D graphene foam & $\mathrm{N}$ & $\mathrm{AlCl}_{3} /[\mathrm{EMIm}] \mathrm{Cl}$ & $1.5-2.25$ & $70(x=1)$ & $100 \%(n=7500, y=4)$ & - & $\mathrm{H}$ & [170] \\
\hline $\mathrm{CuO}$ & N & $\mathrm{AlCl}_{3} /[\mathrm{EMIm}] \mathrm{Cl}$ & $0.1-2.0$ & $250(x=0.05)$ & $45 \%(n=100, y=0.2)$ & - & - & [17ו1] \\
\hline $\mathrm{Mo}_{2.5+y} \mathrm{VO}_{9+z}$ & $\mathrm{~N}$ & $\mathrm{AlCl}_{3} /[\mathrm{EMIm}] \mathrm{Cl}$ & $0.0-1.6$ & $340(x=0.002)$ & - & $8.9 \%(z=50)$ & - & [172] \\
\hline $\mathrm{VS}_{4} / \mathrm{rGO}$ & $\mathrm{N}$ & $\mathrm{AlCl}_{3} /[\mathrm{EMIm}] \mathrm{Cl}$ & $0.1-2.0$ & $407(x=0.1)$ & $20 \%(n=100, y=0.1)$ & $75 \%(z=3)$ & G & [173] \\
\hline SnS & $\mathrm{N}$ & $\mathrm{AlCl}_{3} /[\mathrm{EMIm}] \mathrm{Cl}$ & $0.5-2.5$ & $406(x=0.02)$ & $91 \%(n=100, y=0.1)$ & - & G & [174] \\
\hline $\mathrm{TiO}_{2}$ nanotube & Y & $1 \mathrm{~m} \mathrm{AlCl}_{3}$ & $0.0-1.2$ & $72(x=0.1)$ & - & - & $\mathrm{F}$ & [159] \\
\hline $\mathrm{TiO}_{2} /$ graphene & Y & $1 \mathrm{M} \mathrm{AlCl}_{3}$ & $0.0-1.1$ & $51(x=6.25)$ & $68.6 \%(n=125, y=6.25)$ & - & G & [162] \\
\hline $\mathrm{TiO}_{2}$ nanoleaves & Y & $1 \mathrm{M} \mathrm{Al}\left(\mathrm{NO}_{3}\right)_{3}$ & $0.4-1.4$ & $278.1(x=0.05)$ & $91.6 \%(n=100, y=0.05)$ & $52.1 \%(z=40)$ & $\mathrm{F}$ & [163] \\
\hline CuHCF & Y & $0.5 \mathrm{M} \mathrm{Al}_{2}\left(\mathrm{SO}_{4}\right)_{3}$ & $0.2-1.05$ & $62.9(x=0.05)$ & $54.9 \%(n=1000, y=0.4)$ & - & - & [164] \\
\hline FeHCF & Y & $0.5 \mathrm{M} \mathrm{Al}(\mathrm{OTF})_{3}$ & $0.0-2.0$ & $116(x=0.15)$ & $61 \%(n=100, y=0.15)$ & - & A & [165] \\
\hline $\mathrm{MnO}_{2}$ & Y & $2 \mathrm{~m} \mathrm{Al}(\mathrm{OTF})_{3}$ & $0.4-2.0$ & $380(x=0.1)$ & $44 \%(n=40, y=0.1)$ & - & A & [166] \\
\hline $\mathrm{MnO}_{2}$ & Y & $\begin{array}{c}\left.2 \mathrm{M} \mathrm{Al}_{(\mathrm{OTF}}\right)_{3}+ \\
0.5 \mathrm{M} \mathrm{MnSO}_{4}\end{array}$ & $0.3-1.7$ & $530(x=0.1)$ & $60 \%(n=65, y=0.1)$ & - & $A, B$ & [160] \\
\hline $\mathrm{Al}_{x} \mathrm{MnO}_{2} \cdot \mathrm{nH}_{2} \mathrm{O}$ & Y & $5 \mathrm{~m} \mathrm{Al}(\mathrm{OTF})_{3}$ & $0.5-1.8$ & $467(x=0.03)$ & $58 \%(n=50, \gamma=0.03)$ & - & $A, C$ & [167] \\
\hline $\mathrm{FeVO}_{4}$ & Y & $1 \mathrm{M} \mathrm{AlCl}_{3}$ & $0.0-1.8$ & $350(x=0.06)$ & $8.5 \%(n=20, y=0.06)$ & - & $\mathrm{F}$ & [179] \\
\hline $\mathrm{Bi}_{2} \mathrm{O}_{3}$ & Y & $1 \mathrm{~m} \mathrm{AlCl}_{3}$ & $0.0-1.2$ & $352(x=1.5)$ & $29.8 \%(n=30, y=1.5)$ & - & - & [180] \\
\hline $\mathrm{MoO}_{3}$ & Y & $1 \mathrm{~m} \mathrm{AlCl}_{3}$ & $0.0-1.6$ & $680(x=2.5)$ & $25 \%(n=20, y=2.5)$ & - & - & [181] \\
\hline Graphite & Y & $\begin{array}{c}1 \mathrm{м} \mathrm{AlCl}_{3} \cdot 6 \mathrm{H}_{2} \mathrm{O}: \\
\mathrm{H}_{2} \mathrm{O}=12\end{array}$ & $-1.7-2.3$ & $165(x=0.5)$ & $82 \%(n=1000, y=0.5)$ & - & A & [168] \\
\hline
\end{tabular}

*For the strategies employed: A ("water-in-salt" electrolyte), B (electrolyte additives), C (pre-intercalation strategy), D (heteroatom doping), E (defects engineering), F (size regulation), G (composites and free-standing configuration), $\mathrm{H}$ (advanced characterization and theoretical study).

mechanisms for AIBs are similar to other AMVIBs ((de)intercalation and conversion reactions); however, $\mathrm{Al}^{3+}$ possess a relatively higher charge density $\left(364 \mathrm{C} \mathrm{mm}^{-3}\right.$ ) and larger hydrated ionic radius $(4.75 \AA)$ compared to other multivalent metal ion charge carriers $\left(\mathrm{Zn}^{2+}, \mathrm{Mg}^{2+}, \mathrm{Ca}^{2+}\right)$. The larger ions and the strong interaction between the $\mathrm{Al}^{3+}$ and the host materials elevate the difficulties in designing suitable cathode materials.

One of the most important breakthroughs in the past 30 years is the application of nonvolatile and nonflammable room-temperature ionic liquids (RTILs), through which many achievements (Table 5) have been made based on materials such as 3D graphene foam, ${ }^{[170]} \mathrm{CuO},{ }^{[171]} \mathrm{Mo}_{2.5+x} \mathrm{VO}_{9+\gamma},{ }^{[172]} \mathrm{VS}_{4} /$ rGO, ${ }^{[173]}$ and SnS. ${ }^{[174]}$ Nevertheless, there are some crucial drawbacks when applying RTILs: a) RTILs are highly sensitive to air and moisture; b) potential reaction or corrosion between RTILs and the battery components; c) toxic gas emission (e.g., $\mathrm{Cl}_{2}$ ) from side reactions, such as the oxidation of $\mathrm{AlCl}_{4}$; d) $\mathrm{Al}$ dendrite growth when using RTILs under high current densities; e) poor stability of cathode materials in RTILs may cause an uncontrollable shuttle effect; f). relatively high cost. ${ }^{[159,166,175,176]}$ Therefore, many researchers have focused on the exploration of aqueous aluminum-ion batteries (AAIBs).

As early as 2012, Liu and coworkers reported that an anatase $\mathrm{TiO}_{2}$ nanotube array (NTA) as a cathode candidate that enables reversible (de)insertion of $\mathrm{Al}^{3+}$ in an aqueous electrolyte $\left(1 \mathrm{M} \mathrm{AlCl}_{3}\right){ }^{[159]}$ Theoretical studies demonstrated that the (de) insertion of $\mathrm{Al}^{3+}$ into $\mathrm{TiO}_{2}$ NTA undergoes a redox reaction between $\mathrm{Ti}^{4+}$ and $\mathrm{Ti}^{3+}$ (reversible) or $\mathrm{Ti}^{2+}$ (irreversible); therefore, the redox reaction pair of $\mathrm{Ti}^{4+} / \mathrm{Ti}^{3+}$ facilitates the storage of $\mathrm{Al}^{3+} .{ }^{[177]}$ Then, Liu et al. further investigated the synergistic effect of $\mathrm{Cl}^{-}$on $\mathrm{Al}^{3+}$ (de)insertion into $\mathrm{TiO}_{2} \mathrm{NTA}$ in two aqueous solutions: a) $1.50 \mathrm{~m} \mathrm{NaCl}$ and different concentrations of $\mathrm{Al}_{2}\left(\mathrm{SO}_{4}\right)_{3}$ solutions; b) $0.25 \mathrm{M} \mathrm{Al}_{2}\left(\mathrm{SO}_{4}\right)_{3}$ and different concentrations of $\mathrm{NaCl}$ solutions. ${ }^{[178]}$ This revealed that the presence of $\mathrm{Cl}^{-}$can significantly affect the performance of the cathode (Figure 13a), and this synergistic effect is enhanced with an increase of $\mathrm{Cl}^{-}$concentration over a certain range.

The size regulation and introduction of conductive materials are effective methodologies to further improve the performance of anatase $\mathrm{TiO}_{2}$ cathodes. Based on these strategies, Das et al. synthesized $\mathrm{TiO}_{2} @$ graphene to improve the electronic conductivity of electrode materials, thus successfully enhancing the $\mathrm{Al}^{3+}$ diffusion kinetics. ${ }^{[162]}$ Their estimation revealed that the small fraction of graphene $(<2 \mathrm{wt} \%)$ will induce ultrafast diffusion of $\mathrm{Al}^{3+}$ in $\mathrm{TiO}_{2}$, which is 672 times higher than that of the pristine $\mathrm{TiO}_{2}$. Moreover, Tong et al. creatively synthesized black mesoporous anatase $\mathrm{TiO}_{2}$ nanoleaves with a high surface area $\left(314.2 \mathrm{~m}^{2} \mathrm{~g}^{-1}\right)$ and extraordinary electron-conducting properties, through a solution plasma process. ${ }^{[163]}$ Owing to the interfacial $\mathrm{Al}^{3+}$ storage, the as-fabricated battery demonstrated a specific capacity of $278.1 \mathrm{mAh} \mathrm{g}^{-1}$ at $0.05 \mathrm{~A} \mathrm{~g}^{-1}$ and impressive stability (91.6\% retention after 100 cycles at $0.05 \mathrm{~A} \mathrm{~g}^{-1}$ ). 
(a)
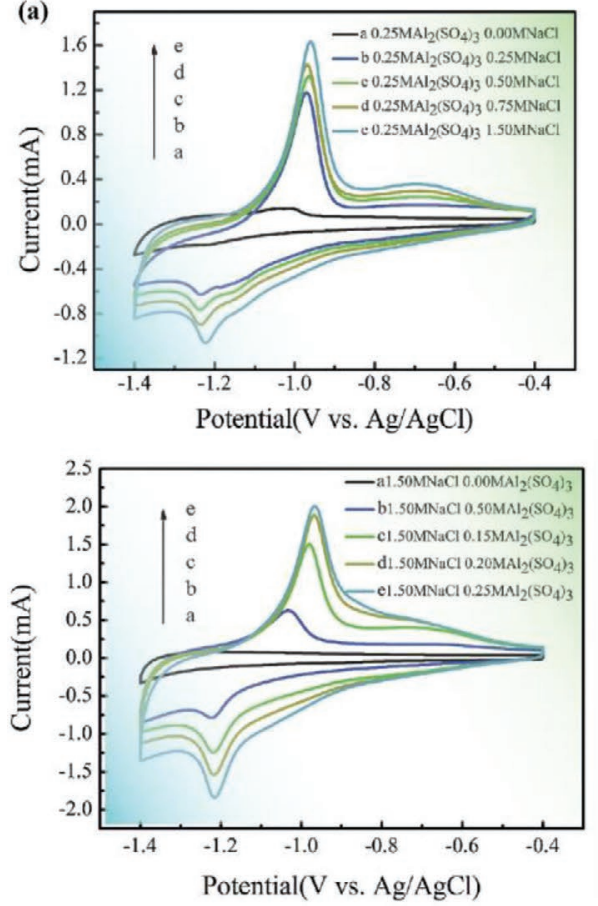

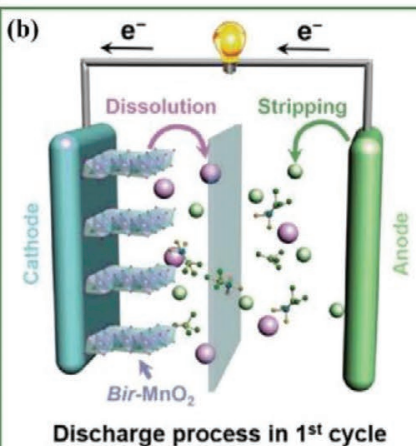

Discharge process in $1^{\text {st }}$ cycle

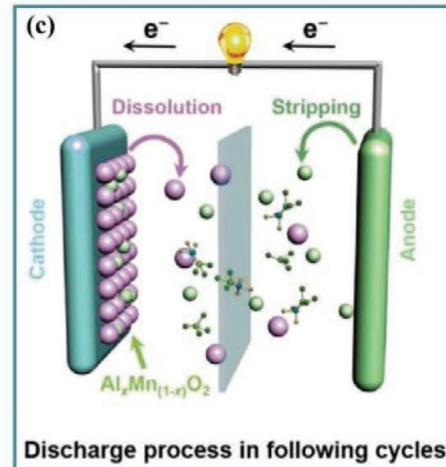

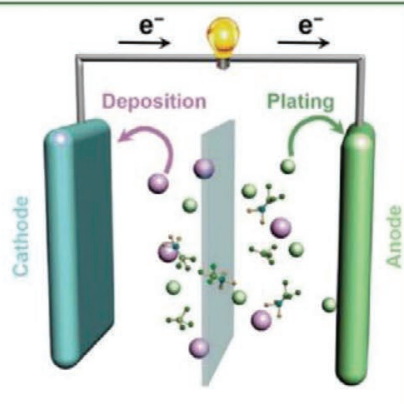

Charge process in the $1^{\text {st }}$ cycle

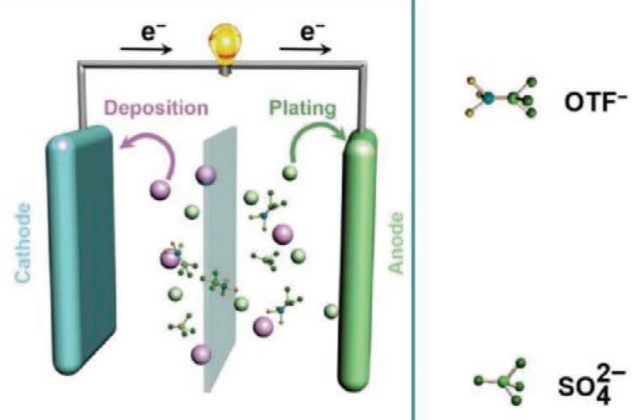

Figure 13. Cathode candidates for AAIBs. a) CV of anatase $\mathrm{TiO}_{2}$ nanotube arrays at $0.1 \mathrm{mV} \mathrm{s}^{-1}$ in different electrolyte. Reproduced with permission. ${ }^{[178]}$ Copyright 2014, Elsevier. Schematic diagram of aluminum-manganese battery in b) the first charge/discharge process, and c) charge/discharge processes in the following cycles. Reproduced with permission. ${ }^{160]}$ Copyright 2019, Wiley.

PBA is a promising electrode material for multivalent batteries due to its excellent electrochemical properties. Gao and colleagues were first to investigate the electrochemical performances of copper hexacyanoferrate (CuHCF) cathode in aqueous electrolyte $\left(0.5 \mathrm{M} \mathrm{Al}_{2}\left(\mathrm{SO}_{4}\right)_{3}\right)$ in 2014. ${ }^{[164]}$ Although it shows a limited specific capacity $\left(62.9 \mathrm{mAh} \mathrm{g}^{-1}\right.$ at $\left.50 \mathrm{~mA} \mathrm{~g}^{-1}\right)$ and stability $\left(54.9 \%\right.$ retention after 1000 cycles at $\left.400 \mathrm{~mA} \mathrm{~g}^{-1}\right)$, it provided a new candidate for AAIBs. To further improve the performance of PBA cathodes, Chen et al. proposed a FeHCF cathode with a high concentration of $5 \mathrm{~m}\left(\mathrm{~mol} \mathrm{~kg}^{-1} \mathrm{H}_{2} \mathrm{O}\right)$ $\mathrm{Al}(\mathrm{OTF})_{3}$ electrolyte (Al-WISE), which demonstrated an initial discharge capacity of $116 \mathrm{mAh} \mathrm{g}^{-1}$ at $150 \mathrm{~mA} \mathrm{~g}^{-1} \cdot{ }^{[165]}$ They also found that the high concentration Al-WISE electrolyte effectively inhibited the dissolution of the PBA cathode, and significantly enhanced the cycle life (39\% capacity fading after 100 cycles).

Since 2019, Mn-based cathodes have made impressive progress. ${ }^{[160,166,167]}$ Through an in situ electrochemical transformation reaction, $\mathrm{Lu}$ and co-workers synthesized $\mathrm{Al}_{x} \mathrm{MnO}_{2} \cdot \mathrm{H}_{2} \mathrm{O}$ that was used as the cathode for AAIB using $5 \mathrm{~m} \mathrm{Al}(\mathrm{OTF})_{3}$ electrolyte. This material exhibits a specific capacity of $467 \mathrm{mAh} \mathrm{g}^{-1}$ and a record high energy density $\left(481 \mathrm{Wh} \mathrm{kg}^{-1}\right) \cdot{ }^{[167]}$ Their further investigations revealed that the superior performance results from the large interlayer spacing and the shielding effects due to the lattice-water, reduces the strong electrostatic interaction between Al-ion and the host framework and facilitates fast $\mathrm{Al}^{3+}$ diffusion. $\mathrm{Yu}$ et al. used a pre-added $\mathrm{Mn}^{2+}$ strategy $\left(2 \mathrm{M} \mathrm{Al}(\mathrm{OTF})_{3}+0.5 \mathrm{~m} \mathrm{MnSO}_{4}\right)$ to improve the performance and the stability of AAIB with a Birnessite-type $\mathrm{MnO}_{2}$ cathode and achieved a record-breaking specific capacity $\left(530 \mathrm{mAh} \mathrm{g}^{-1}\right.$ at $\left.100 \mathrm{~mA} \mathrm{~g}^{-1}\right)$ and remarkable energy density $\left(620 \mathrm{Wh} \mathrm{kg}^{-1}\right) \cdot{ }^{[160]}$ Possible electrochemical reaction steps were proposed based in the study: a) during the first discharge, Birnessite $\mathrm{MnO}_{2}$ cathode reduced as soluble $\mathrm{Mn}^{2+}$ into the electrolyte, while the $\mathrm{Al}$ anode is oxidized to $\mathrm{Al}^{3+}$ to balance the charge (Figure 13b); b) during the first charge process, $\mathrm{Mn}^{2+}$ ions are oxidized to higher valence state and form $\mathrm{Al}_{x} \mathrm{Mn}_{(1-x)} \mathrm{O}_{2}$ on the cathode, accompanied by Al plating on the anode (Figure 13c); c) during the charge/discharge process in the following cycles, the reversible dissolution/deposition of $\mathrm{Mn}^{2+} / \mathrm{Al}_{x} \mathrm{Mn}_{(1-x)} \mathrm{O}_{2}$ and the stripping/plating of $\mathrm{Al}$ take place (Figure 13d). Therefore, the underlying mechanism of the pre-added $\mathrm{Mn}^{2+}$ strategy, possibly resulting from the increase in $\mathrm{Mn}^{2+}$, will facilitate the formation of $\mathrm{Al}_{x} \mathrm{Mn}_{(1-x)} \mathrm{O}_{2}$ during the charge process.

In the recent 2 years, some new electrode candidates have also been developed. For instance, the $\mathrm{Bi}_{2} \mathrm{O}_{3}, \mathrm{FeVO}_{4}$, and $\mathrm{MoO}_{3}$ demonstrate very high initial $\mathrm{Al}^{3+}$ ion storage capacity of $352 \mathrm{mAh} \mathrm{g}^{-1}\left(1.5 \mathrm{~A} \mathrm{~g}^{-1}\right), 350 \mathrm{mAh} \mathrm{g}^{-1}\left(0.06 \mathrm{~A} \mathrm{~g}^{-1}\right)$, and $680 \mathrm{mAh} \mathrm{g}^{-1}\left(2.5 \mathrm{~A} \mathrm{~g}^{-1}\right)$, respectively; however, $\approx 70-80 \%$ of their initial capacity rapidly declined in $\approx 20-30$ charge/discharge cycles. ${ }^{[179-181]}$ Although the mechanisms of these severe capacity losses were not been thoroughly investigated, the authors suggested the further improvement of these electrodes could be focused on: a) in situ tethering the active materials on a collector (e.g., exfoliated graphite); b) electrode coating and the application of concentrated electrolyte to avoid the existence of an electrode-electrolyte interface.

Although the adoption of a WIS electrolyte substantially improved the performance of AAIBs, the current widely used 
$\mathrm{Al}(\mathrm{OTF})_{3}$ electrolyte (766 USD/100 g) is too expensive to be utilized in a practical scenario, compared with typical ionic liquid electrolyte (e.g., $\mathrm{AlCl}_{3} /[\mathrm{EMIm}] \mathrm{Cl}, 357 \mathrm{USD} / 100 \mathrm{~g}$ ) and aqueous electrolyte (e.g., $\mathrm{AlCl}_{3}, 5.8 \mathrm{USD} / 100$ g). ${ }^{[157,158,168]} \mathrm{Pan}$ et al. reported an inexpensive WIS electrolyte $\left(\mathrm{AlCl}_{3} \cdot 6 \mathrm{H}_{2} \mathrm{O}\right)$ and significantly expanded the electrochemical stability window of AAIBs to $\approx 4 \mathrm{~V} \cdot{ }^{[168]}$ Meanwhile, the dual-ion intercalation mechanisms $\left(\mathrm{Al}^{3+}\right.$ and $\left.\mathrm{AlCl}_{4}^{-}\right)$were observed by EDX and Raman spectroscopy, which revealed that the $\mathrm{AlCl}_{3} \cdot 6 \mathrm{H}_{2} \mathrm{O}$ electrolyte possesses the properties of both an ionic liquid and an aqueous electrolyte. However, it is worth noting that the application of highly concentrated electrolyte would significantly increase the weight of the devices, thus reducing the energy and power density.

Overall, electrolyte breakthroughs including ionic liquids and WIS electrolytes have led to the booming development in AAIBs research between 2015 and 2020. The disadvantages of ionic liquid-based systems have emerged, but the recent development of aqueous AIBs is exciting. Currently, to the best of our knowledge, only a few materials (graphite, $\mathrm{TiO}_{2}, \mathrm{PBAs}$, $\left.\mathrm{MnO}_{2}\right)$ and aqueous electrolytes $\left(\mathrm{AlCl}_{3}, \mathrm{Al}\left(\mathrm{NO}_{3}\right)_{3}, \mathrm{Al}_{2}\left(\mathrm{SO}_{4}\right)_{3}\right.$, $\left.\mathrm{Al}(\mathrm{OTF})_{3}\right)$ have been investigated for AAIBs. In order to improve the performance of AAIBs, it is critical to design and synthesize cathode materials with promising properties (e.g., suitable cavity/channel sizes and the strength of interactions with the intercalated ions). This review recommends that the effective strategies extensively studied in other AMVIBs can be investigated in AAIBs, including size regulation and defect engineering.

\section{Aqueous Rechargeable Calcium-Ion Batteries}

Calcium-ion batteries (CIBs) are promising alternative candidates for post-lithium-ion batteries, owing to their low redox potential (-2.87 V versus SHE), low cost, and massive reserves. The first rechargeable CIB was reported in 2015; ${ }^{[182]}$ however, the number of achievements has been limited over the past 5 years. Basically, the energy storage mechanisms of CIBs are similar to that for other kinds of AMVIBs. One of the major challenges is the tremendous difficulty in $\mathrm{Ca}^{2+}$ electroplating and stripping in the conventional aprotic organic electrolytes, due to the vast resistance of SEI to $\mathrm{Ca}^{2+}$ diffusion. ${ }^{[50]}$ Although some innovations have been made to address this issue, such as $\mathrm{Ca}\left(\mathrm{PF}_{6}\right)_{2}$ or $\mathrm{Ca}(\mathrm{TFSI})_{2}$ in $\mathrm{EC} / \mathrm{PC}$ mixed solvent, ${ }^{[183,184]}$ the performance of non-aqueous CIBs is far from requirements. Meanwhile, it needs further investigation whether the Ca metal dendrites will form during the cycling. ${ }^{[185]}$ In addition, although $\mathrm{Ca}^{2+}$ ions possess the same charge density to $\mathrm{Li}^{+}\left(52 \mathrm{C} \mathrm{mm}^{-3}\right)$, its ionic radius $(1 \AA)$ is significantly larger than other multivalent metal charge carriers (Table 1 ). Therefore, it is highly challenging to design and synthesis cathode materials with large and flexible channels for $\mathrm{Ca}^{2+}$ diffusion. To date, most research has focused on organic electrolytes, while aqueous CIB research has made remarkable achievements in recent years (Table 6).

In 2015, manganese hexacyanoferrate (MnHCF) was the first cathode adopted in CIBs with organic electrolyte, which exhibits a capacity of $80 \mathrm{mAh} \mathrm{g}^{-1}$ (at $10 \mathrm{~mA} \mathrm{~g}^{-1}$ ) and $59.3 \%$ capacity retention (after 30 cycles at $10 \mathrm{~mA} \mathrm{~g}^{-1}$ ). ${ }^{[182]}$ However, work from Cui et al. has proven that the presence of water can reduce the charge density, thereby effectively promoting $\mathrm{Ca}^{2+}$ diffusion, which presents a new opportunity for ACIBs based on a PBA cathodes. ${ }^{[186]}$ Jeong and Lee further studied the influence of aqueous electrolyte concentration $\left(\mathrm{Ca}\left(\mathrm{NO}_{3}\right)_{2}\right)$ on the electrochemical performance of CIBs based on a CuHCF cathodes and found that the capacities gradually increase with an increase in electrolyte concentration (Figure 14a)..$^{[187]}$ Raman spectroscopic studies and activation energy investigations revealed that the increase of electrolyte concentration decreases the activation energy, thus increasing the amount of $\mathrm{NO}_{3}{ }^{-}$coordinated by $\mathrm{Ca}^{2+}$. Inspired by previous work, Mitra and colleagues proposed a new ACIB system for stationary energy storage based on the $\mathrm{CuHCF}$ cathode, polyaniline anode, and aqueous electrolyte $\left(2.5 \mathrm{~m} \mathrm{Ca}\left(\mathrm{NO}_{3}\right)_{2}\right) \cdot{ }^{[188]}$ This ACIB exhibits an

Table 6. Representative cathode materials of rechargeable CIBs in recent years.

\begin{tabular}{|c|c|c|c|c|c|c|c|c|}
\hline Materials & $\begin{array}{l}\text { Aqueous } \\
(\mathrm{Y} / \mathrm{N})\end{array}$ & Electrolyte & $\begin{array}{c}\text { Working } \\
\text { potential } \\
{[\mathrm{V}]}\end{array}$ & $\begin{array}{c}\text { Specific capacity } \\
{\left[\mathrm{mAh} \mathrm{g}^{-1}\right] \text { at }} \\
\quad x \mathrm{~A} \mathrm{~g}^{-1}\end{array}$ & $\begin{array}{l}\text { Capacity retention at y } A \\
\mathrm{~g}^{-1} \text { after } n \text { cycles }\end{array}$ & $\begin{array}{l}\text { Rate capability } \\
\text { (capacity retention } \\
\text { at } z \times \times \mathrm{A} \mathrm{g}^{-1} \text { ) }\end{array}$ & Strategies & Reference \\
\hline $\mathrm{MnHCF}$ & $\mathrm{N}$ & $0.2 \mathrm{M} \mathrm{Ca}\left(\mathrm{PF}_{6}\right)_{2}$ in $3: 7 \mathrm{EC}: \mathrm{PC}$ & $0.7-4.0$ & $80(x=0.01)$ & $59.3 \%(n=30, y=0.01)$ & - & - & [182] \\
\hline CuHCF & Y & $8.4 \mathrm{M} \mathrm{Ca}\left(\mathrm{NO}_{3}\right)_{2}$ & $0.1-0.9$ & $77(0.2 \mathrm{C})$ & $90 \%(n=5000,10 \mathrm{C})$ & $64.9(z=200)$ & - & [187] \\
\hline CuHCF & Y & $2.5 \mathrm{M} \mathrm{Ca}\left(\mathrm{NO}_{3}\right)_{2}$ & $0.3-1.2$ & $130(x=0.8)$ & $95 \%(n=200, y=0.8)$ & - & - & [188] \\
\hline $\mathrm{CaV}_{6} \mathrm{O}_{16} \cdot 7 \mathrm{H}_{2} \mathrm{O}$ & Y & $4.5 \mathrm{M} \mathrm{Ca}\left(\mathrm{NO}_{3}\right)_{2}$ & $0.0-1.3$ & $170(x=2)$ & $93 \%(n=200, y=5)$ & $67.6 \%(z=6)$ & - & [190] \\
\hline $\mathrm{Mg}_{0.25} \mathrm{~V}_{2} \mathrm{O}_{5} \cdot \mathrm{H}_{2} \mathrm{O}$ & N & $\begin{array}{c}0.8 \mathrm{M} \mathrm{Ca}\left(\mathrm{PF}_{6}\right)_{2} \text { in } \\
\text { 2:3:2:3 EC:DMC:EC:PMC }\end{array}$ & $-1.5-1.25$ & $90(x=0.05)$ & $88 \%(n=500, y=0.02)$ & - & $\mathrm{C}, \mathrm{H}$ & [213] \\
\hline $\mathrm{Ca}_{2} \mathrm{MnO}_{4}$ & Y & $2 \mathrm{M} \mathrm{Ca}\left(\mathrm{NO}_{3}\right)_{2}$ & $0.0-1.8$ & $196.5(x=0.05)$ & $95 \%(n=1500, y=1)$ & $22.9 \%(z=20)$ & - & [189] \\
\hline $\mathrm{K}_{2} \mathrm{~V}_{6} \mathrm{O}_{16} \cdot 2.7 \mathrm{H}_{2} \mathrm{O}$ & Y & $5 \mathrm{M} \mathrm{Ca}\left(\mathrm{NO}_{3}\right)_{2}$ & $0.0-1.0$ & $113.9(x=0.02)$ & $78.3 \%(n=100, y=0.05)$ & - & C & [214] \\
\hline PTCDA & Y & Saturated $\mathrm{Ca}\left(\mathrm{NO}_{3}\right)_{2}$ & $0.0-1.5$ & $87(x=0.02)$ & $70.1 \%(n=10, y=0.02)$ & - & $\mathrm{H}$ & [150] \\
\hline $\mathrm{CaCO}_{2} \mathrm{O}_{4}$ & Y & $1 \mathrm{M} \mathrm{CaCl} 2$ & $0.0-1.85$ & - & - & - & - & [215] \\
\hline Graphite & $\mathrm{N}$ & $\mathrm{Ca}\left(\mathrm{BH}_{4}\right)_{2}$ in DMAc & $0.2-1.6$ & $87(x=0.1)$ & $75 \%(n=200, y=0.1)$ & - & $\mathrm{H}$ & [216] \\
\hline
\end{tabular}

*For the strategies employed: A ("water-in-salt" electrolyte), B (electrolyte additives), C (pre-intercalation strategy), D (heteroatom doping), E (defects engineering), F (size regulation), $\mathrm{G}$ (composites and free-standing configuration), $\mathrm{H}$ (advanced characterization and theoretical study). 
(a)

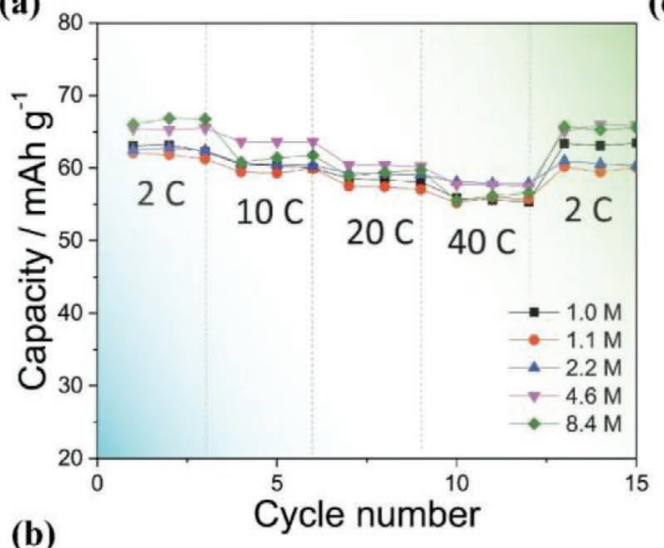

(b)

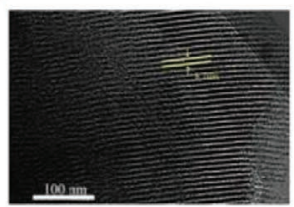

(c)
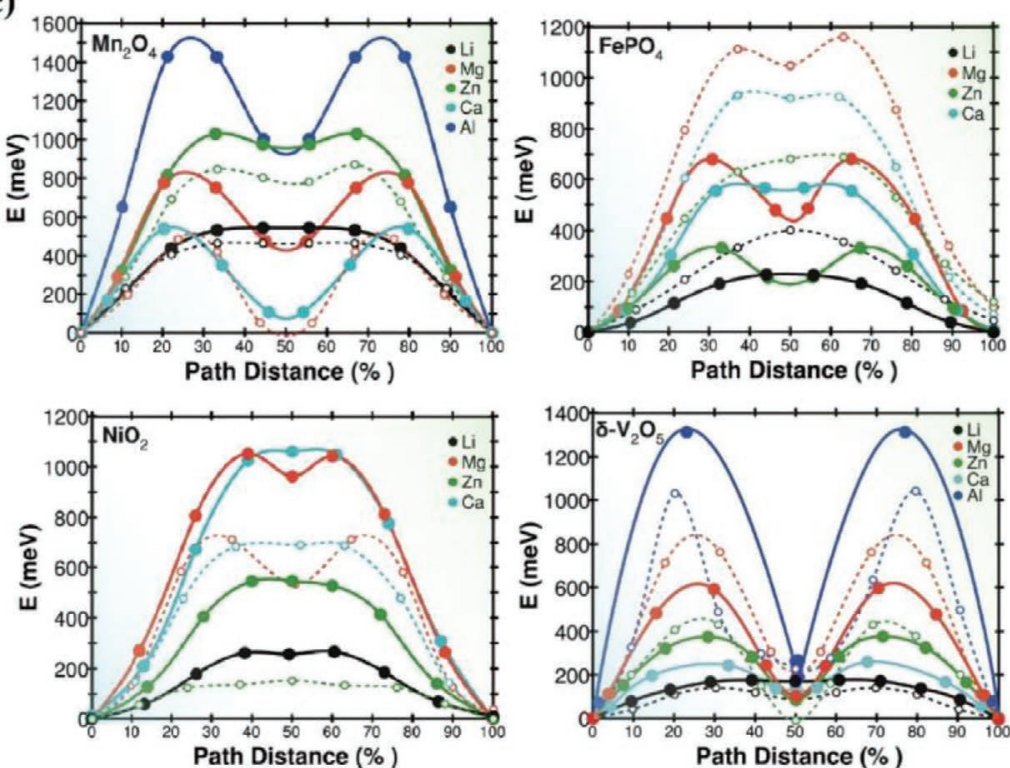

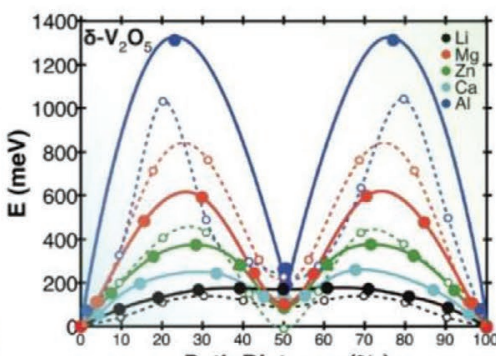

Path Distance (\%)

Figure 14. Cathode candidates for ACIBs. a) EC of CuHCF cathode in different concentration of $\mathrm{Ca}\left(\mathrm{NO}_{3}\right)_{2}$. Reproduced with permission. ${ }^{[187]}$ Copyright 2018, Elsevier. b) TEM of SBA-15@PPTCDI. Reproduced with permission. ${ }^{[189]}$ Copyright 2020, Wiley. c) Migration energies $E_{m}$ in the spinel $\mathrm{Mn}_{2} \mathrm{O}_{4}$, olivine $\mathrm{FePO}_{4}$, layered $\mathrm{NiO}_{2}$, and orthorhombic $\delta \mathrm{V}_{2} \mathrm{O}_{5}$. Reproduced with permission. ${ }^{[191]}$ Copyright 2015, American Chemical Society.

impressive specific capacity of $130 \mathrm{mAh} \mathrm{g}^{-1}$ and $95 \%$ retention after 200 cycles at $0.8 \mathrm{~A} \mathrm{~g}^{-1}$, which is vastly superior to those in non-aqueous PBA-based systems.

Besides PBAs, other types of cathode candidates have also been studied for ACIBs. Cao et al. reported an ACIB consisting of a $\mathrm{CaMnO}_{4}$ (cathode), poly(3,4,9,10-perylentetracarboxylic diimide) (PPTCDI) on SBA-15 (anode), and $2 \mathrm{~m} \mathrm{Ca}\left(\mathrm{NO}_{3}\right)_{2}$, which exhibits ultrahigh stability $(95 \%$ retention after 1500 cycles at $\left.1 \mathrm{~A} \mathrm{~g}^{-1}\right) \cdot{ }^{[189]}$ They proposed that the impressive stability results from two major contributions: a) the unique structure of the anode material enhances the $\mathrm{Ca}^{2+}$ (de)insertion behaviors; b) the shielding effect of polar water molecules on calcium ions. Moreover, Simon and co-workers synthesized highly ordered 1D $\mathrm{CaV}_{6} \mathrm{O}_{16} \cdot 7 \mathrm{H}_{2} \mathrm{O}$ (CVO) via a high-yield and ultrafast (several grams in few minutes) molten salt method (Figure 14b). ${ }^{[190]}$ It shows remarkable stability ( $88 \%$ after 500 cycles) under a low current density $\left(20 \mathrm{~mA} \mathrm{~g}^{-1}\right)$ and this was attributed to two aspects: a) the 1D-nanostructured architecture avoids volume expansion/contraction during charge/discharge cycles; b) the interlayer spacing is increased by crystalline water in the CVO layers.

In general, ACIBs research over the last 5 years has lacked a systematic approach. Theoretical investigations and machine learning methods are effective methodologies to accelerate the progress of finding suitable cathode candidates. By coupling first-principle DFT and nudged elastic band (NEB) approximations, Ceder et al. predicted the migration energies $\left(E_{\mathrm{m}}\right)$ of $\mathrm{Li}^{+}$and multivalent ions $\left(\mathrm{Ca}^{2+}, \mathrm{Mg}^{2+}, \mathrm{Zn}^{2+}, \mathrm{Al}^{3+}\right)$ in extensively studied intercalated structures, including spinel $\mathrm{Mn}_{2} \mathrm{O}_{4}$, olivine $\mathrm{FePO}_{4}$, layered $\mathrm{NiO}_{2}$, and orthorhombic $\delta$ - $\mathrm{V}_{2} \mathrm{O}_{5}$ (Figure 14c). ${ }^{[191]}$ As expected, the migration barriers of $\mathrm{Li}^{+}$in these four intercalation structures are well below or just above the $\approx 525 \mathrm{meV}$ threshold, which is in good agreement with previous experi- mental observations. It is noteworthy that the migration energies of $\mathrm{Ca}^{2+}$ in olivine $\mathrm{FePO}_{4}$ and orthorhombic $\delta$ - $\mathrm{V}_{2} \mathrm{O}_{5}$ will occupy a minimum $50 \%$ diffusion path and are much lower than those of other multivalent ions. Also, machine learning is a highly effective method to make rapid predictions of electrochemical properties for different materials and guide materials development for CIBs. However, to the best of our knowledge, there is no research for ACIBs reported to date based on machine learning predictions. In addition, this work recommends that the mainstream structural optimization strategies which have been proven effective in other AMVIBs, such as hetero-atom doping, defects engineering, size regulation, should be attempted in ACIBs.

\section{Conclusions and Perspectives}

This review introduced and discussed the common challenges, extensively studied materials, and optimization strategies of typical rechargeable aqueous multivalent ion batteries for largescale energy storage applications. The development and perspectives of AMVIBs can be briefly summarized as follows:

\subsection{Aqueous Rechargeable Multivalent Ion Batteries}

Figure 15a provides a rough comparison of electrochemical performances between LIBs and AMVIBs. Although the efforts made in the past few years have greatly improved AMVIBs, there is still a huge gap in performance compared to commercial LIBs. The energy and power density of ACIBs is $1 / 3$ and $1 / 10$ to those of a typical commercial LIBs with a high energy density (250-693 $\mathrm{Wh} \mathrm{kg}^{-1}$ ) and suitable power density (250-340 $\left.\mathrm{W} \mathrm{g}^{-1}\right)$, 
(a)

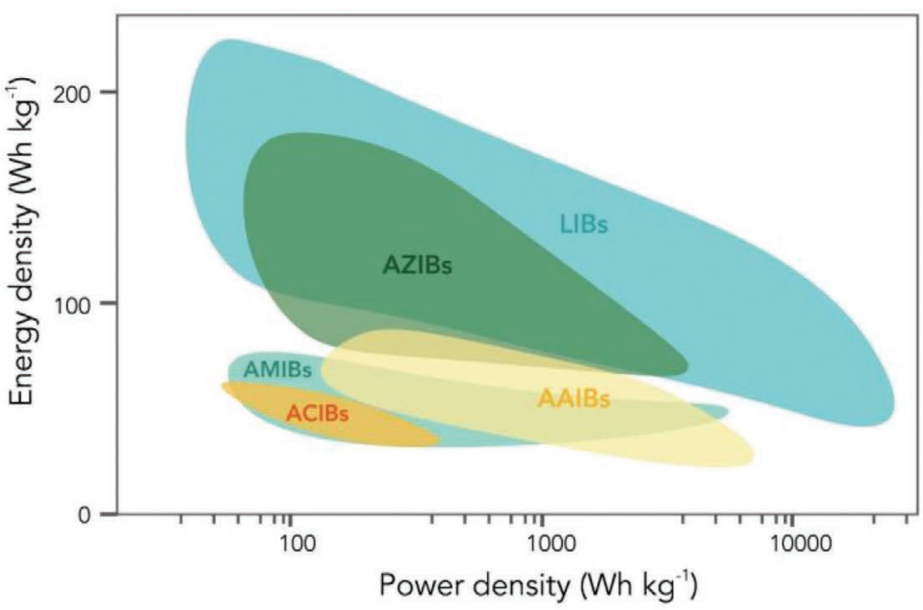

(c)

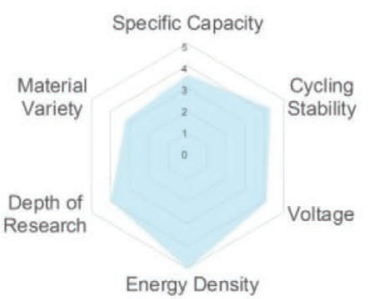

Manganese Oxides

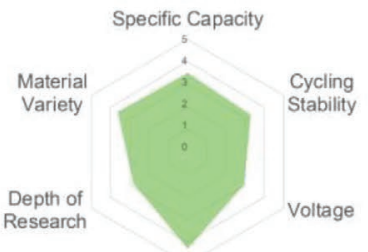

Energy Density

Organic Materials (b)
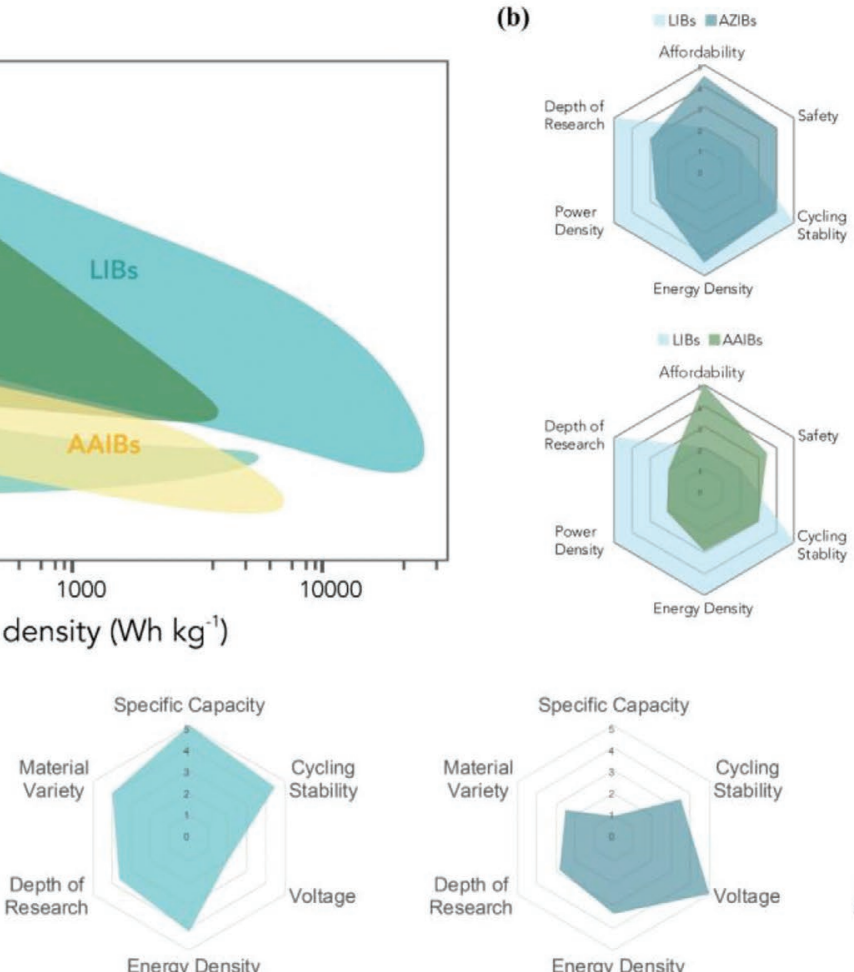

Vanadium Oxides

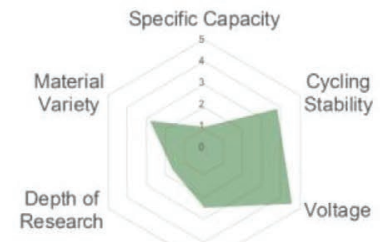

Energy Density

Polyanion Compounds
Specific Capacity

Energy Density

Prussian Blue Analogs

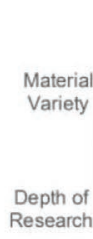

Specific Capacity

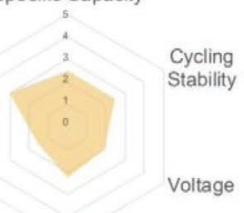

Energy Density

TMDs

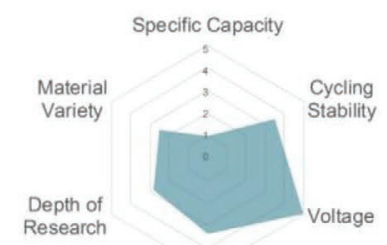

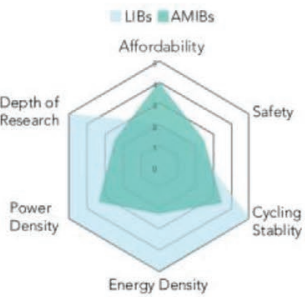

LAB ACIBS

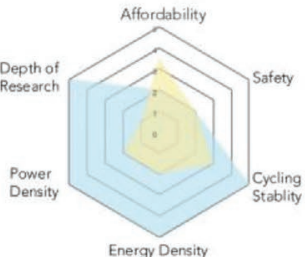

Energy Density

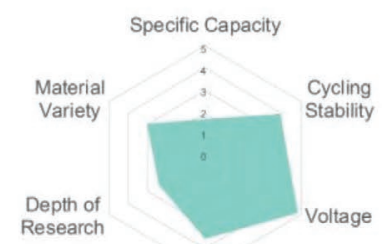

Energy Density

Spinels

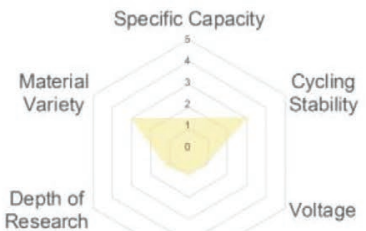

Energy Density

Chevrel Phase

(d)

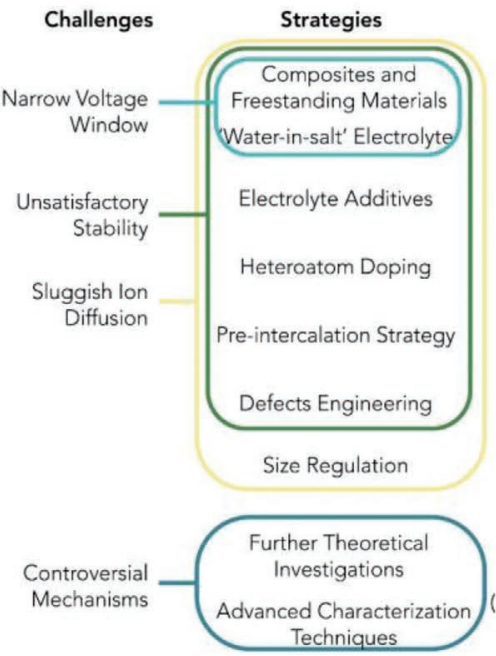

Cathodes

Strategies

Cathodes

Manganese Oxides

Electrolyte Additives

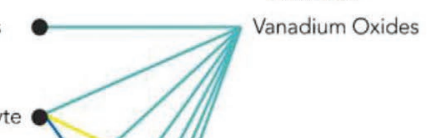

Prussian Blue Analogs
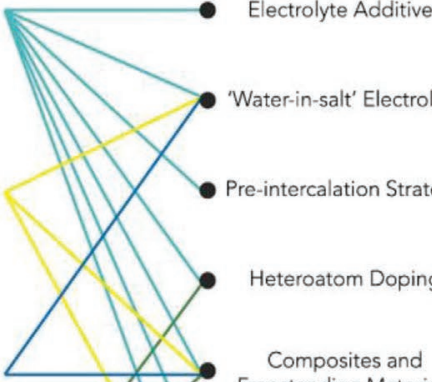

Organic Materials

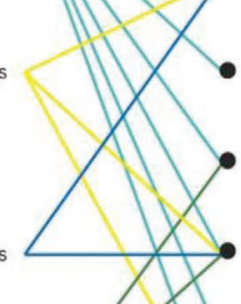

TMDs
(Includes Non-aqueous Researches)

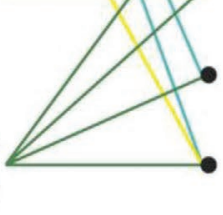
Freestanding Materia

Size Regulation

Defects Engineering

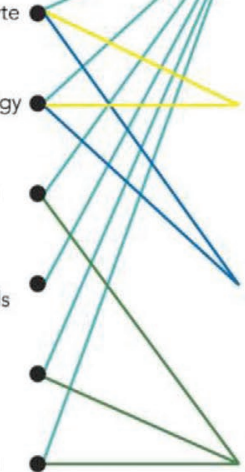

Chevrel Phase

(Includes Non-aqueous Researches)

Figure 15. Summary and conclusion. a) The comparison among LIBs and aqueous rechargeable MIBs; multi-angle comparison among b) LIBs and aqueous rechargeable MIBs and c) widely investigated materials; d) functionalities and application of potentially useful strategies. 
respectively. AZIBs represent the closest electrochemical performances compared to LIBs. For example, the AZIB using a high-performance Mn-based cathode (e.g., an energy density of $280 \mathrm{Wh} \mathrm{kg}^{-1}$ and power density of $2100 \mathrm{~W} \mathrm{~kg}^{-1}$ ) and $\mathrm{Zn}$ anode with balanced capacity, is expected to possess a high device energy density $\left(\approx 140 \mathrm{Wh} \mathrm{kg}^{-1}\right)$ and power density $\left(\approx 1450 \mathrm{~W} \mathrm{~kg}^{-1}\right)$, which is close to or even higher than those of LIBs. In addition, its current production cost is only $\$ 25$ per $\mathrm{kWh}$ (in the laboratory), which is much lower than that for LIBs at $2030(\approx \$ 70$ per $\mathrm{kWh}$ ). Therefore, in the near future, AZIBs are expected to be employed in the fields with particular requirements, such as fast-charging, high safety, and low cost. However, most of the recent research is limited to coin cells and Swagelok-type cells, with limited progress at technological scale. Meanwhile, AAIBs and AMIBs have developed rapidly and significantly expanded their power density in recent years, but the energy density still needs to be further increased. In all cases, the transition from coin cells to technological formats will require a joint approach involving both scientists and engineers.

The safety, cost, and performance are the most important criteria for next-generation commercial energy storage systems; Figure $15 \mathrm{~b}$ demonstrates the multi-angle comparison between LIBs and other AMVIBs. Clearly, AMVIBs are currently inferior to LIBs in electrochemical performance, while they possess lower cost and higher safety level. However, there is great scope for advancement if the attention and volume of research effort can even begin to approach that of LIBs.

\subsection{Cathode Candidates}

First of all, it must be admitted that the current research in this field is mostly based on the over-sized anodes, which is metal or metal-hosting electrode. From the views of electrode design, balancing the capacity of anode and cathode (mass multiplied by specific capacity) is crucial to improve the voltage distribution and increase the utilization rate of the anode materials. Some methodologies, such as control of equilibrium potential by surface charge control (e.g., introduction of functional group, charge injection), are effective to facilitate the capacity balance. Currently, the researches on the capacity balance of anode and cathode of the AMVIB is still in the initial stage.

Figure 15c compares the widely studied cathode materials from the perspective of electrochemical performances (specific capacity, cycling stability, voltage, and energy density), the research depth, and material diversity. Current research toward mainstream materials are still far from sufficient; even for manganese oxides and vanadium oxides, the most widely investigated cathode candidates, hundreds of compounds remain unreported and several controversial energy storage mechanisms are under fierce debate.

Some widely studied cathode candidates for non-aqueous MIBs and AIBs have not been widely reported in aqueous media. For instance, huge research interest in Chevrel phase compounds and TMDs since the discovery of MIBs, compared with only one report using the aqueous electrolyte. Meanwhile, some materials with excellent performance in AZIBs and AMIBs, such as manganese oxides and vanadium oxides, have not received much attention in ACIBs and AAIBs. Theoretically, rechargeable multivalent ion batteries possess similar material design principles, owning to their similar intrinsic challenges. Therefore, it is of great importance for the development of a certain type of rechargeable MIB to learn from previous research based on non-aqueous batteries and the breakthroughs of other aqueous batteries.

\subsection{Promising Strategies}

Figure $15 \mathrm{~d}$ summarizes the strategies that can be adopted to advance the technology; this can be divided into three categories: electrolyte optimization, material structure optimization, and theoretical research. The electrolyte optimization methodologies, including the use of WIS electrolyte and electrolyte additives, offer the potential to enhance material stability, increase the specific capacity, and broaden the voltage window. However, at present, only manganese oxide and vanadium oxide cathode materials have adopted this approach, and the mechanisms are not clear and need further exploration. Meanwhile, the cost of widely used WIS electrolytes (TSFI compounds) are too expensive to be used for most large-scale energy storage applications. Therefore, some low-cost WIS electrolytes are being considered, such as $\mathrm{ZnCl}_{2}$ and $\mathrm{AlCl}_{3}$. In addition, some emerging electrolyte optimization strategies deserve more attention, such as the formation of the eutectic network by coupling hydrated Zn salts with a neutral ligand (e.g., succinonitrile).

There are five mainstream structure optimization methodologies, including pre-intercalation, defect engineering, heteroatom doping, size regulation, and fabrication of composites and freestanding materials. However, they need further development. For instance, the current pre-intercalation strategy mainly focuses on the introduction of crystal water and transition metal ions into the host materials to facilitate the ion diffusion kinetics; however, this may lead to serious issues including excessive structural deformations, the influence from the type and the amount of pre-intercalated species to the stability of the structures and electrochemical performance needs to be further investigated systematically. Also, future exploration based on the same principle but different molecules are recommended, for example, PANI intercalated $\mathrm{V}_{2} \mathrm{O}_{5}$ materials, to evaluate their feasibility. Although heteroatom doping and defects engineering are universal and effective methods for the innovation in cathode design, they still face a series of challenges, such as: a) precise control of the defects/doping concentration; b) exploration on novel synthetic techniques. Other than experimental methods, the relationships between the defects/doping concentration and electrochemical performance can also be studied and predicted via computational techniques (e.g., machine learning and DFT calculation).

The mechanistic understanding of AMVIBs is generally immature, especially the mechanisms of energy storage and capacity decay. A very limited number of materials have been explored by theoretical modeling and calculations; multi-scale characterization with a series of the advanced in situ characterization techniques, such as in situ NMR, in situ Raman, in situ SEM, synchrotron X-ray tomography, neutron scattering, etc., are powerful to promote the progress of theoretical research. In situ characterization techniques are particularly crucial in some cases, for example, the charge storage intermediates sensitive to the air and moisture may not be able to reflect the actual 
situation when carried out ex situ evaluation. To further promote the application of advanced characterization techniques in AMVIBs, it is crucial to derive similar configurations and test procedures to relatively mature batteries (e.g., LIBs).

\subsection{Perspectives}

In general, AMVIBs have made remarkable progress in the past 10 years but key challenges persist. To develop high-performance cathodes and realize the next-generation of large-scale energy storage based on these technologies, recommended approaches and research directions are summarized as follows:

1. Learn from transferring the experiences of previous research based on non-aqueous systems or the achievements of other types of AMVIBs.

2. Search for low-cost WIS electrolytes and conduct more studies to further elucidate the relationships between salt solution concentration and electrochemical properties.

3. Develop more suitable electrolyte additives for various types of cathode candidates and study their structure-performance relationship.

4. Deepen the understanding of the essence of various structural optimization strategies, thus discovering more opportunities and appropriately combining various strategies to fabricate the high-performance cathode candidates.

5. Deepen the understanding of the capacity balance of anode and cathode of AMVIBs, to promote the more appropriate voltage distribution and higher anode utilization rate.

6. Conduct more theoretical investigations and employ advanced characterization techniques required to further elucidate the fundamental mechanisms, especially in terms of energy storage, electrolyte additives, and the impacts of defects, vacancies, and heteroatom doping.

7. Conduct more electrochemical tests based on industrial scenarios and application requirements, rather than merely coin cells or Swagelok-type cells in small scale lab research.

\section{Acknowledgements}

The authors would like to thank the Engineering and Physical Sciences Research Council (EPSRC, EP/L015862/1, EP/533581/1), STFC Batteries Network (ST/R006873/1), RSC Mobility Grant (M19-7656), and Faraday Institution (EP/S003053/1) degradation project (FIRG001) for financial support.

\section{Conflict of Interest}

The authors declare no conflict of interest.

\section{Keywords}

aqueous electrolyte, cathode materials, multivalent ion batteries, structural engineering

Received: December 7, 2020 Revised: December 30, 2020 Published online:
[1] Y. Jiao, L. Kang, J. Berry-Gair, K. McColl, J. Li, H. Dong, H. Jiang, R. Wang, F. Cora, D. J. L. Brett, G. He, I. P. Parkin, J. Mater. Chem. A 2020, 8, 22075.

[2] H. Pan, Y. Shao, P. Yan, Y. Cheng, K. S. Han, Z. Nie, C. Wang, J. Yang, X. Li, P. Bhattacharya, K. T. Mueller, J. Liu, Nat. Energy 2016, 1, 16039.

[3] G. Zampardi, F. La Mantia, Curr. Opin. Electrochem. 2020, $21,84$.

[4] H. Dong, J. Li, S. Zhao, F. Zhao, S. Xiong, D. J. L. Brett, G. He, I. P. Parkin, J. Mater. Chem. A 2020, 8, 22637.

[5] H. Dong, J. Li, S. Zhao, Y. Jiao, J. Chen, Y. Tan, D. J. L. Brett, G. He, I. P. Parkin, ACS Appl. Mater. Interfaces 2020, https://doi. org/10.1021/acsami.0c20388.

[6] C. Qiu, X. Zhu, L. Xue, M. Ni, Y. Zhao, B. Liu, H. Xia, Electrochim. Acta 2020, 351, 136445.

[7] M. Armand, Nature 2001, 414, 359.

[8] T. F. Fuller, Nat. Energy 2016, 1, 16003.

[9] N. Nitta, F. Wu, J. T. Lee, G. Yushin, Mater. Today 2015, 18, 252.

[10] J. Xie, Z. Wang, Z. J. Xu, Q. Zhang, Adv. Energy Mater. 2018, 8, 170359.

[11] A. Yoshino, Angew. Chem., Int. Ed. 2012, 51, 5798.

[12] G. Harper, R. Sommerville, E. Kendrick, L. Driscoll, P. Slater, R. Stolkin, A. Walton, P. Christensen, O. Heidrich, S. Lambert, A. Abbott, K. Ryder, L. Gaines, P. Anderson, Nature 2019, 575, 75.

[13] K. Liu, Y. Liu, D. Lin, A. Pei, Y. Cui, Sci. Adv. 2018, 4, eaas9820.

[14] N. Yabuuchi, K. Kubota, M. Dahbi, S. Komaba, Chem. Rev. 2014, 114, 11636.

[15] J. C. Pramudita, D. Sehrawat, D. Goonetilleke, N. Sharma, Adv. Energy Mater. 2017, 7, 1602911.

[16] Z. Wu, J. Xie, Z. J. Xu, S. Zhang, Q. Zhang, J. Mater. Chem. A 2019, 7, 4259.

[17] S. Wang, C. Sun, N. Wang, Q. Zhang, J. Mater. Chem. A 2019, 7, 10138.

[18] W. Xiong, W. Huang, M. Zhang, P. Hu, H. Cui, Q. Zhang, Chem. Mater. 2019, 31, 8069.

[19] Y. Sun, N. Liu, Y. Cui, Nat. Energy 2016, 1, 16071.

[20] A. Ponrouch, J. Bitenc, R. Dominko, N. Lindahl, P. Johansson, M. R. Palacin, Energy Storage Mater. 2019, 20, 253.

[21] M. Song, H. Tan, D. Chao, H. J. Fan, Adv. Funct. Mater. 2018, 28, 1802564

[22] W. Liu, J. Hao, C. Xu, J. Mou, L. Dong, F. Jiang, Z. Kang, J. Wu, B. Jiang, F. Kang, Chem. Commun. 2017, 53, 6872.

[23] W. Li, J. R. Dahn, D. S. Wainwright, Science 1994, 264, 1115.

[24] Y. Wang, J. Yi, Y. Xia, Adv. Energy Mater. 2012, 2, 830.

[25] A. Eftekhari, Adv. Energy Mater. 2018, 8, 1801156.

[26] H. Li, L. Ma, C. Han, Z. Wang, Z. Liu, Z. Tang, C. Zhi, Nano Energy 2019, 62, 550

[27] G. Fang, J. Zhou, A. Pan, S. Liang, ACS Energy Lett. 2018, 3, 2480.

[28] A. Konarov, N. Voronina, J. H. Jo, Z. Bakenov, Y. K. Sun, S. T. Myung, ACS Energy Lett. 2018, 3, 2620.

[29] D. Selvakumaran, A. Pan, S. Liang, G. Cao, J. Mater. Chem. A 2019, 7, 18209.

[30] R. J. Gummow, G. Vamvounis, M. B. Kannan, Y. He, Adv. Mater. 2018, 30, 1801702 .

[31] J. Muldoon, C. B. Bucur, T. Gregory, Chem. Rev. 2014, 114, 11683.

[32] T. Cai, L. Zhao, H. Hu, T. Li, X. Li, S. Guo, Y. Li, Q. Xue, W. Xing, Z. Yan, L. Wang, Energy Environ. Sci. 2018, 11, 2341.

[33] L. Suo, O. Borodin, T. Gao, M. Olguin, J. Ho, X. Fan, C. Luo, C. Wang, K. Xu, Science 2015, 350, 938.

[34] J. Wan, J. Xie, D. G. Mackanic, W. Burke, Z. Bao, Y. Cui, Mater. Today Nano 2018, 4, 1.

[35] D. R. Gabe, J. Appl. Electrochem. 1997, 27, 908.

[36] F. Wang, X. Fan, T. Gao, W. Sun, Z. Ma, C. Yang, F. Han, K. Xu, C. Wang, ACS Cent. Sci. 2017, 3, 1121.

[37] N. Zhang, F. Cheng, J. Liu, L. Wang, X. Long, X. Liu, F. Li, J. Chen, Nat. Commun. 2017, 8, 405. 
[38] H. Luo, B. Wang, F. Wang, J. Yang, F. Wu, Y. Ning, Y. Zhou, D. Wang, H. Liu, S. Dou, ACS Nano 2020, 14, 7328.

[39] S. H. Lee, R. A. DiLeo, A. C. Marschilok, K. J. Takeuchi, E. S. Takeuchi, ECS Electrochem. Lett. 2014, 3, A87.

[40] N. Zhang, F. Cheng, Y. Liu, Q. Zhao, K. Lei, C. Chen, X. Liu, J. Chen, J. Am. Chem. Soc. 2016, 138, 12894.

[41] W. Xu, C. Sun, K. Zhao, X. Cheng, S. Rawal, Y. Xu, Y. Wang, Energy Storage Mater. 2019, 16, 527.

[42] M. Zhang, W. Wu, J. Luo, H. Zhang, J. Liu, X. Liu, Y. Yang, X. Lu, X. Lu, J. Mater. Chem. A 2020, 8, 11642.

[43] S. H. Choi, J. S. Kim, S. G. Woo, W. Cho, S. Y. Choi, J. Choi, K. T. Lee, M. S. Park, Y. J. Kim, ACS Appl. Mater. Interfaces 2015, 7, 7016.

[44] W. Cho, B. Moon, S.-G. Woo, J.-H. Kim, M.-S. Park, J.-S. Kim, H. Kim, Y.-J. Kim, Bull. Korean Chem. Soc. 2015, 36, 1209.

[45] Y. Cheng, Y. Shao, V. Raju, X. Ji, B. L. Mehdi, K. S. Han, M. H. Engelhard, G. Li, N. D. Browning, K. T. Mueller, J. Liu, Adv. Funct. Mater. 2016, 26, 3446.

[46] Y. Zeng, X. Zhang, Y. Meng, M. Yu, J. Yi, Y. Wu, X. Lu, Y. Tong, Adv. Mater. 2017, 29, 1700274

[47] C. Zhu, G. Fang, J. Zhou, J. Guo, Z. Wang, C. Wang, J. Li, Y. Tang, S. Liang, J. Mater. Chem. A 2018, 6, 9677.

[48] J. Li, K. McColl, X. Lu, S. Sathasivam, H. Dong, L. Kang, Z. Li, S. Zhao, A. G. Kafizas, R. Wang, D. J. L. Brett, P. R. Shearing, F. Corà, G. He, C. J. Carmalt, I. P. Parkin, Adv. Energy Mater. 2020, 10, 2000058.

[49] M. Vujković, I. Pašti, I. S. Simatović, B. Šljukić, M. Milenković, S. Mentus, Electrochim. Acta 2015, 176, 130.

[50] J. Huang, Z. Guo, Y. Ma, D. Bin, Y. Wang, Y. Xia, Small Methods 2019, 3, 1800272.

[51] D. Chao, W. Zhou, F. Xie, C. Ye, H. Li, M. Jaroniec, S. Z. Qiao, Sci. Adv. 2020, 6, eaba4098.

[52] R. Demir-Cakan, M. R. Palacin, L. Croguennec, J. Mater. Chem. A 2019, 7, 20519.

[53] J. Xie, Q. Zhang, Small 2019, 15, 1805061.

[54] M. Li, J. Lu, X. Ji, Y. Li, Y. Shao, Z. Chen, C. Zhong, K. Amine, Nat. Rev. Mater. 2020, 5, 276.

[55] T. Sun, J. Xie, W. Guo, D. Li, Q. Zhang, Adv. Energy Mater. 2020, 10, 1904199.

[56] K. Qin, J. Huang, K. Holguin, C. Luo, Energy Environ. Sci. 2020, 3950.

[57] J. Xie, Q. Zhang, Mater. Today Energy 2020, 18, 100547.

[58] J. Huang, X. Dong, Z. Guo, Y. Wang, Angew. Chem., Int. Ed. 2020, 59, 18322.

[59] J. Ming, J. Guo, C. Xia, W. Wang, H. N. Alshareef, Mater. Sci. Eng., $R$ 2019, 135, 58.

[60] L. Zhang, I. A. Rodríguez-Pérez, H. Jiang, C. Zhang, D. P. Leonard, Q. Guo, W. Wang, S. Han, L. Wang, X. Ji, Adv. Funct. Mater. 2019, 29, 1902653

[61] H. Liang, Z. Cao, F. Ming, W. Zhang, D. H. Anjum, Y. Cui, L. Cavallo, H. N. Alshareef, Nano Lett. 2019, 19, 3199.

[62] X. Zeng, J. Hao, Z. Wang, J. Mao, Z. Guo, Energy Storage Mater. 2019, 20,410.

[63] W. Qiu, Y. Li, A. You, Z. Zhang, G. Li, X. Lu, Y. Tong, J. Mater. Chem. A 2017, 5, 14838

[64] X. Gao, H. Wu, W. Li, Y. Tian, Y. Zhang, H. Wu, L. Yang, G. Zou, H. Hou, X. Ji, Small 2020, 16, 1905842.

[65] Y. Huang, J. Liu, Q. Huang, Z. Zheng, P. Hiralal, F. Zheng, D. Ozgit, S. Su, S. Chen, P. H. Tan, S. Zhang, H. Zhou, npj Flex. Electron. 2018, 2, 21.

[66] M. H. Alfaruqi, V. Mathew, J. Gim, S. Kim, J. Song, J. P. Baboo, S. H. Choi, J. Kim, Chem. Mater. 2015, 27, 3609.

[67] N. Qiu, H. Chen, Z. Yang, S. Sun, Y. Wang, Electrochim. Acta 2018, 272, 154

[68] B. Jiang, C. Xu, C. Wu, L. Dong, J. Li, F. Kang, Electrochim. Acta 2017, 229, 422
[69] M. Sun, D. Li, Y. Wang, W. Liu, M. Ren, F. Kong, S. Wang, Y. Guo, Y. Liu, ChemElectroChem 2019, 6, 2510.

[70] C. Zhong, B. Liu, J. Ding, X. Liu, Y. Zhong, Y. Li, C. Sun, X. Han, Y. Deng, N. Zhao, W. Hu, Nat. Energy 2020, 5, 440.

[71] B. Wu, G. Zhang, M. Yan, T. Xiong, P. He, L. He, X. Xu, L. Mai, Small 2018, 14, 1703850.

[72] G. Fang, C. Zhu, M. Chen, J. Zhou, B. Tang, X. Cao, X. Zheng, A. Pan, S. Liang, Adv. Funct. Mater. 2019, 29, 1808375.

[73] G. Xu, X. Liu, S. Huang, L. Li, X. Wei, J. Cao, L. Yang, P. K. Chu, ACS Appl. Mater. Interfaces 2020, 12, 706.

[74] W. Sun, F. Wang, S. Hou, C. Yang, X. Fan, Z. Ma, T. Gao, F. Han, R. Hu, M. Zhu, C. Wang, J. Am. Chem. Soc. 2017, 139, 9775.

[75] M. Han, J. Huang, S. Liang, L. Shan, X. Xie, Z. Yi, Y. Wang, S. Guo, J. Zhou, iScience 2020, 23, 100797.

[76] J. Huang, Z. Wang, M. Hou, X. Dong, Y. Liu, Y. Wang, Y. Xia, Nat. Commun. 2018, 9, 2906.

[77] D. Wang, L. Wang, G. Liang, H. Li, Z. Liu, Z. Tang, J. Liang, C. Zhi, ACS Nano 2019, 13, 10643

[78] N. Zhang, Y. Dong, M. Jia, X. Bian, Y. Wang, M. Qiu, J. Xu, Y. Liu, L. Jiao, F. Cheng, ACS Energy Lett. 2018, 3, 1366.

[79] P. He, G. Zhang, X. Liao, M. Yan, X. Xu, Q. An, J. Liu, L. Mai, Adv. Energy Mater. 2018, 8, 1702463.

[80] H. Tang, Z. Peng, L. Wu, F. Xiong, C. Pei, Q. An, L. Mai, Electrochem. Energy Rev. 2018, 1, 169.

[81] Z. Li, Z. Li, Y. Ren, L. Mo, C. Liu, K. Hsu, Y. Ding, X. Zhang, X. Li, L. Hu, D. Ji, G. Cao, ACS Nano 2020, 14, 5581.

[82] M. Yan, P. He, Y. Chen, S. Wang, Q. Wei, K. Zhao, X. Xu, Q. An, Y. Shuang, Y. Shao, K. T. Mueller, L. Mai, J. Liu, J. Yang, Adv. Mater. 2018, 30, 1703725.

[83] Q. Li, X. Rui, D. Chen, Y. Feng, N. Xiao, L. Gan, Q. Zhang, Y. Yu, S. Huang, Nano-Micro Lett. 2020, 12, 3.

[84] S. Liu, H. Zhu, B. Zhang, G. Li, H. Zhu, Y. Ren, H. Geng, Y. Yang, Q. Liu, C. C. Li, Adv. Mater. 2020, 32, 2001113.

[85] P. He, Y. Quan, X. Xu, M. Yan, W. Yang, Q. An, L. He, L. Mai, Small 2017, 13, 1702551.

[86] F. Wan, X. Wang, S. Bi, Z. Niu, J. Chen, Sci. China Chem. 2019, 62, 609.

[87] X. Liu, H. Zhang, D. Geiger, J. Han, A. Varzi, U. Kaiser, A. Moretti, S. Passerini, Chem. Commun. 2019, 55, 2265.

[88] R. K. Guduru, J. C. Icaza, Nanomaterials 2016, 6, 41.

[89] R. Trócoli, F. La Mantia, ChemSusChem 2015, 8, 481.

[90] D. Kundu, B. D. Adams, V. Duffort, S. H. Vajargah, L. F. Nazar, Nat. Energy 2016, 1, 16119.

[91] D. Bin, W. Huo, Y. Yuan, J. Huang, Y. Liu, Y. Zhang, F. Dong, Y. Wang, Y. Xia, Chem 2020, 6, 968.

[92] S. Chen, K. Li, K. S. Hui, J. Zhang, Adv. Funct. Mater. 2020, 30, 2003890.

[93] F. Ming, H. Liang, Y. Lei, S. Kandambeth, M. Eddaoudi, H. N. Alshareef, ACS Energy Lett. 2018, 3, 2602.

[94] S. R. Daemi, C. Tan, T. Volkenandt, S. J. Cooper, A. PalaciosPadros, J. Cookson, D. J. L. Brett, P. R. Shearing, ACS Appl. Energy Mater. 2018, 1, 3702.

[95] F. Wan, L. Zhang, X. Dai, X. Wang, Z. Niu, J. Chen, Nat. Commun. 2018, 9, 1656

[96] Q. Zhang, Y. Ma, Y. Lu, L. Li, F. Wan, K. Zhang, J. Chen, Nat. Commun. 2020, 11, 4463.

[97] L. Zhang, L. Chen, X. Zhou, Z. Liu, Adv. Energy Mater. 2015, 5, 1400930.

[98] Z. Liu, P. Bertram, F. Endres, J. Solid State Electrochem. 2017, 21, 2021.

[99] K. Lu, B. Song, J. Zhang, H. Ma, J. Power Sources 2016, 321, 257.

[100] Z. Liu, G. Pulletikurthi, F. Endres, ACS Appl. Mater. Interfaces 2016, $8,12158$.

[101] Z. Hou, X. Zhang, X. Li, Y. Zhu, J. Liang, Y. Qian, J. Mater. Chem. A 2017, 5, 730 . 
[102] G. Ni, B. Han, Q. Li, Z. Ji, B. Huang, C. Zhou, ChemElectroChem 2016, 3, 798.

[103] G. Kasiri, R. Trócoli, A. Bani Hashemi, F. La Mantia, Electrochim. Acta 2016, 222, 74.

[104] F. Wan, L. Zhang, X. Wang, S. Bi, Z. Niu, J. Chen, Adv. Funct. Mater. 2018, 28, 1804975

[105] Q. Zhao, W. Huang, Z. Luo, L. Liu, Y. Lu, Y. Li, L. Li, J. Hu, H. Ma, J. Chen, Sci. Adv. 2018, 4, eaao1761.

[106] Z. Guo, Y. Ma, X. Dong, J. Huang, Y. Wang, Y. Xia, Angew. Chem., Int. Ed. 2018, 57, 11737.

[107] J. Xie, F. Yu, J. Zhao, W. Guo, H. L. Zhang, G. Cui, Q. Zhang, Energy Storage Mater. 2020, 33, 283.

[108] W. Yang, X. Du, J. Zhao, Z. Chen, J. Li, J. Xie, Y. Zhang, Z. Cui, Q. Kong, Z. Zhao, C. Wang, Q. Zhang, G. Cui, Joule 2020, 4, 1557.

[109] K. W. Nam, S. S. Park, R. dos Reis, V. P. Dravid, H. Kim, C. A. Mirkin, J. F. Stoddart, Nat. Commun. 2019, 10, 4948.

[110] Y. Gao, H. Yang, X. Wang, Y. Bai, N. Zhu, S. Guo, L. Suo, H. Li, H. Xu, C. Wu, ChemSusChem 2020, 13, 732.

[111] Y. Tang, X. Li, H. Lv, D. Xie, W. Wang, C. Zhi, H. Li, Adv. Energy Mater. 2020, 10, 2000892.

[112] Y. Zeng, Y. Meng, Z. Lai, X. Zhang, M. Yu, P. Fang, M. Wu, Y. Tong, X. Lu, Adv. Mater. 2017, 29, 1702698.

[113] L. Ma, S. Chen, H. Li, Z. Ruan, Z. Tang, Z. Liu, Z. Wang, Y. Huang, Z. Pei, J. A. Zapien, C. Zhi, Energy Environ. Sci. 2018, 11, 2521.

[114] G. Li, Z. Yang, Y. Jiang, C. Jin, W. Huang, X. Ding, Y. Huang, Nano Energy 2016, 25, 211.

[115] Y. Cheng, L. Luo, L. Zhong, J. Chen, B. Li, W. Wang, S. X. Mao, C. Wang, V. L. Sprenkle, G. Li, J. Liu, ACS Appl. Mater. Interfaces 2016, 8, 13673.

[116] H. Li, L. McRae, C. J. Firby, A. Y. Elezzabi, Adv. Mater. 2019, 31, 1807065

[117] D. Aurbach, Z. Lu, A. Schechter, Y. Gofer, H. Gizbar, R. Turgeman, Y. Cohen, M. Moshkovich, E. Levi, Nature 2000, 407, 724

[118] S. Huang, P. Du, C. Min, Y. Liao, H. Sun, Y. Jiang, J. Fluorescence 2013, 23, 621

[119] M. Mao, T. Gao, S. Hou, C. Wang, Chem. Soc. Rev. 2018, 47, 8804.

[120] Y. Zhang, H. Geng, W. Wei, J. Ma, L. Chen, C. C. Li, Energy Storage Mater. 2019, 20, 118.

[121] P. Saha, P. H. Jampani, M. K. Datta, D. Hong, B. Gattu, P. Patel, K. S. Kadakia, A. Manivannan, P. N. Kumta, Nano Res. 2017, 10, 4415.

[122] S. G. Woo, J. Y. Yoo, W. Cho, M. S. Park, K. J. Kim, J. H. Kim, J. S. Kim, Y. J. Kim, RSC Adv. 2014, 4, 59048.

[123] Y. Gu, Y. Katsura, T. Yoshino, H. Takagi, K. Taniguchi, Sci. Rep. 2015, 5, 12486.

[124] X. Sun, P. Bonnick, L. F. Nazar, ACS Energy Lett. 2016, 1, 297.

[125] K. Liang, K. Marcus, L. Guo, Z. Li, L. Zhou, Y. Li, S. T. De Oliveira, N. Orlovskaya, Y. H. Sohn, Y. Yang, Chem. Commun. 2017, 53, 7608.

[126] Y.-H. Tan, F. Zhou, Z.-H. Huang, W.-T. Yao, T.-W. Zhang, H.-B. Yao, L.-L. Lu, S.-H. Yu, ChemElectroChem 2018, 5, 996.

[127] Y. Tashiro, K. Taniguchi, H. Miyasaka, Electrochim. Acta 2016, 210, 655.

[128] Y. Wang, Z. Liu, C. Wang, X. Yi, R. Chen, L. Ma, Y. Hu, G. Zhu, T. Chen, Z. Tie, J. Ma, J. Liu, Z. Jin, Adv. Mater. 2018, 30, 1802563.

[129] M. Arsentev, A. Missyul, A. V. Petrov, M. Hammouri, J. Phys. Chem. C 2017, 121, 15509.

[130] M. Wu, Y. Zhang, T. Li, Z. Chen, S. A. Cao, F. Xu, Nanoscale 2018, 10, 12526

[131] M. Rabiller-Baudry, M. Sergent, R. Chevrel, Mater. Res. Bull. 1991, 26, 519.

[132] A. Mitelman, E. Levi, E. Lancry, D. Aurbach, ECS Trans. 2019, 3, 109.

[133] A. Mitelman, M. D. Levi, E. Lancry, E. Levi, D. Aurbach, Chem. Commun. 2007, 4212.

[134] Z. Jia, J. Hao, L. Liu, Y. Wang, T. Qi, lonics (Kiel) 2018, 24, 3483.

[135] C. Li, F. Cheng, W. Ji, Z. Tao, J. Chen, Nano Res. 2009, 2, 713.

[136] H. Zhang, D. Cao, X. Bai, J. Power Sources 2019, 444, 227299.
[137] C. Yuan, Y. Zhang, Y. Pan, X. Liu, G. Wang, D. Cao, Electrochim. Acta 2014, 116, 404.

[138] K. W. Nam, S. Kim, S. Lee, M. Salama, I. Shterenberg, Y. Gofer, J. S. Kim, E. Yang, C. S. Park, J. S. Kim, S. S. Lee, W. S. Chang, S. G. Doo, Y. N. Jo, Y. Jung, D. Aurbach, J. W. Choi, Nano Lett. 2015, 15, 4071.

[139] L. Wang, K. Asheim, P. E. Vullum, A. M. Svensson, F. Vullum-Bruer, Chem. Mater. 2016, 28, 6459.

[140] G. Liu, Q. Chi, Y. Zhang, Q. Chen, C. Zhang, K. Zhu, D. Cao, Chem. Commun. 2018, 54, 9474.

[141] H. Zhang, K. Ye, S. Shao, X. Wang, K. Cheng, X. Xiao, G. Wang, D. Cao, Electrochim. Acta 2017, 229, 371.

[142] H. Zhang, K. Ye, K. Zhu, R. Cang, X. Wang, G. Wang, D. Cao, ACS Sustainable Chem. Eng. 2017, 5, 6727.

[143] Q. An, Y. Li, H. Deog Yoo, S. Chen, Q. Ru, L. Mai, Y. Yao, Nano Energy 2015, 18, 265.

[144] T. S. Arthur, K. Kato, J. Germain, J. Guo, P. A. Glans, Y. S. Liu, D. Holmes, X. Fan, F. Mizuno, Chem. Commun. 2015, 51, 15657.

[145] I. E. Rauda, V. Augustyn, L. C. Saldarriaga-Lopez, X. Chen, L. T. Schelhas, G. W. Rubloff, B. Dunn, S. H. Tolbert, Adv. Funct. Mater. 2014, 24, 6717.

[146] R. H. Kim, J. S. Kim, H. J. Kim, W. S. Chang, D. W. Han, S. S. Lee, S. G. Doo, J. Mater. Chem. A 2014, 2, 20636.

[147] P. Novák, J. Desilvestro, J. Electrochem. Soc. 1993, 140, 140.

[148] P. Novák, W. Scheifele, F. Joho, O. Haas, J. Electrochem. Soc. 1995, 142, 2544.

[149] Y. Liang, Y. Jing, S. Gheytani, K. Y. Lee, P. Liu, A. Facchetti, Y. Yao, Nat. Mater. 2017, 16, 841.

[150] I. A. Rodríguez-Pérez, Y. Yuan, C. Bommier, X. Wang, L. Ma, D. P. Leonard, M. M. Lerner, R. G. Carter, T. Wu, P. A. Greaney, J. Lu, X. Ji, J. Am. Chem. Soc. 2017, 139, 13031.

[151] G. Kumar, A. Sivashanmugam, N. Muniyandi, S. K. Dhawan, D. C. Trivedi, Synth. Met. 1996, 80, 279.

[152] C. D. Wessells, S. V. Peddada, R. A. Huggins, Y. Cui, Nano Lett. 2011, 11, 5421.

[153] R. Y. Wang, C. D. Wessells, R. A. Huggins, Y. Cui, Nano Lett. 2013, 13, 5748.

[154] M. Pasta, C. D. Wessells, N. Liu, J. Nelson, M. T. McDowell, R. A. Huggins, M. F. Toney, Y. Cui, Nat. Commun. 2014, 5, 3007.

[155] R. Zhang, F. Mizuno, C. Ling, Chem. Commun. 2015, 51, 1108.

[156] J. Xie, C. Li, Z. Cui, X. Guo, Adv. Funct. Mater. 2015, 25, 6519.

[157] S. W. Lee, N. Yabuuchi, B. M. Gallant, S. Chen, B. S. Kim, P. T. Hammond, Y. Shao-Horn, Nat. Nanotechnol. 2010, 5, 531.

[158] J. Giraudet, D. Claves, K. Guérin, M. Dubois, A. Houdayer, F. Masin, A. Hamwi, J. Power Sources 2007, 173, 592.

[159] S. Liu, J. J. Hu, N. F. Yan, G. L. Pan, G. R. Li, X. P. Gao, Energy Environ. Sci. 2012, 5, 9743.

[160] S. He, J. Wang, X. Zhang, J. Chen, Z. Wang, T. Yang, Z. Liu, Y. Liang, B. Wang, S. Liu, L. Zhang, J. Huang, J. Huang, L. A. O'Dell, H. Yu, Adv. Funct. Mater. 2019, 29, 1905228.

[161] N. Jayaprakash, S. K. Das, L. A. Archer, Chem. Commun. 2011, 47, 12610.

[162] H. Lahan, R. Boruah, A. Hazarika, S. K. Das, J. Phys. Chem. C 2017, 121, 26241.

[163] Y. J. He, J. F. Peng, W. Chu, Y. Z. Li, D. G. Tong, J. Mater. Chem. A 2014, 2, 1721.

[164] S. Liu, G. L. Pan, G. R. Li, X. P. Gao, J. Mater. Chem. A 2015, 3, 959.

[165] A. Zhou, L. Jiang, J. Yue, Y. Tong, Q. Zhang, Z. Lin, B. Liu, C. Wu, L. Suo, Y. S. Hu, H. Li, L. Chen, ACS Appl. Mater. Interfaces 2019, 11, 41356.

[166] Q. Zhao, M. J. Zachman, W. I. Al Sadat, J. Zheng, L. F. Kourkoutis, L. Archer, Sci. Adv. 2018, 4, eaau8131.

[167] C. Wu, S. Gu, Q. Zhang, Y. Bai, M. Li, Y. Yuan, H. Wang, X. Liu, Y. Yuan, N. Zhu, F. Wu, H. Li, L. Gu, J. Lu, Nat. Commun. 2019, $10,73$. 
[168] W. Pan, Y. Wang, Y. Zhang, H. Y. H. Kwok, M. Wu, X. Zhao, D. Y. C. Leung, J. Mater. Chem. A 2019, 7, 17420.

[169] Q. Li, N. J. Bjerrum, J. Power Sources 2002, 110, 1.

[170] M. C. Lin, M. Gong, B. Lu, Y. Wu, D. Y. Wang, M. Guan, M. Angell, C. Chen, J. Yang, B. J. Hwang, H. Dai, Nature 2015, 520, 324.

[171] X. Zhang, G. Zhang, S. Wang, S. Li, S. Jiao, J. Mater. Chem. A 2018, 6, 3084.

[172] W. Kaveevivitchai, A. Huq, S. Wang, M. J. Park, A. Manthiram, Small 2017, 13, 1701296.

[173] X. Zhang, S. Wang, J. Tu, G. Zhang, S. Li, D. Tian, S. Jiao, ChemSusChem 2018, 11, 709.

[174] K. Liang, L. Ju, S. Koul, A. Kushima, Y. Yang, Adv. Energy Mater. 2019, 9, 1802543

[175] Y. Zhang, S. Liu, Y. Ji, J. Ma, H. Yu, Adv. Mater. 2018, 30, 1706310.

[176] H. Wang, S. Gu, Y. Bai, S. Chen, N. Zhu, C. Wu, F. Wu, J. Mater Chem. A 2015, 3, 22677.

[177] M. Manickam, P. Singh, T. B. Issa, S. Thurgate, J. Appl. Electrochem 2006, 36, 599.

[178] Y. Liu, S. Sang, Q. Wu, Z. Lu, K. Liu, H. Liu, Electrochim. Acta 2014, $143,340$.

[179] S. Kumar, R. Satish, V. Verma, H. Ren, P. Kidkhunthod, W. Manalastas, M. Srinivasan, J. Power Sources 2019, 426, 151.

[180] S. Nandi, S. K. Das, Solid State lonics 2020, 347, 115228

[181] H. Lahan, S. K. Das, J. Power Sources 2019, 413, 134.

[182] A. L. Lipson, B. Pan, S. H. Lapidus, C. Liao, J. T. Vaughey, B. J. Ingram, Chem. Mater. 2015, 27, 8442.

[183] A. Ponrouch, C. Frontera, F. Bardé, M. R. Palacín, Nat. Mater. 2016, 15, 169

[184] M. Wang, C. Jiang, S. Zhang, X. Song, Y. Tang, H. M. Cheng, Nat Chem. 2018, 10, 667.

[185] B. Ji, H. He, W. Yao, Y. Tang, Adv. Mater. 2020, 2005501.

[186] R. Y. Wang, B. Shyam, K. H. Stone, J. N. Weker, M. Pasta H.-W. Lee, M. F. Toney, Y. Cui, Adv. Energy Mater. 2015, 5, 1401869.

[187] C. Lee, S. K. Jeong, Electrochim. Acta 2018, 265, 430

[188] M. Adil, A. Sarkar, A. Roy, M. R. Panda, A. Nagendra, S. Mitra, ACS Appl. Mater. Interfaces 2020, 12, 11489.

[189] R. Cang, C. Zhao, K. Ye, J. Yin, K. Zhu, J. Yan, G. Wang, D. Cao, ChemSusChem 2020, 13, 3911.

[190] L. Liu, Y.-C. Wu, P. Rozier, P.-L. Taberna, P. Simon, Research 2019 2019, 6585686

[191] Z. Rong, R. Malik, P. Canepa, G. Sai Gautam, M. Liu, A. Jain, K. Persson, G. Ceder, Chem. Mater. 2015, 27, 6016

[192] T. Liu, X. Cheng, H. Yu, H. Zhu, N. Peng, R. Zheng, J. Zhang, M. Shui, Y. Cui, J. Shu, Energy Storage Mater. 2019, 18, 68

[193] X. Zhao, M. V. Reddy, H. Liu, S. Ramakrishna, G. V. S. Rao, B. V. R. Chowdari, RSC Adv. 2012, 2, 7462.

[194] R. Liu, Z. Liang, Z. Gong, Y. Yang, Small Methods 2019, 3, 1800221.
[195] M. Chandra, T. S. Khan, R. Shukla, S. Ahamad, A. Gupta, S. Basu, M. A. Haider, R. S. Dhaka, Electrochim. Acta 2020, 331, 135293.

[196] K. M. Shaju, G. V. S. Rao, B. V. R. Chowdari, J. Mater. Chem. 2003 , 13, 106.

[197] Z. Hu, Q. Liu, W. Sun, W. Li, Z. Tao, S. L. Chou, J. Chen, S. X. Dou, Inorg. Chem. Front. 2016, 3, 532.

[198] W. Wang, Y. Gang, Z. Hu, Z. Yan, W. Li, Y. Li, Q. F. Gu, Z. Wang, S. L. Chou, H. K. Liu, S. X. Dou, Nat. Commun. 2020, 11, 980.

[199] M. D. Levi, E. Lancry, H. Gizbar, Y. Gofer, E. Levi, D. Aurbach, Electrochim. Acta 2004, 49, 3201.

[200] R. Attias, S. Bublil, M. Salama, Y. Goffer, D. Aurbach, Electrochim. Acta 2020, 334, 135614

[201] Y. Lu, J. Chen, Nat. Rev. Chem. 2020, 4, 127.

[202] W. Li, K. Wang, S. Cheng, K. Jiang, Energy Storage Mater. 2018, 15, 14.

[203] H. Li, C. Han, Y. Huang, Y. Huang, M. Zhu, Z. Pei, Q. Xue, Z. Wang, Z. Liu, Z. Tang, Y. Wang, F. Kang, B. Li, C. Zhi, Energy Environ. Sci. 2018, 11, 941.

[204] J. Hao, J. Mou, J. Zhang, L. Dong, W. Liu, C. Xu, F. Kang, Electrochim. Acta 2018, 259, 170

[205] S. Bai, J. Song, Y. Wen, J. Cheng, G. Cao, Y. Yang, D. Li, RSC Adv. 2016, 6, 40793.

[206] J. Lai, H. Zhu, X. Zhu, H. Koritala, Y. Wang, ACS Appl. Energy Mater. 2019, 2, 1988

[207] K. Lu, B. Song, Y. Zhang, H. Ma, J. Zhang, J. Mater. Chem. A 2017, 5, 23628.

[208] D. Kundu, P. Oberholzer, C. Glaros, A. Bouzid, E. Tervoort, A. Pasquarello, M. Niederberger, Chem. Mater. 2018, 30, 3874.

[209] X. Sun, V. Duffort, B. L. Mehdi, N. D. Browning, L. F. Nazar, Chem Mater. 2016, 28, 534.

[210] X. Fan, F. Wang, X. Ji, R. Wang, T. Gao, S. Hou, J. Chen, T. Deng, X. Li, L. Chen, C. Luo, L. Wang, C. Wang, Angew. Chem. 2018, 130, 7264.

[211] L. Chen, J. L. Bao, X. Dong, D. G. Truhlar, Y. Wang, C. Wang, Y. Xia, ACS Energy Lett. 2017, 2, 1115 .

[212] M. S. Chae, J. Hyoung, M. Jang, H. Lee, S. T. Hong, J. Power Sources 2017, 363, 269.

[213] X. Xu, M. Duan, Y. Yue, Q. Li, X. Zhang, L. Wu, P. Wu, B. Song, L. Mai, ACS Energy Lett. 2019, 4, 1328.

[214] L. W. Dong, R. G. Xu, P. P. Wang, S. C. Sun, Y. Li, L. Zhen, C. Y. Xu, J. Power Sources 2020, 479, 228793.

[215] M. Cabello, F. Nacimiento, J. R. González, G. Ortiz, R. Alcántara, P. Lavela, C. Pérez-Vicente, J. L. Tirado, Electrochem. Commun. 2016, 67, 59.

[216] J. Park, Z. Xu, G. Yoon, S. K. Park, J. Wang, H. Hyun, H. Park, J. Lim, Y. Ko, Y. S. Yun, K. Kang, Adv. Mater. 2020, 32, 1904411.

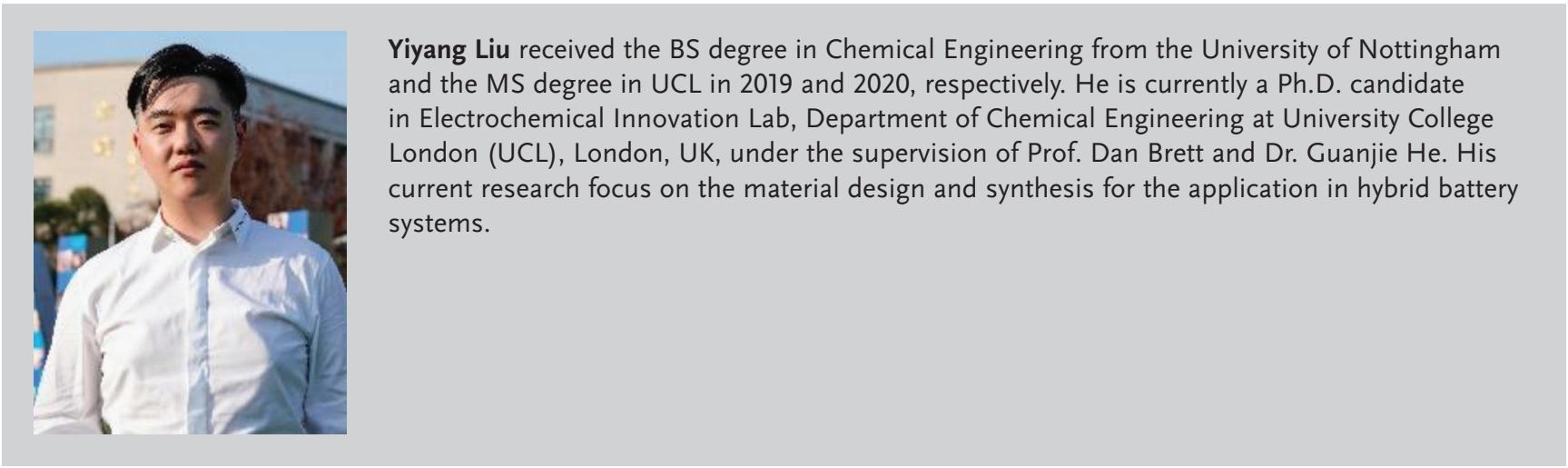




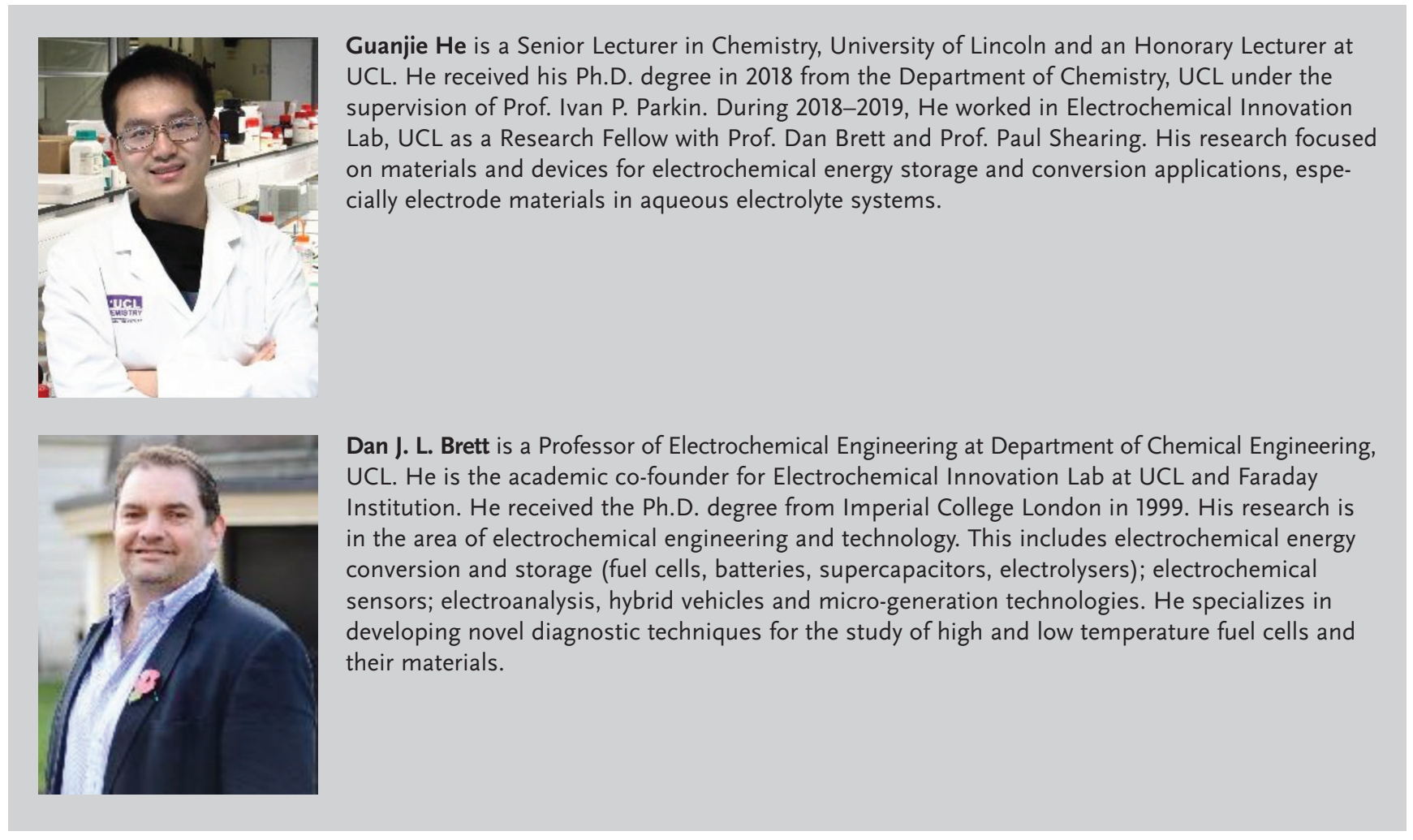

